\title{
COMPARISONS OF FISH SPECIES INSIDE AND OUTSIDE OF MARINE PROTECTED AREAS OFF THE SOUTH CENTRAL COAST OF CALIFORNIA
}

\author{
A Thesis presented to the \\ Faculty of the Biological Sciences Department \\ California Polytechnic State University \\ In Partial Fulfillment \\ Of the Requirements for the Degree \\ Master of Science in Biological Sciences
}

By

David Rasmussen

September 2010 
(C) 2010

David Edward Rasmussen

ALL RIGHTS RESERVED 


\section{COMMITTEE MEMBERSHIP}

TITLE:

COMPARISONS OF FISH SPECIES INSIDE AND

OUTSIDE OF MARINE PROTECTED AREAS OFF THE SOUTH CENTRAL COAST OF CALIFORNIA
AUTHOR:
David Edward Rasmussen

DATE SUBMITTED:

September 2010

COMMITTE CHAIR: $\quad$ Dr. Royden Nakamura, Professor

COMMITTEE MEMBER: Dr. Dean E. Wendt, Professor

COMMITTEE MEMBER: Dr. John S. Stephens Jr., Emeritus Professor 


\section{Abstract}

From 2004-2008 and 2008-2009 Cal Poly University researchers conducted two separate tag and recapture studies of nearshore fish populations along California's central coast. Three locations were sampled that have experienced different degrees of fishing pressure. Big Creek MPA has been closed to all fishing from 1993 onwards and is the farthest from port of all locations. Cambria lies closest to port of the three locations and because of this has the highest fishing pressure. Piedras Blancas lies midway between Cambria and Big Creek. Portions of Cambria and Piedras Blancas were designated as MPAs in 2007. Sampling protocols of these two different studies differed in bait used and size of commercial fish trap. An experiment was conducted to simultaneously compare the different trapping and baiting protocols from the prior studies to find a conversion factor that related catch per unit effort (CPUE), length frequency distributions and captured fish diversity between the two studies, thus providing a means to connect the two data sets for stock assessments and baseline MPA monitoring.

Our sampling showed no significant difference in mean fish length or diversity between the two protocols for the five most common nearshore fish species captured, and three of the five species showed no significant difference in CPUE. Cabezon (Scorpaenichthys marmoratus), showed a significantly lower CPUE (50.5\%) using the MLPA monitoring protocols compared to the commercial fishing protocol and black and yellow rockfish (Sebastes chrysomelas) had a significantly higher CPUE (310\%) using the MLPA monitoring protocol. These findings provide a means of maintaining data continuity across the entire sample region and inclusion of earlier projects in the analyses of nearshore fish populations of the region.

With the linkage of these two studies we provide important baseline data for the Cambria MPA from before it was established in 2007. Fish populations were compared on a year-to-year 
basis within each location, and between the different locations. I found several main factors helped to explain differences in size and abundance across time within individual locations, and across the three locations. These factors were inherent differences in habitat, establishment of MPAs, and changes in fishing pressure and post-larval recruitment.

Cabezon were largest within Big Creek, followed by Piedras Blancas and Cambria which held the smallest fish, suggesting that fishing pressure is influencing fish size. However, cabezon were more abundant at Cambria than either other location suggesting that location is influencing abundance. Within Cambria, we are seeing an MPA effect with abundance within the MPA staying stable while the reference site is declining.

Gopher rockfish (Sebastes carnatus) and black and yellow rockfish had similar trends with size and abundance between locations. Big Creek and Piedras Blancas held the largest fish, while Cambria was smaller. Both rockfish species were most abundant at Big Creek, followed by Cambria then Piedras Blancas. Size for these species is likely influenced by fishing pressure, and abundance is likely influenced by both fishing pressure and location. Both species increased in abundance 2004-2009 at Cambria, and this could be due to improved levels of post-larval recruitment. There is also a possible MPA effect for gopher rockfish at Cambria with a near significant divergence in size of fish between the MPA and reference site.

Kelp greenling (Hexagrammos decagrammus) were similar in size and abundance between all sampling locations. There is a possible MPA effect at Cambria, with a significantly higher abundance than the reference site; however this difference predates the MPA's establishment but could have been exacerbated by it.

Lingcod (Ophiodon elongatus) size did not vary significantly between sites, but they were the most abundant at Cambria, followed by Piedras Blancas, then Big Creek, suggesting 
that habitat is influencing abundance. There was also a possible MPA effect on abundance of lingcod at Cambria with the MPA having a significantly higher abundance than the reference site. Similarly to the kelp greenling, these differences predated the MPA, but could have been exacerbated by its establishment, and abundance within the MPA has stayed stable, while the reference site was declining.

Big Creek and Piedras Blancas have similar Shannon-Weiner diversity values, while Cambria has significantly lower. However, after MPA establishment at Cambria, the MPA has attained significantly higher diversity levels than the reference site.

Over the short period of time that the Piedras Blancas and Cambria MPA have been established the populations within them have changed. However, there are no discernable trends in size, abundance and diversity between the MPA and reference sites at both locations. It is likely that with these slower growing, long-lived fish species that it will take more years for differences between the sites to manifest themselves. 


\section{Acknowledgements}

A great number of individuals have helped me with portions of my research and provided moral support through my graduate career. I wish to thank my advisors Dr. Royden Nakamura and Dr. Dean Wendt and my third committee member Dr. John S. Stephens Jr. I owe a tremendous amount of gratitude for their help in all stages of my research. I would like to thank Dr. Royden Nakamura for helping to set up the project, helping with the experimental design and providing invaluable input throughout my research and assistance in reviewing the drafts of the thesis. Without the tireless efforts of Dr. Dean Wendt in obtaining funding sources and his efforts in designing the new California Collaborative Fisheries Research Program protocols this project would not have been possible. Dr. John S. Stephens Jr. provided much help with the establishment of the various projects I drew data from for this thesis, and helped me to understand what data was available, and how I could use it. Dr. Royden Nakamura, Dr. Dean Wendt and Dr. John S. Stephens Jr. provided much help with the editing, writing and composing of not only this thesis, but also other presentations I have given on this topic.

Many individuals helped me with field collection or laboratory work, and I would like to thank all of them. Carlos Mireles set up the original sampling effort off of Point Estero, and provided help on subsequent trips. Without Erin Nakada's relentless work on not only this project, but also the SMURFs, and CPFV trips, I would not have been able to collect as much quality data. Nate Hall provided help with all parts of this study, and without being able to count on his help my research would have been much more difficult. Other individuals I would like to thank for their help with data collection, and advice are Grant Waltz, Lenora Brewer, Leslie Longabach, Corbin Hodges, Noelle Yochum, Steve Reinecke, Jono Wilson, Owen Hackleman, 
Nic Nesbitt, Genji Nakada, Joey Reggio, Kristen Sanchez, Larisa Ormonde, Melissa Daugherty, Helen Dickenson, Ian Robbins, and John Burns.

Thanks also go out to those who provided valuable input, help and support throughout my research. Thanks to Steve Reinecke and Jono Wilson for starting the CPFV and SMURFs projects which I drew valuable information from. Leslie Rebik for all of her administrative support, and ensuring that everything went smoothly. Andrew Schaffner for helping me to determine the appropriate statistical tests to use and how to interpret them. Tom Moylan, Jason Felton and the Center for Coastal Marine Sciences at Cal Poly for the boat training and use of the pier facilities. Rick Starr and Noelle Yochum for helping to plan the CCFRP sampling protocols used in the MLPA monitoring study. Jen Caselle for her information about recruitment of various nearshore fish species. Alec MacCall, Steve Ralston and Jason Cope from NOAA Fisheries for providing guidance on how to design the conversion experiment. Brenda Irwin, Jeni Nowell and Matthew Michie at California Department of Fish and Game for providing data on licensed nearshore fishermen in Morro Bay, historic landing data and historic recreational and commercial fishing regulations. Tom Hafer and Roger Cullen for taking us out on all of the sampling trips. Special thanks to the funding sources of the project, the Packard Foundation, the Ocean Protection Counsel and the Resource Legacy Fund, without their support none of this research would have been possible.

Without the continued love and support of my parents, Glen and Susan Rasmussen, and my girlfriend Evelyn Ma, none of this would have been possible. Without their help, and the timely distractions provided by my friends Jim Cegelink and Jon King I would probably be running feral in the South Pacific with nothing but a surfboard for company. 


\section{TABLE OF CONTENTS}

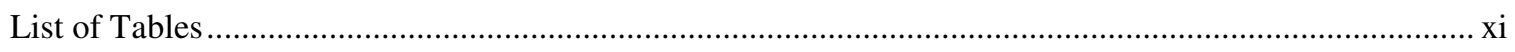

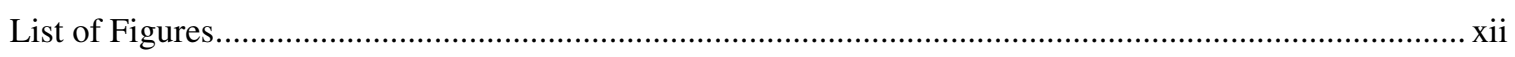

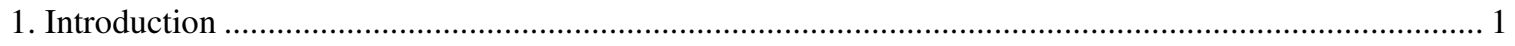

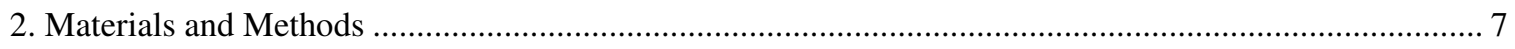

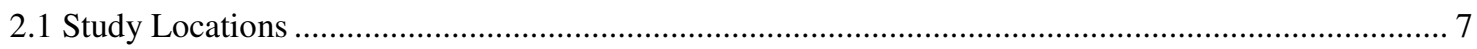

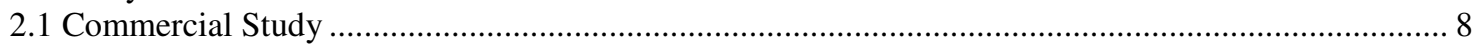

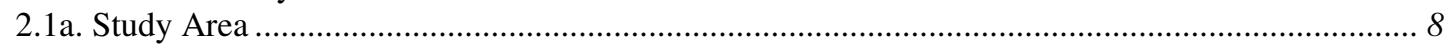

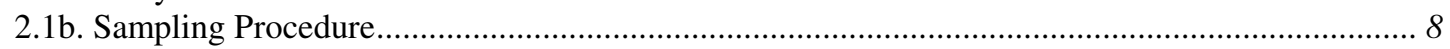

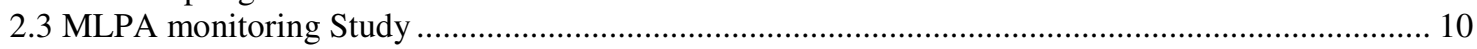

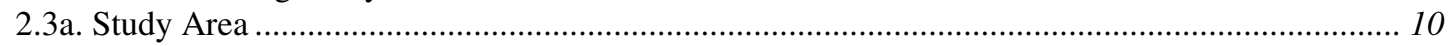

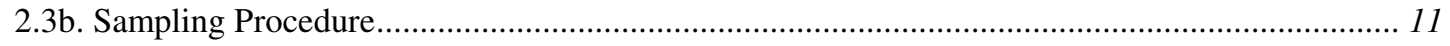

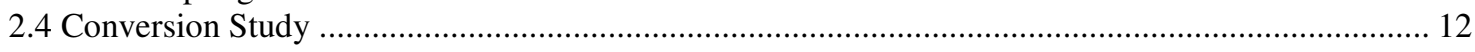

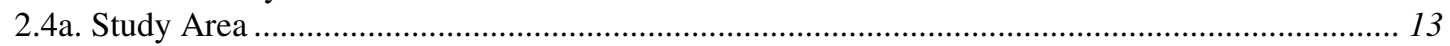

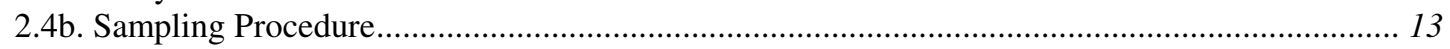

Statistical Analyses

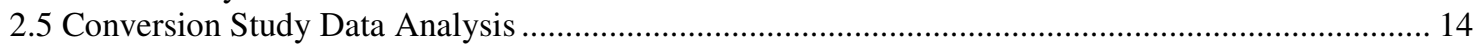

2.5a. Catch per unit effort differences between bait and soak time ................................................. 14

2.5b. Fish length differences between bait and soak time .............................................................. 15

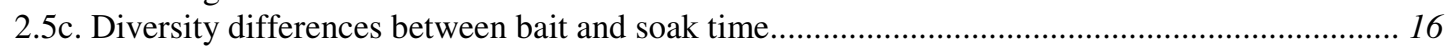

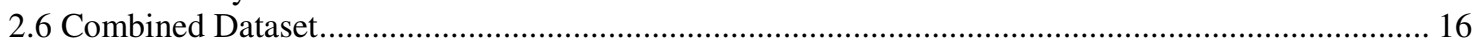

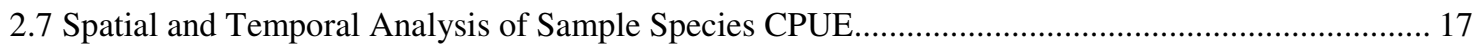

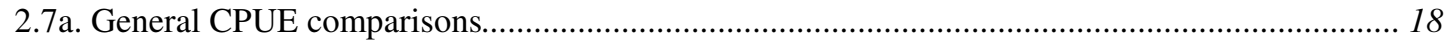

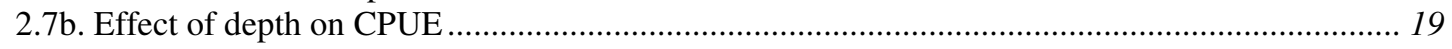

2.8 Analysis of population structure based upon length frequency analyses ......................................... 19

2.8a. General spatial and temporal comparisons of sample species length........................................... 20

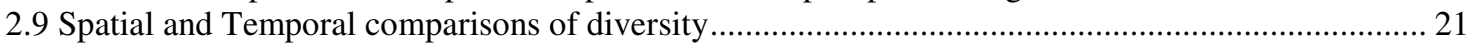

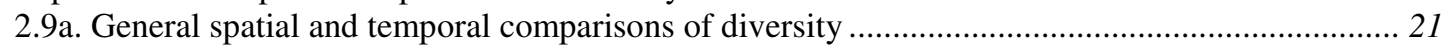

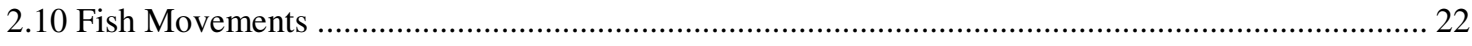

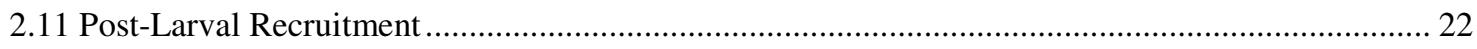

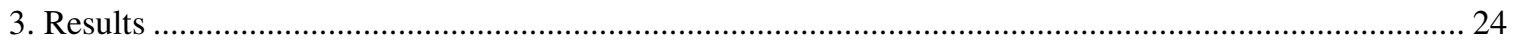

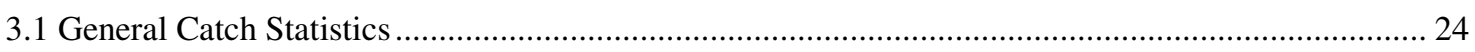

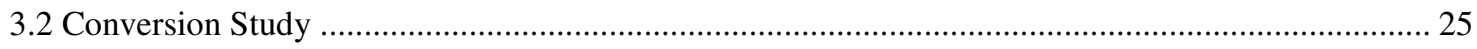

3.2a. Catch per unit effort differences between bait and soak time ................................................. 25

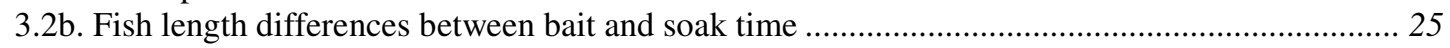

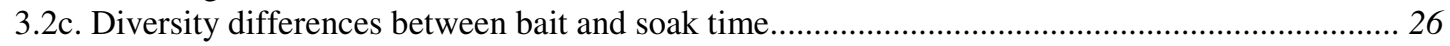

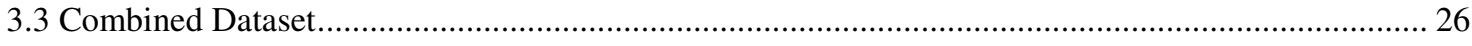

SPATIAL AND TEMPORAL ANALYSIS OF SAMPLE SPECIES CPUE

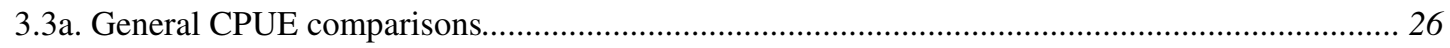

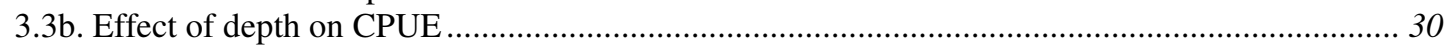

ANALYSIS OF POPULATION STRUCTURE BASED UPON LENGTH FREQUENCY ANALYSES

3.3c. General Spatial and Temporal Comparisons of Sample Species Length ........................................ 30

SPATIAL AND TEMPORAL COMPARISONS OF DIVERSITY

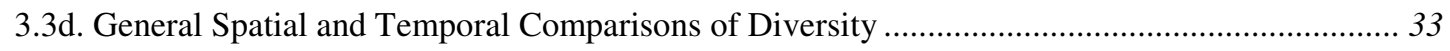

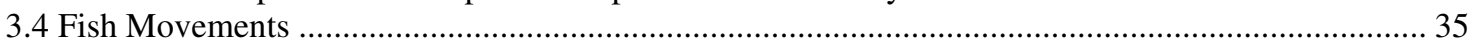

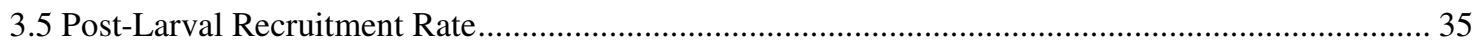

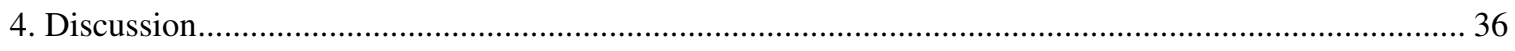

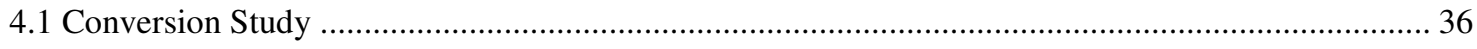

SUMMARY OF ANALYSES BY SPECIES 


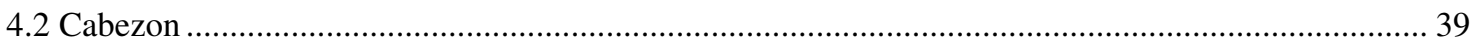

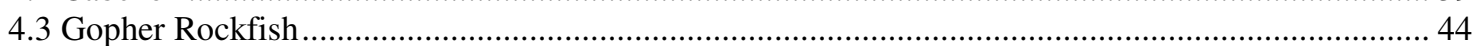

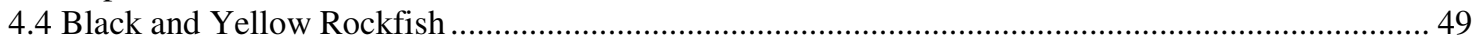

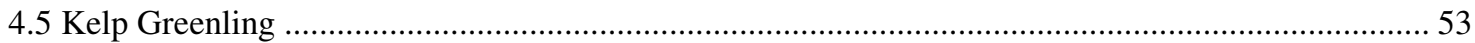

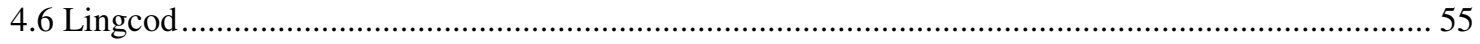

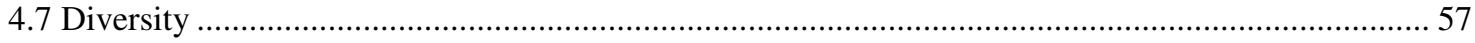

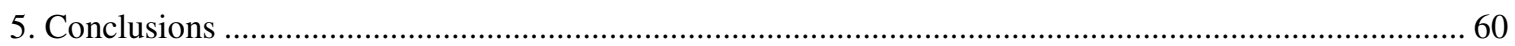

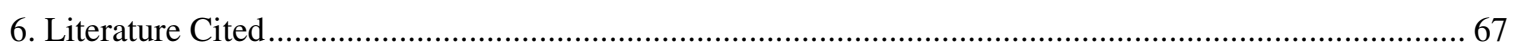

Appendix 1: Interpretation of Ordinal and Binary Logistic Regression Models ...................................... 72 


\section{List of Tables}

Table 1. Sampling Periods and Protocols used at the different sampling locations..................... 100

Table 2. Counts of fish captured and tagged throughout all studies .......................................... 100

Table 3. Numbers of individual species captured at each sampling location .............................. 101

Table 4. Summary of effects of MPA establishment, fishing intensity, habitat and post-larval

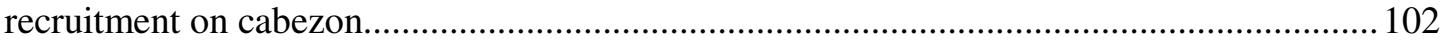

Table 5. Summary of effects of MPA establishment, fishing intensity, habitat and post-larval

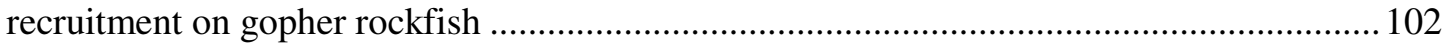

Table 6. Summary of effects of MPA establishment, fishing intensity, habitat and post-larval recruitment on black and yellow rockfish

Table 7. Summary of effects of MPA establishment, fishing intensity, habitat and post-larval recruitment on kelp greenling

Table 8. Summary of effects of MPA establishment, fishing intensity, habitat and post-larval recruitment on lingcod.... 


\section{List of Figures}

Figure 1. Locations of Cambria, Piedras Blancas and Big Creek …............................................ 74

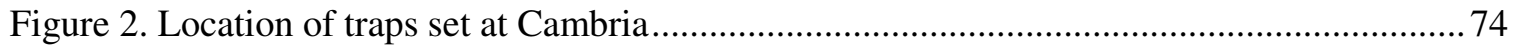

Figure 3. Location of traps set at Piedras Blancas ..................................................................... 75

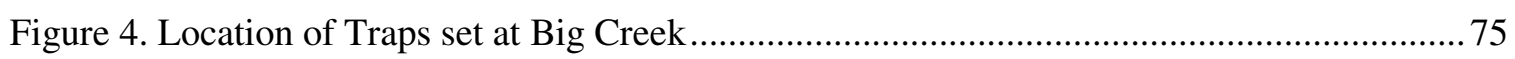

Figure 5. Location of both MLPA monitoring study and Commercial study traps set in two cells of Piedras Blancas MPA during Conversion Study . .................................................... 76

Figure 6. Percentage of traps returning with different numbers of fish. ........................................ 76

Figure 7. Effect of soak time on CPUE from conversion experiment. .......................................... 77

Figure 8. Effect of bait on CPUE from conversion experiment................................................. 78

Figure 9. Mean total length of nearshore fish species under different treatments in conversion

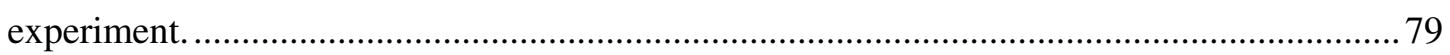

Figure 10. Shannon-Weiner diversity values under different treatments in conversion

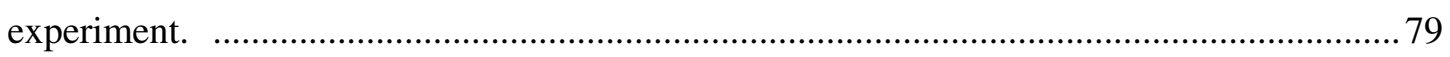

Figure 11. Differences in CPUE between locations across all sampling years.............................. 80

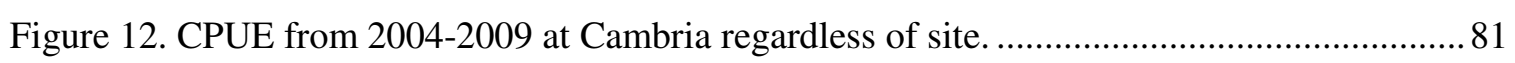

Figure 13. CPUE from 2006-2008 at Big Creek...................................................................... 82

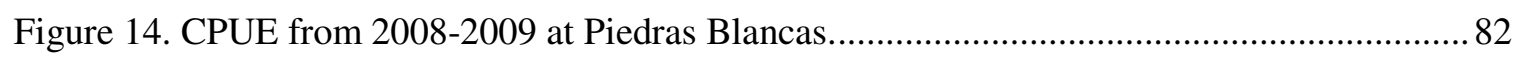

Figure 15. CPUE from 2004-2009 at Cambria separated into MPA and reference sites...............83

Figure 16. CPUE from 2008-2009 at Piedras Blancas separated into MPA and reference sites...84

Figure 17. Differences in CPUE between MPA and reference sites within years and across all years at Cambria.

Figure 18. Differences in CPUE between MPA and reference sites within years and across

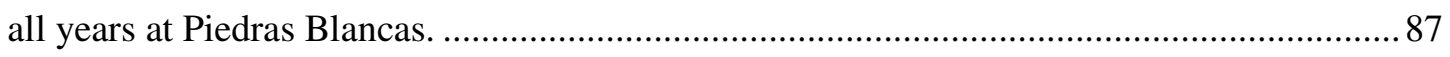

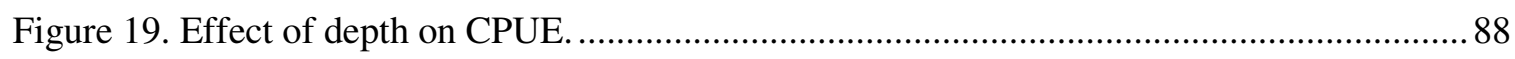

Figure 20. Main effects plot of length across sampling locations and all years. ............................ 89

Figure 21. Main effects plot of length across all sampling years at Cambria...............................90

Figure 22. Main effects plot of length across all sampling years at Piedras Blancas. ...................91

Figure 23. Main effects plot of cabezon length across all sampling years at Big Creek. ............. 91

Figure 24. Main effects plot of length across all sampling years in the MPA and reference site

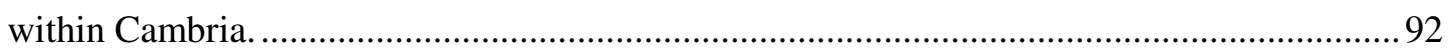

Figure 25. Main effects plot of length across sampling years in the MPA and reference site within Piedras Blancas. 
Figure 26. Average Shannon-Weiner diversity values for the three sampling locations across

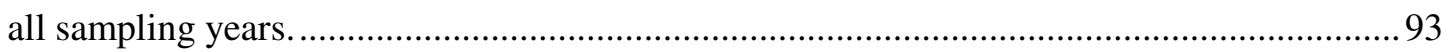

Figure 27. Species richness for all sampling locations and years............................................. 94

Figure 28. Shannon-Weiner diversity values for Cambria, Piedras Blancas and Big Creek for

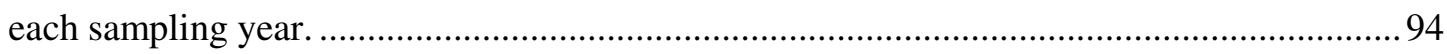

Figure 29. Shannon-Weiner diversity values for Cambria MPA and reference site across all years 95

Figure 30. Shannon-Weiner diversity values for Piedras Blancas MPA and reference site

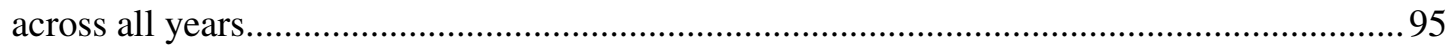

Figure 31. Mean recapture distance for cabezon, gopher rockfish and kelp greenling..................96

Figure 32. Average recruits per day for cabezon and KCGB complex from 2004-2008..............96

Figure 33. Average number of recruits per day at different SMURF stations from 2004-2008 ...97

Figure 34. Number of commercial fishermen operating out of Morro Bay with nearshore

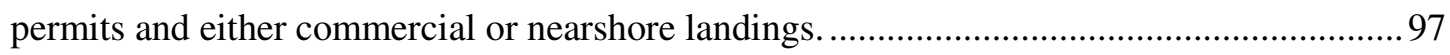

Figure 35. von Bertalanffy growth curves for analyzed fish species..........................................98

Figure 36. Commercial landings of analyzed fish species in Morro Bay from 2000-2008 .......... 98

Figure 37. Length frequency histogram of cabezon total length at Big Creek during 2006 and 2008 . 


\section{Introduction}

Marine Protected Areas (MPA) are important conservation tools for fisheries managers. They have been shown to harbor increased diversity, higher abundance and larger organisms than adjacent fished areas (e.g., Duran and Castilla 1989, Jennings et al., 1996, Bohnsack 1998, Gell and Roberts 2003). In addition, they have also been shown to dramatically increase the biomass and abundance of non-migratory fish species (e.g., Gell and Roberts, 2003). When comparing the populations of exploited fish species in established MPAs to adjacent unfished areas, the mean size and density in protected areas exceeds that of fished areas (e.g., Mosqueira et al., 2000).

Using the metric catch per unit effort (CPUE), which is a proxy for the abundance and density of fish in an area, researchers have shown dramatic increases in catch inside MPAs. CPUE has been used as a proxy for relative abundance and density of nearshore fish species by researchers when appropriate habitats are targeted (Haggarty and King 2006). For example, after 30 years of protection inside an MPA, populations of a commercially important sparid fish, Chrysoblephus laticeps, were estimated to be 42 times higher than in adjacent, fished areas (Buxton and Smale, 1989). Within the same MPA, CPUE showed that four nearshore fish species had densities 5-21 times greater inside the MPA than in areas open to fishing (Cowley et al., 2002). In a Mediterranean MPA established for 13 years, densities of 11 different fish species were up to 5 times higher inside reserves than in fished areas (Francour 1991). Likewise, a longterm study on fish assemblages inside and outside of MPAs in Tasmania following 10 years of protection showed a significant increase in abundance of large fish (Barrett et al., 2007). However, it must also be recognized that behavior of fish species also affects how protected areas will affect their populations. Species with high site fidelity and small home range sizes will 
receive the strongest benefits from MPAs, while species with larger home ranges will benefit less, and spill over into adjacent fished areas (Kramer and Chapman 1999).

Differences between MPAs and fished areas are not limited to density alone. Fish in protected areas and fished areas have been shown to be dramatically different in size. A study of temperate rocky reef MPAs in New Zealand, with a minimum protection of 5 years, showed an increase of legal sized snapper by an order of 14 times (Willis et al., 2003). In Everglades National Park, the modal length of grey snapper, Lutjanus griseus, was $25-30 \mathrm{~cm}$ in MPAs compared to $15-20 \mathrm{~cm}$ in fished areas (Faunce et al., 2002). Within two small $\left(<6 \mathrm{~km}^{2}\right)$ MPAs in subtropical eastern Australia, the mean size of fish was shown to be significantly greater within protected areas (Pillans et al., 2007). In addition, a study on temperate reef fish in Southern California found that the size structure of fish was shifted towards larger sizes in protected areas than in areas open to commercial and/or recreational fishing (Schroeder and Love, 2002).

Another indicator affected by cessation of fishing is biodiversity. Biodiversity is one of the main indicators of ecosystem health, and losses of marine biodiversity tend to be highest in coastal areas (Magurran 2004, Gray 1997). Diversity of fish species inside marine reserves has been shown to be higher than adjacent fished areas, indicating that MPAs harbor healthier ecosystems. A study of six Mediterranean MPAs, established for ten or more years, found a significant increase in species richness within the reserves compared to outside areas (HarmelinVivien et al., 2008). Likewise, the 10-year study in the Tasmanian MPA mentioned previously showed a doubling of species richness of large fish relative to an outside control site (Barrett et al., 2007). Similar studies from around the world have found increases in species richness and diversity within protected areas (e.g. Jennings et al., 1996, Johnson 1999, Claudet et al., 2006). 
Unfortunately, many of the studies showing increases in fish density, size and diversity lack important baseline data from before the MPAs were established. The absence of this information may confound the interpretation of observed differences between fished and protected locations (Edgar et al., 2004, Dayton et al., 1998). Without baseline information, any changes measured after establishment between a fished and protected location must be inferred, rather than directly attributed to changes in fishing pressure.

From 2004-2009 Cal Poly University researchers conducted two tag and release studies of nearshore fish populations in central California. In these studies we combined the knowledge of local fisherman with scientific protocols to ensure proper sampling. Sampling locations included a 11.8 mile $(19 \mathrm{~km})$ stretch of rocky reef habitat from Killers Reef in Cayucos to Leffingwell Landing, Cambria, 18 miles, $(28 \mathrm{~km})$ centered on the Lighthouse at Pt. Piedras Blancas, CA, and the waters inside of Big Creek MPA south of Big Sur. Forty miles (64 km) separate the two farthest sites, Cambria and Big Creek, and all sites contain similar habitats and species (Figure 1). These nearshore rocky reef habitats support many fish species and are currently, or were in the past, subject to commercial or recreational fishing. The species that inhabit these areas are of particular management concern due to their narrow depth ranges and limited amount of available habitat. This can result in smaller nearshore fish populations than for species that inhabit deeper waters (California Department of Fish and Game 2002). In addition, many fish species living in the nearshore area are residential as adults with small home ranges. Replenishment of these local areas is accomplished from larval dispersal rather than adult movement (Love, Yoklavich and Thorsteinson 2002, California Department of Fish and Game 2002). Because of these factors, increased fishing pressure, combined with years of poor 
recruitment, the populations of many nearshore fish stocks have been depressed (CDFG 2002, Love and Caselle 1998).

The primary fishing port accessing these areas is Morro Bay, CA, located approximately $19 \mathrm{~km}$ (11.8 miles) south of our nearest sampling location. The nearshore waters around Morro Bay have been fished commercially and recreationally since the turn of the century and, after the advent of the live-fish fishery, catch levels for nearshore fish species increased (O'Connell 1953). For example, the most commonly captured fish in these two studies, the cabezon (Scorpaenichthys marmoratus), had its first recorded commercial catch, $1590 \mathrm{~kg}(3,505 \mathrm{lbs})$, in 1925 (O’Connell 1953). Catches increased slowly until the 1990's when the live-fish fishery became prevalent. At that point, catch levels for cabezon increased significantly until 1998, with a record catch of 169,092 $\mathrm{kg}(372,784 \mathrm{lbs})($ Leet et al., 2001).

Since 1998, catch levels for cabezon and other nearshore fish have dropped due to declines in fishable stock, prompting regulatory changes, including seasonal closures, species closures, catch quotas, limited access fisheries, gear limitations and size limits. Studies by commercial passenger fishing vessels (CPFV) in California have also noted declines in catch rates and length of rockfish species (Reilly et al., 1993, Reilly et al., 1998, Karpov et al., 1995, Mason 1998, and Stephens et al., 2006). The combined pressure of CPFVs, recreational and commercial fisherman have driven declines in nearshore fish such as lingcod, cabezon, gopher rockfish, blue rockfish, and have prompted the call for further protection of these areas in the form of marine protected areas (Key et al.,2008, Key et al.,2005, Cope and Key 2009, Hamel, Sethi and Wadsworth 2009). 
MPAs were put in place around Cambria and Pt. Piedras Blancas in 2007 as part of the California State Marine Life Protection Act. Big Creek MPA has been closed to fishing since 1993.

Our sampling program at Cambria began in 2004 and includes comprehensive data on nearshore fish populations both inside and outside of where the Cambria (White Rock) MPA is currently situated. Sampling continued after the MPA was put into place (2007), allowing for changes in the populations to be tracked and compared to the baseline data from before the establishment of the marine reserve. Sampling inside and outside of the MPA at Piedras Blancas began in 2008, also allowing changes to be tracked over time. Big Creek MPA was sampled in 2006 and 2008 and allows for comparisons to be drawn to Pt. Estero and Pt. Piedras Blancas, which have been open to fishing more recently.

There is little information about the nearshore fish populations in California, and most of the species analyzed in this study are from stocks classified to be data poor (CDFG 2002). No comprehensive, long-term studies have been conducted on the fish species in this sampling area. The objective of this document is to present a comprehensive comparison of catch, length and diversity of five nearshore fish species from areas close spatially, with similar habitats but differing in levels of fishing pressure experienced.

In this study trends for fish length and catch per unit effort were analyzed on a per species basis in all sampling locations across all years (Table 1). Likewise, trends in diversity across fish assemblages were also analyzed. Before analyzing how nearshore fish populations have changed throughout the course of the Commercial and MLPA monitoring studies we first needed to answer several questions. 1) How do the different sampling protocols affect sample species CPUE? 2) How do the different sampling protocols affect sample species size 
composition? 3) How do the different sampling protocols affect diversity levels of captured fish? After these questions were answered, we asked several other questions about how nearshore fish populations were changing over the course of the two studies. 4) How has fishing intensity, protection inside an MPA, location and post-larval recruitment affected the CPUE of sample fish species? 5) How has fishing intensity, protection inside an MPA location and postlarval recruitment affected the size composition of sample fish species? 6) How has fishing intensity, protection inside an MPA, location and post-larval recruitment affected diversity levels across fish assemblages? In addition, trends in mean length, CPUE and diversity were included within and between sampling locations to assess how fish populations changed on a year-to-year basis. Additionally, von Bertalanffy growth curves, and catch data from commercial and recreational fishers were used to explain variations in CPUE and mean fish length across sampling years. 


\section{Materials and Methods}

\subsection{Study Locations}

\section{Cambria}

Cambria lies across Estero Bay from the fishing port at Morro Bay, and of the three locations it receives the heaviest fisher concentration largely due to its proximity to Morro Bay (Figure 2). The Cambria area is largely free of the nautical hazards that abound in the Big Creek and Piedras Blancas areas, making it a safer fishing ground in poor weather. The Cambria waters are heavily fished by California Collaborative Fisheries Research Program (CCFRP) vessels, recreational and commercial fisherman. The MPA and associated comparison reference sites receive similar amounts of swell and wind, and have similar bottom topography.

\section{Piedras Blancas}

Piedras Blancas lies midway between Big Creek and Cambria (Figure 3). This site had moderate levels of fishing from CCFRP vessels, recreational and commercial fishers before parts of it were established as an MPA. Due to its greater exposure to swell and winds, the areas above the lighthouse cannot be safely fished the majority of the year. The region below the lighthouse is in the lee of the point, and is a safe haven for nearshore fishers in periods of heavier winds and larger swells. The area north of the lighthouse is revered by nearshore fisherman for holding large numbers of cabezon, while the area south holds more patchy reef and is generally considered less productive (Hafer, T and R. Cullen, pers. comm.).

\section{Big Creek}

Big Creek is the furthest north of the sampling locations (Figure 4). It has been closed to all fishing since 1993 and, due to the distance from port, Big Creek and the surrounding areas likely have much lower fishing pressure than either Piedras Blancas or Cambria. Bottom 
topography is more jagged in Big Creek than the other locations, with depths dropping off more quickly, in addition to large shallow reefs.

\subsection{Commercial Study}

From 2004-2008 an in-depth tagging study on local nearshore fish populations was conducted as part of a multifaceted characterization of the commercial trap fishery off the central coast of California (Table 1)(Mireles, 2005, Rasmussen, 2006). Local fisher knowledge was combined with a scientific monitoring framework to assess the populations of fish in the nearshore environment. Two nearshore fishing vessels were contracted and the fishermen were told to fish normally and attempt to maximize catch.

\section{2 a. Study Area}

The waters between Killers Reef, Cayucos and Leffingwell Landing, from now on referred to as Cambria, were sampled in 2004 and 2006, while the waters in Big Creek Marine Reserve were sampled in 2006-2008 (Table 1). Big Creek was designated as an MPA in 1993, and has been closed to fishing since that date. The entire Cambria sampling area was open to all forms of fishing during this study. Sampling was conducted between 3526.500 N, 12056.647 W and 3533.000 N, 121 56.647 W. Sampling within Big Creek Marine Reserve was conducted between $3603.673 \mathrm{~N}, 12135.492 \mathrm{~W}$ and 36 5.577, $12137.795 \mathrm{~W}$. Over 2,700 cabezon were tagged, measured and released. No other fish species were tagged during this study (Figure 2,4).

\section{2 b. Sampling Procedure}

Two local commercial fishing vessels were chartered throughout this study. The 2004 Cambria sampling took place over 10 days from September 2004 to January 2005. The 2006 Cambria sampling took place over 12 days from September 2006 to January 2007 (Figure 2). Big 
Creek Marine Reserve was sampled in 2006 over three consecutive days from July 19 to 21 . In 2008 it was sampled from June 28 to 30 (Figure 4).

Both vessels utilized traps constructed of a 2" mesh with funnels on either end each containing a 5" otter exclusion ring. On the FV Kathryn H (vessel 1), the traps were 24" x 24" x 10 ," and on the FV Dorado (vessel 2) the traps were 18" x 24" x 8". Both traps had a centrally located bait box. All traps were baited with a mixture of chopped squid and abalone trimmings. After each trap was set and recovered, additional bait was added to the bait box to refresh its attractant quality. Forty-four traps were used by each vessel, and each trap was identified by a unique number on its floating buoy.

During sampling, each vessel completed three sets of the traps each day. One set is defined as when all 44 traps are set in the water and then recovered. Traps were set and pulled in the same order and every trap number, GPS coordinate, time set and time recovered, and depth the trap was set at were recorded. During the 2004 Cambria, and 2006 Big Creek sampling, cabezon was the main species of interest. Other species were considered by-catch and were identified to the species level. The number of each species in the trap was recorded, and then released. Cabezon was the only species that was measured (fork length) and tagged. In subsequent sampling years, 2006 Cambria and 2008 Big Creek, every fish that was captured had its fork length measured, but cabezon remained the only species tagged. Cabezon were tagged using colored 5/8" T-Bar anchor tags (Floy Tag, model FD-94), inserted into the musculature between the second and third dorsal fin rays on the left side of the body. After measuring and/or tagging, the captured fish were released as close to their initial capture point as possible. 
During sampling the fishermen were asked to fish as they normally would in order to maximize catch. All 44 traps were set in prime nearshore rocky reef habitat at depths of 8-62ft (2.5-19 m.) and an average set time of 1 hour and 55 minutes.

\subsection{MLPA MONITORING STUDY}

In September of 2007 five MPAs were established in south central California. In an effort to collect baseline information and assess the population of nearshore fish species in these MPAs, sampling protocols were developed in cooperation with Moss Landing Marine Labs and the fishing community to monitor several MPAs and co-located reference sites. With continued monitoring both inside the MPAs and at outside reference sites (see below) we will be able to evaluate changes within and between the sites and locations over time. Collected baseline data was used to assess changes among the various sampled nearshore species. Data were made available to federal and state agencies to facilitate development of accurate stock assessments and to evaluate the impact of MPAs on nearshore fishes.

\section{3 a. Study Area}

Working with the same commercial fishermen from the prior commercial fishing study, we sampled inside Cambria and Piedras Blancas MPAs and in their corresponding reference sites. Cambria MPA encompasses an area of 2.3 square miles $\left(6 \mathrm{~km}^{2}\right)$ and Piedras Blancas 10.4 square miles $\left(27 \mathrm{~km}^{2}\right)$. The reference sites for these locations were chosen based on similar size, habitat, bathymetry and oceanographic conditions as their adjacent MPAs. Within both the MPA and reference site, $500 \mathrm{~m}$ x $500 \mathrm{~m}(1,640 \mathrm{ft}$ x 1,640 ft) cells were created and overlaid upon nearshore rocky reef habitats in less than $20 \mathrm{~m}(65 \mathrm{ft})$ of water. This depth was chosen to minimize released fish mortality and barotrauma. These cells were created as a way to randomly select sampling locations while fishing. All cell locations were confirmed with fisherman to 
ensure they contained suitable habitat for target fish species. Twenty-eight cells were created in Cambria and 36 cells in Piedras Blancas (Figures 2, 3).

The Cambria MPA and reference site lie in the same place area as the commercial study in the Cambria area previously sampled in 2004-2006 (Figure 2)(Table 1).

\section{3 b. Sampling Procedure}

Sampling of each MPA and Reference site was conducted with the same commercial fisherman as from the prior Commercial Study. Sampling dates ranged from July to November 2008 and July to September 2009 (Table 1). Cambria MPA and reference sites were each sampled for six days in 2008, and four days in 2009 (Figure 2, Table 1). Piedras Blancas MPA and reference sites were sampled for four days each in 2008 and 2009 (Figure 3).

Both vessels used identical custom-built live fish traps with dimensions of 24 " x 24 " x 10", with funnels placed on either side of the trap with a 5"otter exclusion ring, and a central bait box. Each trap was baited with a pint of chopped squid, and this bait was replaced after each set. Each set was defined as when all 20 traps aboard the boat were deployed, allowed to soak for 1 hour, and then recovered. The 20 traps were subdivided into two groups of 10, with one group set in the shallower (shoreward) side of the cell, and the other group set in the deeper (seaward) side of the cell. Which group of 10 traps was set first was alternated between sets. All traps were set in less than $80 \mathrm{ft}$. of water to prevent barotrauma.

During sampling, two vessels were used each day at the same time, one sampling the MPA and the other the reference site. Each vessel sampled three different cells that were chosen randomly. The order that the cells were sampled was determined by how the tide, wave height and wind speed would affect sampling. Cells more exposed to the elements were sampled first to minimize wind and wave height, and shallower cells were sampled at higher tides for safety 
reasons. In each cell a total of 20 traps were set. Each trap had its GPS coordinates, time set, time recovered and depth recorded. Every fish and invertebrate species found in the trap or funnel area were also recorded to the species level, and fish were measured for total length. Fish longer than $20 \mathrm{~cm}$ (7.9 inches) were tagged using external T-bar anchor tags in the musculature between their second and third dorsal fin rays and then released as close as possible to their location of capture.

\subsection{Conversion Study}

Sampling was conducted at Cambria in 2004 and 2006, and Big Creek MPA 2006 and 2008 utilizing the Commercial Study sampling protocols. In 2007, a portion of the sampling site at Cambria was designated as an MPA as was Piedras Blancas. Establishment of the MPAs (2007) required a standardization of protocols, gear and bait to monitor and assess differences between Cambria and Piedras Blancas and other MPAs located elsewhere. Cambria and Piedras Blancas were both sampled in 2008 and 2009 using the MLPA monitoring study protocols to allow for comparisons to be made between the protected sites, and outside non-protected sites (Table 1). An assessment of the different sampling protocols (Commercial and MLPA Monitoring) was needed to determine the effects that gear configuration, bait type and soak time had upon catch. This assessment, termed the Conversion study, was conducted using a blending of the two protocols in 2008 at Piedras Blancas.

The commercial and MLPA monitoring study had slightly different protocols, and the two datasets were thus not directly comparable. They differed in the type of bait used, and the soak time of the traps. In the prior commercial study, traps were baited using a mixture of chopped squid and abalone trimmings, while in the current MLPA monitoring study the traps were baited with squid alone. Soak times in the prior commercial study ranged from 1:05 to 3:20, 
while in the current study soak times averaged one hour. Linking the datasets allows for comparisons to be made between studies and it allows for the development of conversion factors so the data sets are comparable for use in stock assessments.

\section{4 a. Study Area}

This study was conducted concurrently with the 2009 sampling season in the Piedras Blancas MPA and reference site (Table 1). Traps were set within the gridded cells described in the MLPA Monitoring Study (see Section 2.2 a) in the area shown on Figure 5.

\section{4 b. Sampling Procedure}

Sampling was conducted in the MPA and reference site at Piedras Blancas at the same time as the MLPA Monitoring study. Sampling took place over two days using a modified protocol from the MLPA monitoring study. This protocol merged elements of the Commercial study and the MLPA monitoring study to determine how bait type and soak time affected the catch composition of the traps. National Marine Fisheries Service resource managers Steve Ralston and Alec McCall recommended a similar blending of protocols to link the datasets.

Both vessels used eighteen of the MLPA monitoring study traps. Vessels One and Two each had an additional fourteen traps from the prior commercial study. Fourteen of the MLPA traps and ten commercial traps were randomly assigned a number from one to 24 to determine the order in which they were set. The fourteen MLPA traps were baited with one pint of chopped squid, while the ten commercial traps were baited with chopped squid and abalone trimmings. These traps were then set in the chosen cell in two groups of 12 (one set shoreward and one seaward) for a soak time of one hour. Which group of 12 traps were set first was alternated between sets. 
Eight additional traps were also set in the same cell, four MLPA traps baited with one pint of squid, and four commercial traps baited with squid and abalone trimmings. These traps were randomly assigned the order in which they would be set. These traps were set for a soak time of two hours.

\section{Statistical Analyses}

\subsection{Conversion Study Data Analysis}

Traps selected for use in the conversion study were first analyzed to ensure that no major variations in catch occurred at different depths. It was found that at depths greater that $45 \mathrm{ft}$ (13.7 m) that catch was highly variable and dominated by a single species, gopher rockfish. In addition, the Cambria 2004 sampling had a maximum depth of $45 \mathrm{ft}$. To ensure continuity of depth across studies a maximum depth of $45 \mathrm{ft}$ was applied to all traps for use in the conversion experiment, and all subsequent analyses.

\section{5 a. Catch per unit effort differences between bait and soak time}

To assess whether the catch per unit effort for the top five captured fish species varied between bait and soak time, all traps set in less than $45 \mathrm{ft}(13.7 \mathrm{~m})$ of water were selected. The top five species captured were cabezon (Scorpaenichthys marmoratus), gopher rockfish (Sebastes carnatus), black and yellow rockfish (Sebastes chrysomelas), kelp greenling (Hexagrammos decagrammus) and lingcod (Ophiodon elongatus). These species composed $97 \%$ of the catch during the conversion study.

Differences in CPUE were analyzed using a multiple logistic regression model, with each of the five species analyzed independently. The more powerful parametric tests could not be used, as CPUE was highly variable between traps and had highly inflated levels of zero catch, resulting in a highly skewed dataset (Figure 6). Ordinal levels for catch were assigned by looking 
for CPUEs for each species that were similar and clumped. If no obvious clumps were located, ordinal levels were assigned by rounding the CPUE for each trap to the nearest tenth. Potential variables that could explain some of the trap-to-trap variation of CPUE (explanatory variables) that were included in these models were "bait type" (either chopped squid, or a mixture of squid and abalone trimmings), "soak time" (either one hour, or two hours), "depth trap set at," "site" (either MPA or reference site) and "fisherman" that set the trap. All models were checked to ensure goodness of fit, and non-significant variables were removed as long as the fit of the models was not sacrificed. If an explanatory variable had a p-value $<0.05$, that variable was considered to have a significant effect on the CPUE of the fish species.

If the explanatory variable "bait" was found to be significant, a conversion factor between the two baits was estimated by combining all traps that contained the same bait into one unit. Then, the mean CPUE for the analyzed fish species was found for one bait type and then divided by the mean CPUE for the other bait. The quotient arrived at was the conversion factor, or the number needed to convert CPUE from one bait type into the other. If soak time was found to be significant, a conversion factor would be found in a similar manner.

\section{5 b. Fish Length differences between bait and soak time}

Differences in fish length between bait and soak time for the top five captured species were determined using a General Linear Model for all fish captured in less than $45 \mathrm{ft}$. (13.7 m) of water. As length data for these nearshore fish populations is inherently skewed due to a bias imposed by the fishing gear, all lengths were log transformed to normalize these data. Potential explanatory variables that could explain the variation in length of captured fish that were examined were "bait type," "soak time," "depth trap set at," "site" and "fisherman." All nonsignificant variables were removed from the models as long as their removal did not hurt the fit 
of the model. Models were checked to ensure adequate fit, and to ensure that no confounding variables were included. If an explanatory variable had a p-value $<0.05$ it was considered to have a significant effect on the length of the captured fish species.

If the explanatory variable bait or soak time was found to be significant, a conversion factor between the lengths of the fish species for that variable was found using the method outlined in $2.4 \mathrm{a}$.

\section{5 c. Fishable Diversity differences between bait and soak time}

Fishable diversity levels were assessed using a Shannon-Weiner Diversity test. All values were calculated based upon the total number of each fish species captured in each sampling group. The four sampling groups are as follows: 1. Squid bait, One-hour soak time, 2. Squid and Abalone bait, One-hour soak time, 3. Squid bait, Two-hour soak time, 4. Squid and Abalone bait, Two-hour soak time. Diversity t-tests between sampling groups were performed using the software PAST, which uses a bootstrapping method to determine statistical significance (Hammer, Harper and Ryan 2001). Shannon-Weiner diversity t-tests were performed for all combinations of baits and soak time. A p-value of 0.05 was used to determine statistical significance.

If the either bait or soak time was found to be significant, a conversion factor between the calculated Shannon-diversity value for that variable was found using the method outlined in 2.4

a.

\subsection{Combined Dataset}

To ensure the datasets were comparable across sampling periods, only traps that were set in less than $45 \mathrm{ft} .(13.7 \mathrm{~m})$ of water and for a soak time of less than 2:05 were selected for analysis. The soak time of 2:05 was chosen as this was the average soak time of the two hour 
traps in the conversion experiment, and as pickup times were very accurate and precise in this experiment it would be inappropriate to extrapolate that soak times longer than 2 hours and 5 minutes would have no effect on CPUE, length of the captured fish or on diversity. At depths greater than $45 \mathrm{ft}$. catch was highly variable and dominated by gopher rockfish. In addition, the Cambria 2004 sampling had a maximum depth of $45 \mathrm{ft}$. To ensure continuity of depth across studies a maximum depth of $45 \mathrm{ft}$ was applied to all traps for all analyses.

Sampling at Cambria 2004 and 2006 occurred prior to the designation of Cambria MPA, so traps were designated as MPA or reference site based upon the future coordinates of those sites.

\subsection{Spatial and Temporal Analysis of Sample Species CPUE}

Cabezon and black and yellow rockfish had significantly different CPUE due to bait type, and thus their CPUE was adjusted to reflect the conversion factor. Conversion was completed on the commercial study datasets (Cambria 2004, Cambria 2006, Big Creek 2006 and Big Creek 2008) to reflect what their CPUE would have been if the MLPA monitoring studies protocols had been used throughout.

Comparisons were conducted using a multiple ordinal logistic regression model. For species often found singly in traps such as kelp greenling and lingcod, it was occasionally inappropriate to use the ordinal model, so a binary model was used instead.

An ordinal model as described previously, has distinct number values assigned to CPUEs which are similar to one another, or that are clumped together. For example, traps with a CPUE for cabezon of zero would have an ordinal value of zero assigned to it. Traps with a CPUE ranging from 0.9 to 1.2 would be assigned a value of 1, traps that ranged from 1.8-2.1 would be assigned a value of 2, and so on. A binary model uses a simpler presence/absence classification 
method, where if an individual trap has a CPUE of zero for the species being analyzed it is assigned a value of zero for the model. If the CPUE for the species in question is any number other than zero, it is assigned a value of 1 . See Appendix 1 for how to interpret an Ordinal or Binary Logistic Regression.

It was also occasionally necessary to bin traps together into groups of 2 or 3 to meet adequate fit requirements for the models. Grouping was conducted by combining the traps based upon the order they were set in the water. This served to decrease trap-to-trap variability and allowed adequate fit to be obtained.

All potential variables were included in the model during testing; Then, through a process of elimination, all non-significant variables were removed as long as fit of the model was not harmed. All models were checked to ensure goodness of fit, and if an explanatory variable yielded a p-value $<0.05$, it was considered significant predictor of CPUE for that species.

\section{7 a. General CPUE Comparisons}

Traps from individual locations were grouped together regardless of year to determine statistical differences between locations. Tests were conducted using a multiple ordinal logistic regression model on all combinations of years with all five fish species. Potential explanatory variables for this model included "year," "location," "depth trap set at," "soak time, "site" and "fisherman."

Statistical analyses on CPUE were conducted year to year within all three sampling locations, to assess and track changes within the locations across years. Potential explanatory variables for these models were identical to those above except for Big Creek did not contain the explanatory variable site as only the MPA was sampled at this location. 
Within each sampling location, traps designated as either MPA or reference site were analyzed independently of one another to assess changes within the sites at each location across all sampling years. These tests were performed in the same manner as described above, but lacked the explanatory variables "location" and "site."

To assess changes between the MPA and reference sites at Cambria and Piedras Blancas, catch per unit effort was compared between sites within individual sampling years, and across all sampling years. This was to determine if the two sites within a location were similar to one another, or diverging across years. These tests were conducted similarly to above. For within year comparisons made between sites, potential explanatory variables "year," and "location" were excluded. Tests comparing the two sites across all sampling years were conducted similarly to above with the inclusion of "year" as an explanatory variable.

\section{7 b Effect of Depth on CPUE}

All traps at Cambria were analyzed to determine the effect that depth has on CPUE for the five species. This was accomplished by using ordinal and binary logistic regression models as outlined above. Variables included "year," "site," "depth trap set at," "soak time" and "fisherman."

\subsection{Analysis of Population Structure based upon Length Frequency Analyses}

Using the data from the conversion experiment there were no significant differences in fish lengths between the different bait types and soak times. As there was no significant difference for fish lengths, these data did not need to be converted to ensure comparability between studies. However, in the commercial study fork length was measured for all captured fish, while in the MLPA monitoring study total length was measured. These two measurements produce different lengths on fish with forked tails, resulting in the need to convert the 
commercial study length data to total length. These conversions were completed using published conversions factors (Karpov and Kweicien 1988). All length data was also log-transformed to meet the assumptions of normality required to use a general linear model statistical test.

Statistical testing was performed using a general linear model with potential explanatory variables of "year," "location," "site," "depth trap set at," "soak time" and "fisherman." During testing all appropriate potential variables that could have an effect on fish length were included in the model, and through a process of elimination all non-significant variables and covariates were removed as long as fit of the model was not harmed. All models were checked to ensure goodness of fit, and if an explanatory variable yielded a p-value less than 0.05 was considered significant predictor of total length for that species.

\section{8 a. General Spatial and Temporal Comparisons of Sample Species Length}

Total length of the sample species was compared between Cambria, Piedras Blancas and Big Creek using a general linear model. All combinations of locations were tested for each species to determine the effect that location had on fish length. Variables tested included "location," "year," "site," "depth trap set at," "soak time" and "fisherman."

Statistical analyses on fish length were conducted year to year within all three sampling locations. This was done to assess and track changes in fish length within each location across sampling years. A general linear model was used for all tests, run for all combinations of years and fish species. Statistical tests were similar to those outlined above, with the exclusion of the variable "location." Tests for Big Creek did not use the "site" variable.

Within each sampling location, traps designated as either MPA or reference site were analyzed independently of one another to assess changes in fish length within the sites at each 
location across all sampling years. These tests were performed in the same manner described above, but lacked the potential explanatory variables "location" and "site."

To assess changes between the MPA and reference sites at Cambria and Piedras Blancas, fish length was compared between sites within individual sampling years, and across all sampling years. This was to determine if sites within a location were similar to one another, or diverging across years. To assess changes between sites within a single sampling year, tests were conducted similarly to above with the exclusion of potential explanatory variables "year," and "location." Tests comparing the two sites across all sampling years were conducted similarly to above with the inclusion of "year" as an explanatory variable.

\subsection{Spatial and Temporal Comparisons of Fishable Diversity}

Using the PAST software and the data from the conversion experiment there was no significant differences in diversity between bait type and soak time. As there was no significant difference, these data did not need conversion to ensure comparability between the commercial and MLPA monitoring studies.

Shannon diversity index t-tests are conducted in PAST through a bootstrapping method, and P-values $<0.05$ signified significant differences in diversity levels (Hammer, Harper and Ryan 2001).

\section{9 a. General Spatial and Temporal Comparisons of Fishable Diversity}

Shannon diversity index values were compared for Cambria, Piedras Blancas and Big Creek using the PAST software. For these tests, data from each location was merged regardless of year sampled and all combinations of sampling location were analyzed to determine how Shannon diversity varied between sampling locations. 
Shannon diversity t-tests were conducted for all combinations of years within Cambria, Piedras Blancas and Big Creek to assess how diversity changed over time within each location. Tests were conducted similarly to above.

Shannon diversity t-tests were conducted between sites at each location for each individual sampling year at Cambria and Piedras Blancas. In addition, Shannon Diversity t-tests were conducted between sites across all sampling years at each location. This was to determine if sites within a location were similar to one another, or diverging across years. Big Creek was not tested in this manner because we did not sample outside of the MPA. All tests were conducted similarly to above.

\subsection{Fish Movements}

For all fish recaptured after being tagged in a prior sampling period, the distance between the initial capture point and subsequent recapture point was measured. Fish that had travelled a distance of greater than half a kilometer were excluded from this analysis, as these were considered indicative of a change in home range location rather than the day-to-day movement patterns of the fish. The mean average distance from recapture was obtained for each species.

\subsection{Post-Larval Recruitment}

Post-Larval recruitment of cabezon and the KCGB complex (kelp rockfish, copper rockfish, gopher rockfish and black and yellow rockfish) were assessed using Standard Monitoring Unit for Recruitment of Fish traps (SMURF) traps at Avila Beach and Cayucos CA from 2004 to 2008. Construction and deployment of these traps is outlined in Wilson, 2006. In addition, the 2004-2006 data was adapted from Wilson, 2006. To ensure data continuity between sampling years only data from June $15^{\text {th }}$-August $24^{\text {th }}$ were used for analysis, as all years 
had data within this range. Recruitment rates were calculated by determining the average number of recruits settling in each SMURF trap per day. Statistical analyses were conducted using ANOVA tests for all combinations of years. 


\section{Results}

\subsection{General Catch Statistics}

Three thousand, four hundred and sixty fish were captured in 3,951 live fish trap sets between 2004-2009 in waters less than $45 \mathrm{ft}$ deep and with a soak time of less than 2 hours and 5 minutes. At the Cambria location 257 fish were captured in 2004. Of those, 175 cabezon were tagged and measured. In 2006, 1,175 total fish were captured and measured at the Cambria location, with 740 cabezon tagged. At the Big Creek MPA 465 fish were captured in 2006, with 145 cabezon tagged and measured.

During 2008 three locations were sampled (Big Creek, Cambria and Piedras Blancas). Big Creek had 330 fish measured and 103 cabezon tagged, while Cambria and Piedras Blancas had 548, and 217 fish tagged and measured respectively (Table 2). Overall, cabezon (Scorpaenichthys marmoratus) accounted for $44.6 \%$ of the catch, gopher rockfish (Sebastes carnatus) $13.4 \%$, black and yellow rockfish (Sebastes chrysomelas) $24.7 \%$, kelp greenling (Hexagrammos decagrammus) $11.4 \%$ and lingcod (Ophiodon elongatus) $3.1 \%$ (Table 3).

In both the commercial and the MLPA monitoring studies, $50 \%$ of the traps returned no fish (Figure 6.) Because of this, catch per unit effort was highly variable. All species had a highly skewed catch frequency, with the majority of traps capturing no individuals, although a few captured high numbers. Capture rates as measured by CPUE for these captured fish species suggest that significant variation exists between sampling locations, between sampling years at the same location, and between the two sites at each location (MPA and reference site).

Length data was not as variable as CPUE. Total length for the different species did not vary widely across years at the same location. As noted above, for sampling begun in 2004 at Cambria and 2006 in Big Creek, only cabezon were measured. In subsequent sampling years at 
Cambria, Big Creek and Piedras Blancas, all fish species were measured. We noted significant differences in length for cabezon, gopher and black and yellow rockfish between the sampling locations. There were also significant differences in fish length across sampling years at the same location.

\subsection{Conversion Study}

\section{2 a. Catch per unit effort differences between bait and soak time}

In the conversion study, CPUE varied between bait type and soak time for the captured fish species. None of the five species showed a significant difference in CPUE between different soak times (Figure 7 a-e). Gopher rockfish, kelp greenling and lingcod did not exhibit significantly different CPUE between bait types (Figure 8 b,d,e). In contrast, cabezon and black and yellow rockfish did show significantly different CPUE between bait types (Figure $8 \mathrm{a}, \mathrm{c}$ ). Traps baited with abalone and squid had significantly higher CPUE for cabezon $(\mathrm{p}<0.016)$, while the traps baited with squid alone had significantly higher CPUE for black and yellow rockfish $(\mathrm{p}<0.009)$. Traps baited with squid alone showed 50.5\% lower CPUE for cabezon, while black and yellow rockfish levels were $310 \%$ higher.

\section{2 b. Fish Length differences between bait and soak time}

Mean length was not significantly different between the different bait types and soak times for any of the captured species ( $p>0.1$ ) (Figure 9). No conversion was needed to make these data comparable between studies. 


\section{2 c. Diversity differences between bait and soak time}

Fishable Diversity values were not significantly different between the different trapping and baiting protocols using Shannon-Diversity t-test (p-value >0.1) (Figure 10). No conversion was needed to make these data comparable between studies.

\subsection{Combined Dataset}

For analysis of data across all years and sampling locations, the datasets from the two different studies were linked together. This was done by converting the CPUE for cabezon and black and yellow rockfish from the commercial study to reflect what these levels would have been if the MLPA monitoring study protocols had been used throughout. The conversion factors found in 3.1a were used to accomplish this.

\section{Spatial and Temporal Analysis of Sample Species CPUE}

\section{3 a. General CPUE Comparisons}

Four of the five sample species had significant differences in CPUE between the different sampling locations when the linked data was analyzed across all sampling years. The CPUE for cabezon was significantly different between Cambria and the other two locations, with Cambria having the highest CPUE, while Big Creek and Piedras Blancas had similar CPUEs (Figure 11 a). Gopher and black and yellow rockfish were significantly different between all sampling locations, with Big Creek having the highest CPUE and Piedras Blancas having the lowest levels (Figure 11 b,c). Kelp greenling CPUE was statistically indistinguishable across all sampling locations, but neared significance with higher levels at Big Creek than at either Cambria or Piedras Blancas (p-values $<0.062$ and 0.073 respectively) (Figure $11 \mathrm{~d}$ ). Lingcod had 
significantly higher CPUE at Cambria than at Big Creek, but Piedras Blancas was not different than either (figure $11 \mathrm{e}$ ).

When the data from Cambria were analyzed across all sampling years (2004-2009), no differences in CPUE were found for kelp greenling (Figure $12 \mathrm{~d}$ ). Cabezon and lingcod CPUE were statistically indistinguishable between individual years, but across all sampling years both species experienced a significant decline in CPUE (Figure $12 \mathrm{a}, \mathrm{e}$ ). Gopher rockfish CPUE fluctuated significantly across years, with 2008 having the highest levels, and 2004 the lowest (Figure 12 b). Black and yellow rockfish followed a similar trend, with 2008 having the highest CPUE and 2006 the lowest (Figure 12 c). CPUE in 2004 and 2009 were not significantly different from one another, however both rockfish species experienced a significant increasing trend in CPUE across sampling years.

Big Creek was sampled over a shorter period, 2006 and 2008, so longer-term trends in CPUE could not be analyzed. Three species (gopher rockfish, black and yellow rockfish, and lingcod) had statistically indistinguishable CPUE over the sampling period (Figure 13 b,c,e). Cabezon and kelp greenling had significantly different CPUE between years, with 2008 having higher levels (Figure 13 $\mathrm{a}, \mathrm{d})$.

Piedras Blancas was only sampled for two years (2008 and 2009). No species over this period had significant differences in CPUE between sampling years (Figure 14 a,b,c,d,e).

When the trap data from each location was split into traps set in either the MPA or the reference site, there were still changes in CPUE across sampling years. Within the Cambria MPA, cabezon CPUE was stable across all sampling years with no significant differences. By contrast, CPUE within the Cambria reference site showed a significant trend of decreasing CPUE, with each year having lower levels than the previous (Figure 15 a). 
Gopher rockfish CPUE within the Cambria MPA and the reference site show a significant increasing trend across years (Figure $15 \mathrm{~b}$ ). Inside of the MPA, CPUE did not vary significantly between individual years. The reference site followed a similar trend as the MPA, but 2008 had significantly higher CPUE values than 2004 (Figure 15 b).

Catch per unit effort for black and yellow rockfish showed a significant increasing trend at the reference site across the sampling years, while CPUE within the MPA was statistically indistinguishable across all years. Both sites experienced significantly lower catch levels in 2006 than in other years. Catch levels increased in 2008, and these increases were significant in the reference site. Both sites had lower levels in 2009 (Figure 15 c).

Kelp greenling CPUE inside of the Cambria MPA and reference site fluctuated across all sampling years but no significant trends were detected. At both sites none of the years were significantly different from one another. The MPA experienced fluctuating CPUE with increases in 2006 and 2009 and lower levels in 2004 and 2006, while the reference site increased from 2004 to 2006 and experienced stable catch levels from 2006-2009 (Figure 15 d).

CPUE for lingcod within the MPA and reference site at Cambria did not differ significantly between sampling years, or across all years (Figure $15 \mathrm{e}$ ). Due to low sample size for lingcod in the Cambria reference site, a Kruskall Wallace test was used instead.

At Piedras Blancas (2008-2009), there were no significant differences in CPUE in either the MPA or reference site across sampling years for cabezon, gopher rockfish, kelp greenling and lingcod (Figure 16 a,b,d,e). Black and yellow rockfish had significantly higher CPUE in the MPA in 2009 sampling compared to 2008; no significant difference was found within the reference site (Figure $16 \mathrm{c}$ ). 
Between sites (MPA and reference site) at the same location there was often variability in CPUE. Within Cambria, cabezon and gopher rockfish were statistically indistinguishable between sites for every year except 2006, when the MPA had significantly higher CPUE for both species than the reference site. However, across all sampling years (2004-2009) cabezon had significantly higher CPUE inside the MPA than at the reference site, while gopher rockfish CPUE was not significantly different between sites (Figure 17 a,b). Black and yellow rockfish at the Cambria sampling location had statistically indistinguishable CPUE at both the MPA and reference site within each sampling year, and there was no significant difference between sites across all sampling years (Figure $17 \mathrm{c}$ ). Kelp greenling experienced significantly higher CPUE in the MPA in 2006 and 2009, and across all years, the MPA had significantly higher levels (Figure 17 d). Lingcod had significantly higher CPUE in the MPA in 2006, and across all sampling years (Figure 17 e).

Inside Piedras Blancas there were species dependent variations in CPUE between the MPA and reference sites. Two species, kelp greenling and lingcod, did not show significant variation between sampling sites within each year or across all years (2008-2009)(Figure 18 d,e). Cabezon CPUE was consistently higher in the MPA than in the reference sites, with a significant difference in 2008, and near significance in 2009 (p-value 0.058). Across all years the cabezon had significantly higher CPUE in the MPA than the reference site (Figure 18 a). Gopher rockfish had consistently higher CPUE in the reference site than the MPA, with 2009 being significantly different, and across all years CPUE was significantly higher in the reference site (Figure $18 \mathrm{~b}$ ). Levels for black and yellow rockfish were higher in the MPA across all years, but this difference was not significant, although in 2009 CPUE was significantly higher in the MPA than in the reference site (Figure $18 \mathrm{c}$ ). 


\section{3 b. Effect of depth on CPUE}

The depth at which individual traps were set at was rounded to the nearest foot, and analyzed to establish how depth affects CPUE of the different species. For three species (cabezon, gopher rockfish, and kelp greenling) depth was a significant predictor of CPUE. Lingcod was near significant with a p-value $<0.078$. Cabezon CPUE was negatively correlated with depth, with an increase in depth of one foot correlated to a decrease in CPUE of $\sim 6 \%$ for this species. The other species experienced increases in CPUE with increasing depth. Kelp greenling had a modest $~ 2 \%$ increase in CPUE for every foot a trap was set deeper, while gopher rockfish had a very large effect of depth on CPUE, with an increase of $\sim 33 \%$ for every increase in depth (Figure 19).

\section{Analysis of Population Structure of Sample Species based upon Length Frequency Analyses}

\section{3 c. General Spatial and Temporal Comparisons of Sample Species Length}

The mean total length for the five analyzed fish species was variable across all sampling locations. Total cabezon length was not significantly different between Big Creek and Piedras Blancas with averages length of 42.8 and $40.8 \mathrm{~cm}$ respectively. These locations were both significantly different from Cambria, which had a mean length of 38.6 (Figure 20 a). Gopher and black and yellow rockfish shared a similar trend to cabezon, with both Big Creek and Piedras Blancas harboring statistically indistinguishable sized fish, and Cambria significantly smaller fish. Gopher rockfish in Big Creek and Piedras Blancas averaged $28.3 \mathrm{~cm}$, while Cambria averaged $25.4 \mathrm{~cm}$ (Figure $20 \mathrm{~b}$ ). Black and yellow rockfish in Big Creek and Piedras Blancas both averaged $28 \mathrm{~cm}$, while Cambria averaged $25.3 \mathrm{~cm}$. (Figure $20 \mathrm{c}$ ). Kelp greenling and 
lingcod did not show significant differences in length between sampling locations, with mean lengths for kelp greenling around $36 \mathrm{~cm}$ and $63 \mathrm{~cm}$ for lingcod (Figure $20 \mathrm{~d}$,e).

Total length of the different fish species at each sampling location on a year-to-year basis was less variable than CPUE. Cabezon, the only species measured across all sampling years and locations, averaged $38 \mathrm{~cm}$ at Cambria from 2004 to 2008, followed by a statistically significant increase in 2009 to a total length of $40 \mathrm{~cm}$ (Figure 21 a). Gopher rockfish total lengths were statistically indistinguishable across all sampling years at Cambria, with a mean total length across years of $25.6 \mathrm{~cm}$ (Figure $21 \mathrm{~b}$ ). Mean total length of black and yellow rockfish was more variable than other species with all years having significantly different total lengths. The highest mean length was in 2006, $26.2 \mathrm{~cm}$, followed by 2009 and 2008, with lengths of 25.4 and 24.9 respectively (Figure 21 c). Kelp greenling mean length increased from 2006 to 2009 at Cambria, with lengths increasing from 35.7 to $36.1 \mathrm{~cm}$, but this trend was not significant (Figure $21 \mathrm{~d}$ ). Lingcod had no discernable trend in mean total length across sampling years at Cambria, all sampled years had statistically indistinguishable measured lengths (Figure $21 \mathrm{e}$ ).

Three of five species (cabezon, black and yellow rockfish and lingcod) did not show significant differences in total length at Piedras Blancas (Figure 22 a,c,e ). Gopher rockfish total lengths decreased significantly from $2008(28.6 \mathrm{~cm})$ to 2009 (27.7 cm) (Figure $22 \mathrm{~b}$ ). Kelp greenling experienced a significant increase in total length from 2008 to 2009, with lengths of 36.3 and $37.2 \mathrm{~cm}$ respectively (Figure $22 \mathrm{~d}$ ).

Only one species, the cabezon, was measured for total length over both sampling years at Big Creek. This species showed statistically indistinguishable lengths across the two years, with 2006 having an average total length of $43.2 \mathrm{~cm}$ compared to $42.1 \mathrm{~cm}$ in 2008 (Figure 23). 
Mean cabezon length within the Cambria MPA declined in length from 2004-2008, from $39.6 \mathrm{~cm}$ in 2004 to $37.9 \mathrm{~cm}$ in 2008. Although this was followed by an increase in 2009 to 39.9 $\mathrm{cm}$, there was no significant difference in total length between years. The reference site had an average total length of $37.8 \mathrm{~cm}$ from 2004 to 2008 , followed by a significant increase to $40.4 \mathrm{~cm}$ in 2009 (Figure 24 a). Gopher rockfish experienced a near significant increasing trend in the MPA at Cambria (p-val. <0.085) with lengths increasing from 25.7 to $27.5 \mathrm{~cm}$ (Figure $24 \mathrm{~b}$ ). Within the reference site, gopher rockfish lengths experienced a slight increase in mean length, but this increase was not significant, and of a lesser magnitude than the MPA. Black and yellow rockfish lengths followed similar trends inside the MPA and reference site. In both sites 2006 had the highest total length followed by 2009, 2008 had the shortest fish. The lengths within the MPA did not vary significantly across years, but the reference site did have significant differences across years with a decreasing trend in length. Total length within the reference site experienced an overall significant decline between 2006 and 2008 from $27 \mathrm{~cm}$ to $25.4 \mathrm{~cm}$, followed by a near significant increase in length from 2008 to 2009 to $26 \mathrm{~cm}$ (Figure $24 \mathrm{c}$ ). Kelp greenling within both the MPA and reference site at Cambria did not experience significant changes in total length over the course of sampling (Figure $24 \mathrm{~d}$ ). Lingcod length increased significantly across sampling years inside of the Cambria MPA with mean total lengths in 2006, 2008 and 2009 of 57.5, 67.1 and $64 \mathrm{~cm}$ respectively (Figure $24 \mathrm{e}$ ).

When separated into MPA and reference sites there were no significant changes in total length at Piedras Blancas for all analyzed fish species from 2008 to 2009 (Figure 25 a-d). A lack of data for lingcod in 2009 prevented the use of the general linear model, but using the KruskallWallace test no significant difference was found between years. 
For the two sites at Cambria, cabezon did not show significantly different total lengths between sites in 2006, 2008 and 2009, although the MPA showed significantly longer fish than the reference site in 2004 (Figure 24 a). Gopher rockfish and lingcod total lengths did not differ significantly between sites at Cambria for individual years (Figure $24 \mathrm{~b}$,e). Every sampling year the reference site held significantly longer black and yellow rockfish than the MPA (Figure 24 c). In 2006 and 2009 the Cambria MPA had significantly longer kelp greenling than the reference site (Figure $24 \mathrm{~d}$ ).

At Piedras Blancas there were no significant differences between sites every sampling year for gopher rockfish, kelp greenling and lingcod (Figure 25 b,d). In 2008, the reference site at Piedras Blancas had significantly longer cabezon and black and yellow rockfish than the MPA, but 2009 was statistically indistinguishable between sites for both species (Figure 25 a,c).

Both sites at Cambria and Piedras Blancas held statistically indistinguishable sized cabezon, gopher rockfish, and lingcod across all years (Figure 24 a,b,e, Figure 25 a,b). At both Cambria and Piedras Blancas black and yellow rockfish were significantly longer within the reference sites than inside the MPAs across all years (Figure 24c, Figure 25 c). In addition, kelp greenlings within the Cambria MPA were significantly longer across all years than those residing in the reference site (Figure $24 \mathrm{~d}$ ).

\section{Spatial and Temporal Comparisons of Diversity}

\section{3 d. General Spatial and Temporal Comparisons of Diversity}

Fishable Diversity comparisons were performed on merged data from each sampling location, regardless of year sampled. These data included numbers of every fish species captured in the traps (Table 3). Shannon-diversity indexes show significant differences between the different sampling locations, with Cambria having the lowest diversity value of 1.37 , followed 
by Piedras Blancas at 1.547 and Big Creek at 1.563 . Fishable Shannon diversity was not significantly different between Piedras Blancas and Big Creek, but Cambria was significantly lower than both locations (Figure 26).

Species richness was also compared between the different locations, with eleven different species of fish captured in both Cambria and Piedras Blancas, and twelve captured in Big Creek (Figure 27).

At the Cambria sampling location Shannon-diversity values steadily increased from a low in 2004 of 1.008 to a high of 1.419 in 2009. Cambria experienced a near significant increase in diversity between 2004 and 2006 (p-val. 0.069), followed by a significant increase between 2006 and 2008. 2008 and 2009 were statistically indistinguishable. Both Piedras Blancas and Big Creek had statistically indistinguishable Shannon-diversity index values across all sampling years (Figure 28).

Species richness at Cambria fluctuated between eight and nine species, while at Piedras Blancas richness was ten in 2008 and 7 in 2009. Inside of the Big Creek MPA nine species were captured in 2006 and ten in 2008 (Figure 27).

At a finer scale, the reference site at Cambria experienced significant increases in diversity between 2004-2006 and 2006-2008 but not between 2008-2009, while the MPA only experienced significant increases between 2006 and 2008 (Figure 29). Shannon-diversity index values for the reference site and the MPA at Piedras Blancas were not significantly different across sampling years (Figure 30).

The MPA at Cambria consistently held higher diversity values than the reference site. These differences were not significant in 2004 and 2006, but were significant in 2008 and 2009. Both sites had a trend of increasing diversity across years (Figure 29). At Piedras Blancas, 
Shannon-diversity index values were higher in the reference site than within the MPA. This difference was significant in 2008 with the MPA having a value of 1.371 and the reference site 1.642. In 2009, this difference was not significant with the diversity values at the reference site dropping to 1.448 and the MPA staying similar at 1.377 (Figure 30).

\subsection{Fish Movements}

A total of 138 cabezon, 11 gopher rockfish and 2 kelp greenlings that had been tagged during prior sampling periods were recaptured. Upon analysis, fish that had a mean recapture distance of greater than half a kilometer were excluded; only 4 fish met this criterion, and all were cabezon. After these cabezon were excluded, mean distance between captures was measured for the remaining fish. Cabezon had an average recapture distance of 49.5 meters (162 ft), gopher rockfish $19.2 \mathrm{~m}$ (63 ft) and kelp greenling 25m (82 ft) (Figure 31).

\subsection{Post-larval Recruitment Rate}

Recruitment for both cabezon and the KCGB (kelp, copper, gopher, black and yellow rockfish) complex peaked in 2005, with an average of 0.64 KCGB recruiting to the SMURF trap per day, and 0.01 cabezon. Across the sampling years (2004-2008) there was no significant difference in cabezon recruitment (p-value $<0.074$, while KCGB were significantly different across years. For these species 2004, 2006, 2007 and 2008 are statistically indistinguishable, but 2005 was significantly different (Figure 32). Between SMURF locations, the Cambria location had the lowest recruitment rate for cabezon and second lowest for the KCGB complex. Port San Luis recruitment for cabezon was similar to Cayucos, but this site received significantly higher KCGB recruitment than any other site. Avila Beach had the lowest overall recruitment for KCGB, but the highest recruitment for cabezon (Figure 33). 


\section{Discussion}

\subsection{Conversion Experiment}

Prior to conducting comparisons between the Commercial and MLPA monitoring studies, tests needed to be run to ensure data comparability. The conversion experiment blended the two protocols together to assess their effects on CPUE, mean total length, and diversity of fish species captured. Traps were set for two different lengths of time (1 hour and 2 hours) and subjected to different baiting regimes (Squid alone, or squid and abalone trimmings). The traps used in this experiment were analyzed to determine if the different treatments had significant effects on the sample fish species. The end goal of the analysis was to link the datasets from the two studies to support longer-term comparisons.

When traps are left in the water for increasing time periods a phenomenon known as trap saturation occurs. Longer soak times typically results in lower CPUE levels, as the number of new fish entering the traps decreases as time increases. This can be due to such factors as dwindling amounts or attractive quality of the bait, limitations of space in the trap, and predator/prey interactions (Sheaves 1995). With the conversion experiment we tested to determine if different soak times (1 hour and 2 hour) had significant effects on CPUE for the commonly captured fish species. The one hour and two hour soak times did not have a significant effect on CPUE (Figure 7).

In addition to changes in CPUE due to soak time, bait was analyzed to determine its effect on CPUE. The commercial study traps were baited with a mixture of squid and abalone trimmings, while in the MLPA monitoring study traps were baited with squid alone. It is known that different baits will have different attractant qualities to fish species (Kasumyan and Doving 2003). Three species (gopher rockfish, kelp greenling, lingcod) did not have significantly 
different CPUEs under the different baiting protocols. The baits did not alter how often these fish entered a trap and were captured (Figure $8 \mathrm{~b}, \mathrm{~d}, \mathrm{e}$ ). However, two of the species (cabezon, black and yellow rockfish) had significantly different CPUE under the different baiting protocols. With the squid alone treatment, cabezon experienced lower CPUE (50.5\%), while black and yellow rockfish had a higher CPUE (310\%) when compared to the squid and abalone treatment (Figure 8 a,c). Adult cabezon are natural predators on abalone, and its presence explains why CPUE was higher in traps that contained it (Love 1996, Griffiths and Gosselin 2008). Adult black and yellow rockfish typically feed on zooplankton, crustaceans, cephalopods and small fish (Love 1996). It is probable based upon their diet that black and yellow rockfish prefer squid to abalone and when it is present in smaller volumes as happens in the squid and abalone mixture, that the traps attractant qualities are lessened, resulting in a lower CPUE. It is also possible that the mixture of squid and abalone trimmings attracts increased numbers of larger fish like cabezon and lingcod, and these exclude the smaller black and yellow rockfish.

Gopher rockfish have a similar diet and size range to the black and yellow rockfish, making it likely that their CPUE is affected by the baiting protocols as well (Love 1996). This species had a lower CPUE with the squid and abalone mixture than with squid, but this difference was not significant (Figure 8 b). Gopher Rockfish catch is highly affected by the depth at which the traps are set, and they were commonly captured only in traps set in greater that $35 \mathrm{ft}$ (10.7 m) of water (Figure 19). In addition, CPUE was highly clumped, with many traps containing zero gopher rockfish followed by several traps showing upwards of five individuals captured. With increased sampling this variability will be accounted and possibly show a significant effect of bait on the CPUE of gopher rockfish. 
As fish mature and increase in size they prefer different prey species (Love, 1996). Younger cabezon are known to feed primarily on crustaceans, while adults switch to larger crustaceans, abalone, cephalopods and fish. Smaller gopher and black and yellow rockfish primarily eat zooplankton, while larger individuals eat larger prey such as crabs, shrimp, fish and cephalopods. Kelp greenling, according to Milton Love, "will eat about anything that is not nailed to the bottom". Lingcod are highly predatory and will consume fish and cephalopods (Love 1996). Based upon these diets we would not expect to find differences in length due to the bait, as only adults from the five analyzed species would be attracted to the squid or abalone used for bait. In addition, smaller fish that enter the traps can exit more easily and avoid capture than larger individuals (Sheaves 1995). The results confirm this expectation with bait having no significant effect on the length of captured fish (Figure 9). These two baiting protocols do not capture significantly different sized fish.

Traps set for different soak times might capture different sized fish. As mentioned previously, it is possible that smaller fish can enter the traps, feed upon the bait, and more easily exit the traps once satiated than larger fish can. If a trap is retrieved after a short soak time it is possible that higher numbers of small fish would be present than in a longer soak, creating a difference in mean total length of captured fish. The results show that this is not the case; soak time had no significant effect on the mean total length of analyzed fish (Figure 9). Neither bait type nor soak time affected fish length.

For diversity testing all fish species that entered the traps were used. Using Shannondiversity t-tests it was found that the different baiting and trapping protocols had no significant effect on diversity. However, there was a decreasing trend in diversity with increasing soak time, with the traps set for 2 hours having a lower average diversity value than the $1 \mathrm{hr}$. traps (Figure 
10). It is possible that with increased sampling that we would find a significant effect of soak time on piscine diversity. Diversity levels were similar between the two bait types, but it is possible that bait type might affect the diversity of fish captured, as the different baits attract different species.

The results of the conversion experiment show that there is no need to convert the CPUE for 3 of 5 species to make these data comparable between studies. Likewise, there is no need to convert lengths of captured fish or diversity to ensure comparability between studies. Catch per unit effort for cabezon and black and yellow rockfish were converted to reflect the levels that catch levels if MLPA monitoring protocols were used throughout. This conversion allows for the datasets to be linked, and for comparisons to be made across all study periods. After linking the datasets comparisons were made across all sampling periods and locations to analyze changes in CPUE, mean total length, and diversity of nearshore fish species.

\section{Summary of Analyses By Species}

\subsection{Cabezon}

Of the three sampling locations, Cambria had the highest CPUE for cabezon, while Big Creek and Piedras Blancas have similar levels, indicating that cabezon resided in higher abundances at Cambria, as CPUE is considered a proxy for abundance (Figure 11 a)(Haggarty and King 2006). Abundance of cabezon at Cambria as approximated by CPUE was $77 \%$ higher than the other locations. However, the mean total lengths in the different locations show a different trend, with all sites having significantly different fish. Cambria holds the smallest average cabezon with an average length of $38.6 \mathrm{~cm}$ (15.2 in), followed by Piedras Blancas at $40.8 \mathrm{~cm}$ (16 in) and Big Creek at 42.8cm (16.9 in) (Figure 20 a). It is likely that cabezon in Big Creek and Piedras Blancas attain greater lengths due to either absence of fishing pressure, or 
reduced fishing pressure. Typical thinking on MPAs is that with reduced fishing pressure the populations of fish will increase in length and become more numerous (Barrett et al., 2007). We did not find this to be the case here. Shroeder and Love, 2002, found similar results when comparing fishable to protected areas where the fishable areas had higher abundances of smaller fish.

A possible explanation for the differences in CPUE is that the larger fish in Big Creek and Piedras Blancas have larger home ranges and increased metabolic needs, and are excluding smaller fish. This would result in a decrease in number of individuals in an area, and an increase in average home range size (Kramer and Chapman 1999). However, the data for mean distance between capture points (proxy for home range size) for cabezon of different lengths does not support this. Mean recapture distance and size of cabezon is not correlated ( $p$-value $<0.279$, $\mathrm{n}=134$ ). For the size range analyzed, larger cabezon were not recaptured at greater distances than smaller cabezon, indicating that home range size appears to not be affected by length of the fish. It is possible that all locations hold larger cabezon that cannot fit into the traps and are not being captured, as the traps have an upper size limit of approximately $56 \mathrm{~cm}$ (22 in) and this species is known to attain lengths of greater than 90cm (35.4 in)(Eschemeyer et al.,1983, Love 1996). It appears that Cambria is more productive for cabezon than the other locations as it has the highest fishing pressure, but also consistently has the highest abundance. This is likely due to the amount and quality of habitat at Cambria suiting cabezon better than at other locations.

Within Cambria CPUE has consistently declined across sampling years (Figure 12 a). However, when the data are split into MPA and reference site, it shows that this overall decline is mainly due to a significant drop in CPUE within the reference site, while the MPA stays stable (Figure 15 a). This drop in the reference site was more dramatic in 2009 than in previous years, 
while the MPA had an increase in CPUE during that years sampling. The number of fishers operating out of Morro Bay with nearshore permits has not declined dramatically from 2003 onwards, and Morro Bay landings from 2005 on have likewise stayed fairly stable (Figures 34, 36)(CDFG 2000-2008). Morro Bay commercial landings of cabezon in 2000 were 96,500lbs $(43,771 \mathrm{~kg})$, dropped to $\sim 50,000 \mathrm{lbs}(22,679 \mathrm{~kg})$ in 2002 and stayed stable until 2005 when catch was dropped again to $\sim 30,000 \mathrm{lbs}(13,607 \mathrm{~kg})$. With the establishment of the MPA available fishing habitat decreased. The drop in CPUE in the reference site could be due to concentrating fishers into a smaller area than was previously available, while catch levels remained the same. This could be causing the declines in abundance seen within the reference site while the MPA is not declining.

Based upon von Bertalanffy growth curves, cabezon grow quickly, and are legally fishable at approximately four years of age $(>38 \mathrm{~cm}, 15 \mathrm{in})$, allowing for legally fishable recruits to enter the fishery in a shorter period of time than many other species (Figure 35) (Grebel 2003, Eschemeyer et al.,1983, Love 1996). Length at $50 \%$ maturity for this species varies by sex. Males mature at a younger age and shorter length $(1.9 \mathrm{yrs}, 29.7 \mathrm{~cm})$ than females $(2.3 \mathrm{yrs}$, $33.7 \mathrm{~cm}$.$) (Grebel, 2003) This indicates that by the time these fish are legally harvestable they$ are sexually mature and have likely spawned previously.

At Cambria the average fish captured is between four and five years old, indicating that abundance of this species and replacement of fished biomass is dependent upon recent postlarval recruitment events (Lea et al., 1999). Years of good or poor post-larval recruitment translate into variations in CPUE when that year class enters as fishable biomass (Morgan et al.,1982, Roughgarden et al.,1988). Cabezon experienced great recruitment in 1997 and 1998 followed by poor recruitment up to 2005 (Cope and Key 2009). At the Cayucos and Avila Beach 
SMURF sampling locations from 2004-2008 there was no significant difference between years in cabezon recruitment although there was a near significant increase in post-larval recruitment in 2005 (Figure 32). Post-larval cabezon begin recruiting in March and continue through the fall, while the SMURF traps are have typically been deployed in mid-May (Wilson 2006, Love 1996). A portion of the post-larval recruits might be missed due to this each year. With continued years of poor post-larval cabezon recruitment, it is possible that fewer individuals entered the fishery to replace fished individuals. This in combination with stable allowable catch in a smaller available area is likely driving the declines in CPUE in the reference site, while the MPA is staying stable.

Post-larval recruits from the 2005 year class should have begun to enter fishery as early as 2009 and this might partially be responsible for the increase in CPUE in the MPA in 2009 (Figures 15 a, 35). Although, when analyzing post-larval recruitment across four SMURF sampling locations (Cambria, Cayucos, Avila Beach, Shell Beach) we find cabezon recruitment is highly variable (Wilson 2006). Across all years sampled the Cambria SMURFs, which are located on the south side of the reference site, consistently had the lowest post-larval recruitment levels of cabezon (Figure 33). Larval fish prefer to recruit in the leeside of headlands, and the Cambria location is not in the lee of any headlands (Wilson 2006, Warner et al., 2000). This suggests that the Cambria location does not receive the level of post-larval recruits that other locations do, and possibly why we do not see an increase in CPUE across both the MPA and reference site in 2009.

Within Piedras Blancas there was no significant difference in either total length or CPUE between years at both the MPA and reference site (Figures 14 a, 22 a). This suggests that over the short period of protection (2007-onwards) this MPA is not having an effect on cabezon 
populations. It is likely that within the reference site that fishing levels are low enough to have little effect on abundance or mean total length of cabezon over this short period. With the larger 2005 post-larval recruit class of cabezon entering the fishery between 2009 and 2010 it is possible that CPUE will increase.

Big Creek has not been fished recreationally or commercially since 1993. Due to their fast growth and maximum age of 13 years the cabezon population within this location is likely mature (Grebel 2003)(Love 1996). As long as natural mortality and post-larval recruitment levels remain stable we would not expect significant changes in CPUE or mean length of fish within Big Creek. However between 2006 and 2008 there is a significant increase in CPUE and a nonsignificant decline in total length at this location (Figures 13a, 23).

Big Creek is in the lee of several headlands and could be receiving higher numbers of recruits than either Cambria or Piedras Blancas due to localized currents and eddies. There is also evidence of a large recruitment class entering as fishable biomass in 2008 at Big Creek. In 2008 , there is a large percentage increase of individuals in the $\sim 38 \mathrm{~cm}$ (15in) range, which is indicative of fish that recruited four years previously (Figure 37). In 2006, these fish would have been approximately $31 \mathrm{~cm}(12.2 \mathrm{in})$ and below the fishable size of the traps. A surge in post-larval recruits explains the significant increase in CPUE in 2008 in addition to the decrease in mean length of cabezon.

Prior work at Cal Poly using mtDNA and microsatellites from cabezon has shown that California contains at least six distinct subpopulations (Villablanca and Nakamura 2008). This indicates that there is little intermixing between populations which are spatially nearby. It is possible that the fish found within Big Creek are from a different subpopulation than the fish found within either Piedras Blancas or Cambria. The increase in CPUE at Big Creek in 2008 
could be due to a surge in post-larval recruitment of a subpopulation of cabezon that is distinct from those found at Cambria, which had lower recruitment levels for that year. This could explain why CPUE increased in 2008 at Big Creek while at Cambria CPUE stayed the same.

\subsection{Gopher Rockfish}

Catch per unit effort for gopher rockfish across all years was significantly different between locations. CPUE within Big Creek was 2.3x higher than Cambria and 3.3x higher than Piedras Blancas (Figure 11b). This suggests that between the sites Big Creek has over twice the abundance of gopher rockfish than either Cambria or Piedras Blancas, as CPUE is considered a proxy for abundance (Haggarty and King 2006). Mean total length was similar between Big Creek and Piedras Blancas at $28.3 \mathrm{~cm}$ (11.1in) while Cambria was significantly shorter at $25.4 \mathrm{~cm}$ (10in) (Figure $20 \mathrm{~b})$.

If growth rates are similar between Big Creek and Piedras Blancas, we can assume that the populations at both locations have a similar age structure. This suggests that both Big Creek and Piedras Blancas hold similarly mature populations as they have attained a near identical mean total length. It seems likely that with mature populations at both locations, that the differences in CPUE are due to the location and not fishing pressure. If fishing pressure alone were responsible, we would expect to see a depression in mean length in the population at Piedras Blancas as larger individuals are selectively removed (Bianchi et al., 2000). However, the population within Cambria is significantly smaller and less numerous than the mature population at Big Creek. It is likely that increased fishing pressure at Cambria is decreasing the population size and mean total length of gopher rockfish. Differences in location could also be contributing to differences in abundance. 
Within Cambria gopher rockfish populations have increased significantly across all years in both the MPA and reference site (Figure 15 b). In both sites, the years 2004 and 2006 had low CPUE levels followed by large increases into 2008 and $2009(\sim 5 \mathrm{x}$ in MPA and $\sim 8 \mathrm{x}$ in reference site). Possible explanations of this are inshore movement of the populations, massive population increases, the fish were not attracted to the traps in 2004 and 2006, or the two fishing protocols were causing a difference in catch levels.

Gopher rockfish are highly territorial fish and recaptured individuals were recovered on average 14.4 meters (47ft) away from their initial capture point (Figure 31) (Love, 1996). This suggests that these fish do not move great distances from their established territories. As this species was not tagged in the Commercial study, it is not possible to determine if these fish held similar territories in 2004-2006 as in 2008-2009. It cannot be discounted that large numbers of this species came into our sampling location between 2006 and 2008. Similarly, it is possible that during the 2004 and 2006 sampling at Cambria that this species was not attracted to the traps, but sampling occurred across a three-month period and the large number of individuals captured in 2008 and 2009 were not seen (Table 1, 3, Figure 12 b).

Gopher rockfish grow at a slower rate than cabezon, and take between 5 and 6 years to attain the mean length of individuals at Cambria. Once they reach this length average growth is approximately $1 \mathrm{~cm}$ per year (Figure 35)(Lea et al., 1999). Length at 50\% maturity for this species is $17.7 \mathrm{~cm} .(7 \mathrm{in})$ and length at $100 \%$ maturity is $21 \mathrm{~cm}(8.3 \mathrm{in}$.) indicating that the vast majority of captured fish were sexually mature, and likely had spawned prior to capture (Key et al.,2005). If a massive surge of gopher rockfish entered the fishery between 2006 and 2008 a larger proportion of $\sim 21 \mathrm{~cm}$ (8.3in) fish would have been captured in the 2006 , but we do not see this. 
Post-larval recruitment levels were low prior to 2000, and increased into 2001 and remained stable until 2004 (Key et al., 2005). This mild increase in post-larval recruitment alone is not likely to have caused the massive increase in CPUE in 2008 and 2009. However, commercial landings in Morro Bay for gopher rockfish were $\sim 50,000 \mathrm{lbs}(22,679 \mathrm{~kg})$ in 2000 2002, and dropped rapidly in 2003. From 2003 onwards catch hovered around 20,0001bs (9,071 kg)(Figure 36) (CDFG 2000-2008). Recreational fishers are thought to account for approximately $71 \%$ of catch, and still had high catch levels in 2003 until dropping dramatically in 2004 (Key et al., 2005). It is possible that the elevated catch levels prior to 2004 decreased the abundance and mean total length at Cambria, and once fishing mortality decreased, the populations were allowed to rebound, and this rebound could account for some of the increase in CPUE in 2008 and 2009.

Catch per unit effort for this species was highly dependent upon depth, and they were rarely captured in waters shallower than $35 \mathrm{ft}(10.7 \mathrm{~m})$ (Figure 19). Also, catch was highly clumped where many traps would return with no individuals followed by a trap set at a similar depth that contained many individuals. This clumped nature of CPUE existed in the conversion experiment as well. The clumped catch distribution combined with highly depth dependent catch resulted in a CPUE that was much more variable on a trap-by-trap basis than the other species. This variability made it difficult to analyze whether the different baiting and trapping protocols had a significant effect on CPUE for this species. With increased sampling using the conversion experiment protocols I believe it is likely that there will be a significant difference in CPUE between either bait type or soak time. Black and yellow rockfish, which have very similar diets, and are nearly genetically indistinguishable from gopher rockfish, had a significant effect of bait on CPUE in the conversion experiment (Love et al., 2002). Possible differences in CPUE due to 
bait or soak time in addition to changes in mortality associated to fishing pressure and improved recruitment post 2001 would account for the low levels of CPUE in 2004 and 2006 followed by the increases in 2008 at Cambria.

The Cambria MPA had a near significantly higher CPUE than the reference site when analyzed regardless of sampling year (p-value $<0.054)$. However, when looking at differences in individual years CPUE between the MPA and reference site are similar every year except for 2006 when the reference site had a much lower CPUE than the MPA (Figure $17 \mathrm{~b}$ ). The CPUE from this year is an outlier and imparts a large skew on the CPUE when comparing the MPA to the reference site. When analyzed without the 2006 data, the sites contain similar CPUE. It is likely that between 2004 and 2009 no significant differences in CPUE exist between sites. Currently the MPA is not altering the abundance of fish relative to the reference site.

Similarly to CPUE, mean total length of gopher rockfish within the Cambria MPA and reference site were not significantly different on a year-to-year basis, or across all sampling years (2004-2009)(Figure 24 b). This suggests that fish within the MPA have not diverged significantly in length from those in the reference site. However, in 2009 sampling the mean total length within the MPA increased from $25.9 \mathrm{~cm}$ to $27.5 \mathrm{~cm}$ (10.2in to $10.8 \mathrm{in}$ ), while the reference site stayed stable at $25.7 \mathrm{~cm}(10.1 \mathrm{in})$. It is possible that this difference will increase in later years and become significant indicating that fish within the MPA are becoming larger on average than the fish within the reference site.

Piedras Blancas was only sampled using the MLPA monitoring protocols, and CPUE was more stable between years than Cambria. Within the MPA and reference site at this location there were no significant differences in CPUE across years, suggesting that there were no changes in population abundance across sampling years (Figure 16 b). Similarly to CPUE, 
gopher rockfish within the MPA and reference site were of similar lengths, as mean total length did not differ significantly between sites (Figure 25 b). However, CPUE is significantly higher within the reference site than the MPA by an order of 1.9x (Figure $18 \mathrm{~b}$ ). Gopher rockfish prefer the location within the reference site over the MPA and reside in abundances approximately twice as high in this location relative to the MPA. As these differences were present in 2008, it is likely to predate the establishment of the MPA.

Gopher rockfish in Big Creek had similar CPUE in the two years sampled, indicating that there were no significant changes in abundance between 2006 and 2008 (Figure 13). During the 2006 sampling, only cabezon length was measured, so we cannot compare the lengths of gopher rockfish across years.

Post-larval recruitment rates measured by SMURF traps for the KCGB (Kelp, Copper, Gopher and Black and Yellow) complex of rockfish were highly variable between sampling years. Recruitment was similar in 2004, 2006, 2007 and 2008 with around 0.1 recruits per day, while 2005 averaged 0.65 recruits per day (Figure 32). Based upon von Bertalanffy growth curves for this species we would expect a surge in CPUE in 2010 due to this year class beginning to show up in our sampling (Lea et al., 1999). This year class will be approximately $24 \mathrm{~cm}(9.5 \mathrm{in})$ long in 2010, and 26cm (10.2in) long in 2011 (Figure 35). However, similarly to other larval fish, it is likely that the KCGB rockfish complex tend to be recruited in the lee of headlands and had the lowest recruitment at the Cambria sampling location where coastline and topography are not major impediments to dominant currents (Warner et al., 2000). The increase in fishable biomass due to a new incoming year class of fishable recruits might be more evident at places such as Piedras Blancas, Big Creek, and Point Buchon than at Cambria. 


\subsection{Black and Yellow Rockfish}

Similar to the results from gopher rockfish, the three sampling locations all had significantly different CPUE for black and yellow rockfish. Big Creek contained abundances approximately two times higher than Cambria, and three times higher than Piedras Blancas, as CPUE is considered to be a proxy for biomass (Figure 11 c)(Haggarty and King 2006). Mean total length did not differ significantly between Big Creek and Piedras Blancas with both locations having a length of $28 \mathrm{~cm}$ (11in), while Cambria held smaller individuals with an average length of $25.3 \mathrm{~cm}$ (10in) (Figure $20 \mathrm{c}$ ). Lengths at $50 \%$ maturity vary between sex, with males maturing at $\sim 16 \mathrm{~cm}(6.3 \mathrm{in})$ and females at $\sim 15 \mathrm{~cm}$ (5.9in), indicates that most, if not all individuals captured were sexually mature (Echeverria 1987).

Due to absence of fishing pressure for 16 years and the relatively fast growth rate and generational times as predicted by von Bertalanffy growth curves, we can assume this population has attained a near maximum mean total length (Figure 35)(Lea et al., 1999). If growth rates are similar between Big Creek and Piedras Blancas, it is likely that both locations hold a similarly mature population. This suggests that the differences in CPUE between Big Creek and Piedras Blancas are not solely due to fishing pressure, but instead to location. If the differences were due to fishing pressure alone we would expect to see a depression in mean length in the population at Piedras Blancas as larger individuals are selectively removed by fishermen, but this is not the case (Bianchi et al.,2000).

Black and yellow rockfish within Cambria are smaller in size and less abundant than those in Big Creek (Figures 11c, 20 c). It is likely that increased fishing pressure at Cambria is contributing to the decreases in mean total length and abundance. Commercial Landings in Morro Bay have stayed stable at around 10,000lbs (4,535kg) harvest annually between 2000 and 
2006, this harvest has increased into 2008 with a recorded harvest of $\sim 19,000 \mathrm{lbs}$

$(8,618 \mathrm{~kg})($ Figure 36)(CDFG 2000-2008). This does not include take of recreational fisherman, but as this species prefers depths of less than 60ft (18.3m), it is rarely captured by CPFV vessels (Love 1996, Reinecke 2006). Due to this, recreational take is likely less than that of gopher rockfish. Although, the take of this species is less than the gopher rockfish, this species has less available habitat due to its narrower preferred depth range, and is likely less numerous than the gopher rockfish. It is possible that the relative percentage removed from the population of black and yellow rockfish is comparable to that of the gopher rockfish.

Within Cambria, CPUE increased significantly from 2004-2009, and when subdivided into MPA and reference site, the reference site increased significantly as well. The MPA experienced an increasing trend, but this was not significant (Figures 12c, $15 \mathrm{c}$ ). Mean total length varied significantly from 2006-2009, with 2006 having the highest mean length of $25.9 \mathrm{~cm}, 2008$ at 24.5 and 2009 at $24.8 \mathrm{~cm}(10.2,9.6$ and 9.8 inches respectively) (Figure $21 \mathrm{c}$ ). This suggests that the year with the lowest abundance of fish, 2006 also had the largest fish, and 2008, which was the year with the highest abundance held the shortest fish. 2009 lies midway between the two in terms of length and abundance of fish.

Post-larval black and yellow rockfish recruit similarly to gopher rockfish, and gopher rockfish had low levels of post-larval recruitment in the late 90's until 2000 (Wilson 2006, Key et al., 2005). Growth rate is also similar to gopher rockfish, indicating that the fish captured in 2006 were averaged between 6 and 7 years of age (Figure 35)(Lea et al., 1999). With consistent levels of fishing between 2000 and 2006, and low numbers of individuals entering the fishery due to low post-larval recruitment levels, it is likely that fishing levels decreased the abundance at Cambria (Figure 36). Post-larval recruitment for the KCGB complex greatly improved in 2001 
and stayed stable into 2004 (Key et al., 2005). With improved post-larval recruitment starting in 2001, larger numbers of individuals would have begun to enter the fishery as legally fishable biomass between 2006 and 2007. At this time, the post-larval recruits from 2001 would be approximately $24 \mathrm{~cm}$ (Figure 35). This corresponds well to the changes observed in CPUE and length in 2008, with an increase in CPUE and a decrease in mean length (Figures 12 c, $21 \mathrm{c}$ ). Fishing pressure from 2006-2008 was also increasing, and more individuals were being removed from the population (Figure 36). This could account for the non-significant decrease in CPUE seen in 2009 at Cambria.

The MPA and reference site at Cambria did not have significantly different CPUE when analyzed at the year level, or across all sampling years. This suggests that the abundances of black and yellow rockfish were similar between the two sites (Figure $17 \mathrm{c}$ ). However, the reference site consistently held fish that were approximately $1 \mathrm{~cm}$ longer on average than the MPA, but this difference predates establishment of the MPA (Figure $24 \mathrm{c}$ ). This suggests that the MPA at Cambria is not currently increasing the abundance or size of black and yellow rockfish relative to the reference site.

Within Piedras Blancas, CPUE and mean total length did not vary significantly across sampling years, indicating that the abundance and mean length of the population did not change from 2008 to 2009 (Figures 14 c, 22 c). Although, when the data are split into traps set within the MPA and reference site we find that the abundance increased significantly within the MPA between 2008 and 2009, while the reference site did not (Figure 16 c). Also, in 2009 the MPA held significantly more black and yellow rockfish than the reference site (Figure $18 \mathrm{c}$ ). Although when the data from both years are combined, there is no significant difference between the two sites (Figure $18 \mathrm{c}$ ). Mean total length also varied significantly between sites with the MPA 
holding consistently smaller fish, $26.7 \mathrm{~cm}(10.5 \mathrm{in})$, than the reference site, $28.5 \mathrm{~cm}$

\section{(11.2in)(Figure $24 \mathrm{c})$.}

As mean total length between years did not vary significantly in either the MPA or reference site at Piedras Blancas, the increase in abundance found in the MPA cannot be directly attributed to an increase of recruits entering the fishery as fishable biomass. If due to a prior increase in post-larval recruitment causing a subsequent increase in legally fishable biomass alone, the mean total length should decline as increased numbers of smaller fish were captured, but this did not occur. The difference in abundance between the two sites cannot be attributed entirely to fishing pressure either, as no significant decline in abundance within the reference site was observed between 2008 and 2009 (Figure 16 c). Decreased mortality in the MPA could have allowed for a subsequent increase in abundance of black and yellow rockfish relative to the reference site. It is also possible that the cells randomly chosen in the MPA in 2009 contained better habitat for black and yellow rockfish than the cells randomly chosen in 2008 did, and not all cells were sampled each year.

Big Creek did vary significantly for CPUE between sampling years suggesting that the abundance of black and yellow rockfish did change (Figure 13c). Lengths were not measured in 2006, so comparisons of length cannot be made between sampling years.

Post-larval recruitment rates using SMURF traps were identical to those described for the gopher rockfish (Figures 32, 33). Post-larval recruitment peaked in 2005, and based upon the growth of this species we can expect an increase in CPUE of fishable biomass in 2010 and 2011 (Figure 35). In 2010 the 2005 post-larval recruitment class will be approximately $23 \mathrm{~cm}$ (9in) long in 2010, and 25cm (9.8in) long in 2011. This rockfish complex prefers to recruit in the lee of headlands and had the lowest recruitment at the Cambria sampling location. The increase in 
fishable biomass due to a new incoming year class of fishable recruits might be more evident at places such as Piedras Blancas, Big Creek, and Point Buchon than at Cambria.

\subsection{Kelp Greenling}

Catch per unit effort and mean total length for kelp greenling did not vary significantly between sampling locations (Figure $11 \mathrm{~d}, 20 \mathrm{~d}$ ). As no significant differences appear in either CPUE or mean total length between these locations it appears that location, relative fishing pressures and location are not causing significant differences in the of kelp greenling, as CPUE is a proxy for biomass (Haggarty and King 2006).

Kelp greenlings were not identified in the SMURF traps, preventing local analysis of post-larval recruitment events. Post-larval kelp greenling were also absent from SMURF traps set in Santa Barbara, indicating that little is known about how these fish recruit (pers. comm. Caselle, J). However, using post-larval recruitment numbers from Oregon, levels were stable in the late 90's to 2004, with the exception of 2003 when kelp greenling failed to recruit (Cope and MacCall 2005). According to von Bertalanffy growth curves, this species grows quickly and attains a legal size of $30.5 \mathrm{~cm}$ between three and four years of age (Figure 35) (Bryant 1978, Cope and MacCall 2005).

Kelp greenling within Cambria did not vary significantly in CPUE or mean total length across all sampling years, indicating that abundance and length of the population stayed the same (Figures $12 \mathrm{~d}, 15 \mathrm{~d}, 21 \mathrm{~d}$,). Although, the MPA had a significantly higher CPUE than the reference site did (figure $17 \mathrm{~d}$ ). In addition, mean total length within the MPA was significantly higher than the reference site across all sampling years (Figure $24 \mathrm{~d}$ ). As habitat and orientation are similar between the MPA and reference site, the significant differences in CPUE and mean total length are likely not attributed to physical differences between sites. 
The major difference between the two sites is fishing pressure. As the MPA is further from port than the reference site, it is likely that the two sites received different recreational and commercial fishing pressure prior to the establishment of the MPA. After the MPAs establishment these differences were exacerbated. Commercial landings for kelp greenling in Morro Bay were 8,422lbs (3,820kg) in 2000 and dropped into 2005 where catch levels have hovered at around 1,200lbs (544kg) per year (Figure 36)(CDFG 2000-2008). Although commercial catch has been low, this species is popular with recreational anglers (Love 1996). In addition, of the analyzed fish species, this fish appears to be the most sensitive to capture. They often cannot handle the trauma of being captured and released, and even with short handling times to measure and tag these fish they are often released and do not actively swim away, but more drift downwards without any movement. The commercial fishermen we worked with had similar experiences with kelp greenling and considered them to be the most sensitive species that they commonly captured (Hafer, T and R. Cullen, pers. comm.).This species lacks a swim bladder, making it difficult to ascertain if the animal is alive or dead upon release, as they do not float like the rockfish. As they are often captured, and subsequently released due to restricted catch it is possible that high levels of this species are dying due to trauma, resulting in a higher removal rate than landings report (Cope and MacCall, 2005). Schroeder and Love (2002) outlined how catch and release of the robust giant sea bass (Stereolepis gigas) result in high mortality. Higher mortality due to fishing, coupled with recreational take, is possibly depressing CPUE levels and mean total length within the reference site when compared to the MPA. In addition, this species is highly territorial, and mean recapture distance in this study was approximately $28 \mathrm{~m}(92 \mathrm{ft})$, indicating this species is relatively sedentary and rarely makes long 
distance movements (Love, 1996)(Figure 31). As fish are not moving between the MPA and reference site this compounds the effect of fishing pressure.

Within Piedras Blancas, CPUE and mean total length did not vary between years or sites (Figures 14 d, 16 d, 18 d, 25 d). However, when data from the MPA and reference site is combined, there is a significant increase in length between 2008 and 2009 (Figure 22 d). This suggests that from 2008 to 2009 the abundance of kelp greenling did not change, but that the average fish length increased. As this location receives lower fishing pressure than Cambria it is possible that low levels of catch and mortality at Piedras Blancas are not affecting the structure of the population.

Kelp greenling populations within Big Creek experienced a significant increase in CPUE in 2008 (Figure 13 d). As total length for this species was not measured in 2006 it is not possible to determine if there was a change in mean length over this time period as well. Similar to the significant increase in CPUE for cabezon at this location, it is possible that the increases are due to a post-larval recruitment event. The lack of local post-larval recruitment data for kelp greenling prevents us from knowing if a large recruitment event could have caused this increase in CPUE.

\subsection{Lingcod}

Lingcod CPUE was significantly different between Cambria and Big Creek, with Cambria having approximately 2x higher levels. CPUE for Piedras Blancas lies between these locations, and was not significantly different than either (Figure $11 \mathrm{e}$ ). This suggests that abundances for lingcod in Cambria are twice that of Big Creek, and abundances in Piedras Blancas lie between these sites, as CPUE is a proxy for abundance (Haggarty and King 2006). Mean total length was not significantly different between all locations (Figure 20 e). Within 
Cambria there was a significant decreasing trend in CPUE from 2004-2009, indicating a decline in abundance of lingcod (Figure 12 e). When split into reference site and MPA this trend is no longer discernable, likely due to low numbers of individuals captured (Figure 15 e). However, when comparing the MPA and reference site across all sampling years (2004-2009) the MPA has significantly higher CPUE (Figure $17 \mathrm{e}$ ). It is possible that declines in CPUE are due to decreases in abundance of lingcod in the reference site. However, the difference predates the establishment of the MPA, so could be due to recreational and commercial anglers preferring to fish the reference site that lies closer to port than the MPA. Commercial landings in Morro Bay for lingcod increased from 6,000lbs $(2,721 \mathrm{~kg})$ in 2000 to $25,000 \mathrm{lbs}(11,339 \mathrm{~kg})$ in 2004 ; these catch levels have remained stable into 2008 (Figure 36)(CDFG 2000-2008). Recreational take is also high for this species (Love 1996, Hamel et al., 2009). High catch levels could be decreasing abundance within the reference site, while the MPA remains stable.

Post-larval recruitment for lingcod was high from 1999-2003 and with this species fast growth rate these fish will attain legal size at between four to five years of age (Figure 35)(Hamel et al., 2009, Smith and McFarlane 1990). Based upon von Bertalanffy growth curves, these fish would begin to show up in the catch at two to three years after post-larval recruitment. There is a non-significant increase in CPUE in 2006, and this could possibly attributed to the continued years of high post-larval recruitment (Figure $12 \mathrm{e}$ ).

Both Piedras Blancas and Big Creek receive less fishing pressure than Cambria, and within these locations CPUE did not change significantly across the sampling period (Figures 13 e, 14 e). This suggests that abundance for lingcod within these locations did not change. Likewise, mean total length did not vary significantly across sampling years for these locations (Figure $22 \mathrm{e}$ ). The lingcod populations were stable at these locations. 
Lingcod were captured in low numbers across all studies, resulting in a data poor condition (Table 3). With low numbers of individuals captured, there is increased uncertainty with the models, making it difficult to analyze changes in population structure across years, and it is possible that we failed to detect changes that were occurring. In addition, there are indications that this species makes long distance movements, so movements into and out of these sites, and also into deeper waters compound the analysis of CPUE and mean total length for this species (Love 1996, Martell et al., 2000). Lingcod also have a size limit and the apparent rebound of the species is still made up of sublegals not yet entering the legally fishable stock, further compounding analysis.

\subsection{Diversity}

Species Richness was highly variable both within sites at the same location and between different locations (Figure 27). This variability was due to rare capture events of species that normally inhabit deeper waters, or rarely enter traps. Species such as vermillion rockfish (Sebastes miniatus), China Rockfish (Sebastes nebulosus), Copper Rockfish (Sebastes caurinus) and Treefish (Sebastes serriceps) only had one capture event during sampling. In addition, other species such as the Wolf Eel (Anarrhichthys ocellatus), Swell Shark (Cephalloscylium ventriosum), Blue Rockfish (Sebastes mystinus) and Brown Rockfish (Sebastes auriculatus) had fewer than eight capture events (Table 3). These rarely captured species have a large effect on species richness values, but make up only a miniscule proportion of number of fish captured, making this a poor metric to assess diversity.

The Shannon-Weiner diversity index improves upon species richness as it takes into account number of species and the evenness of the species. This study did not measure true ecological diversity, as we did not capture all fish species that are commonly found within these 
locations. Instead we captured the species that would enter, and remain within the traps. This is a measure of diversity that commercial nearshore trap fishermen can expect to see when fishing in these locations. Fishable Shannon diversity was significantly different between Cambria and the other two locations. Across all sampling years Cambria had a diversity value of 1.37, while Big Creek and Piedras Blancas had values of 1.547 and 1.563 respectively (Figure 26). This suggests that Cambria holds lower fish diversity than either Big Creek or Piedras Blancas, which are statistically indistinguishable to one another. However, in the conversion experiment the traps set for two hours consistently had lower fishable diversity, albeit non-significant, than the one-hour traps, making it possible that Big Creek actually has a higher Shannon diversity level than is reported. Increased sampling using the conversion experiment protocols would increase the power of the tests, and possibly determine if there is in fact a significant difference between soak times.

Within Cambria, the MPA consistently held higher fishable diversity than the reference site (Figure 29). This difference was near significant in 2004, and significant in both 2008 and 2009. The MPA consistently had higher diversity prior to 2008 , indicating that differences in diversity were present before establishment of the MPA. Possible reasons for existing higher diversity in the MPA are due to decreased fishing pressure due to being further from port, and from potentially holding better habitat (Hafer, $\mathrm{T}$ and R. Cullen, pers. comm.). No recaptured fish have been found to move between the two sites, indicating that little to no spill over is occurring and there is little mixing between sites. It should be noted that diversity within the reference site has increased on a year-to-year basis, indicating that this area is becoming more diverse over time as well (Figure 29). It is possible that decreased landings of fish is allowing for a more diverse population (Figure 36)(CDFG 2000-2008). However, it is likely that these differences 
between the sites were exacerbated by the protection of the MPA, as the differences between sites only became significant after the MPA was established. These results suggest that the MPA is increasing diversity faster relative to the reference site.

Piedras reference site consistently had higher fishable diversity than the MPA, and this difference was significant in 2008 (Figure 30). This suggests that the reference site holds a more diverse assemblage of fish than the MPA. As sampling was not conducted before the establishment of the MPA it is not known whether these differences were preexisting, or are due to protection. Sampling at Big Creek was conducted solely in the MPA, but there was no significant difference in Shannon-diversity between sampling years, indicating that diversity of the fish assemblages did not change (Figure 28). 


\section{Conclusions}

The conversion experiment blended the protocols of the Commercial and MLPA monitoring study on nearshore fish populations, allowing for analysis on how different soak times and baits affect CPUE, mean total length, and diversity of captured fish. For the soak times utilized (1 hour, 2 hour) there was no significant effect on CPUE indicating that between those times catch rates remain stable. However, bait type had a significant effect on two species (cabezon, black and yellow rockfish), and it is likely that gopher rockfish will show an effect as well with continued sampling. Catch per unit effort for the affected fish species was altered to reflect what it would have been if the subsequently developed MLPA monitoring protocols had been used throughout. Bait type and soak time had no effect on the mean total length or Shannon-diversity of captured fish species. After conversion of CPUE for cabezon and black and yellow rockfish, the two datasets were linked, allowing comparisons to be made between the different sampling years and locations. This allowed for longer term comparisons to be conducted at Cambria, and included baseline data from before MPA establishment. It also allowed comparisons to be made between Big Creek, Cambria and Piedras Blancas.

Cabezon abundance and mean length can be affected by fishing mortality, location differences, and past recruitment levels. Cabezon are likely more abundant at Cambria due to better available habitat for cabezon, while Big Creek and Piedras Blancas have similar habitat and support similar population levels. Cambria has higher fishing mortality, possibly removing larger individuals and depressing mean total length. Big Creek and Piedras hold larger cabezon due to either decreased fishing mortality, or no fishing mortality allowing for more mature populations. Declines in abundance within Cambria are likely due to continued fishing pressure in the reference site coupled with years of poor recruitment slowing replacement of fished 
individuals. The MPA at this location stayed relatively stable due to the lack of fishing pressure post 2007, possibly due to the MPAs protection. Piedras Blancas has stayed stable across years in both sites, most likely due to low fishing pressure and stable levels of recruits entering the fishery. The fluctuations in Big Creek are likely due to a surge of individuals entering the fishery between 2006 and 2008 causing an increase in abundance and a subsequent decrease in total length (Table 4).

Gopher rockfish were more abundant at Big Creek than either of the other locations, but mean total length was similar between Big Creek and Piedras Blancas. With similar lengths between populations, it is likely they are composed of a similar age structure, and the populations are of similar maturity. Due to this, it is likely that differences in abundance are due to location, and not necessarily fishing pressure, as we see no depression of length. Cambria holds smaller and less numerous fish, which is likely caused by higher fishing pressure than the other locations in addition to differences in habitat. Cambria has increased in CPUE from 20042009, likely due to improved recruitment post 2001, decreased fishing mortality due to changes in allowable catch and possible effects of MLPA protocols on catch. In addition, the MPA increased in length in 2009 relative to the reference site, possibly indicating that the MPA is beginning to cause increases in length. Piedras Blancas was stable across years, with the reference site holding higher abundances than the MPA. It is unknown whether these differences were preexisting, but it is likely due to gopher rockfish preferring the location in the reference site over the MPA. Abundance within Big Creek remained stable across years (Table 5).

Black and yellow rockfish had similar results to gopher rockfish, with higher abundances in Big Creek than the other locations, and similar lengths between Big Creek and Piedras Blancas with shorter fish found in Cambria. Similar to gopher rockfish, it is likely that 
differences in abundance between Big Creek and Piedras Blancas are due to location, and not necessarily to fishing pressure, while fishing pressure is likely causing the depression in mean length at Cambria. However, from 2004-2009 Cambria has increased in abundance. These increases occurred after fishing pressure decreased in 2004 and recruitment improved post 2000, making these likely driving forces. The Cambria MPA and reference site are not diverging from one another, and are currently not showing the expected effects of an MPA for this species. Piedras Blancas was more stable across sampling years with no changes in mean total length. Although, in 2009 the MPA increased in abundance, while the reference site remained stable, the MPA held the significantly higher abundances than the reference site in 2009. In subsequent sampling years it will be possible to determine if the MPA is causing these increases in abundance over the reference site. Abundance of black and yellow rockfish was stable within Big Creek across sampling years (Table 6).

Kelp greenling abundances and lengths were not different between the locations sampled. Within Cambria, abundance did not change across sampling years, but the MPA consistently held higher abundances of larger fish than the reference site. As habitat within the MPA and reference site are similar, these differences are likely not location driven, and are possibly driven by increased fishing related mortality in the reference site. These differences predate the MPAs establishment so cannot be directly attributed to protection, and is likely due to differential fishing pressure with more fishers utilizing the closer to port reference site. It is likely these differences will be exacerbated in future years. Piedras Blancas was stable across sampling years, while Big Creek experienced an increase in abundance in 2008, which could be due to a larger incoming recruit class (Table 7). 
Lingcod abundances were higher overall within Cambria than either Big Creek or Piedras Blancas, but there were no differences in length. Within Cambria, the MPA held higher abundances than the reference site, and overall the location experienced a decline in lingcod abundance across years, possibly due to increased mortality in the closer to port reference site. Big Creek and Piedras Blancas were stable across sampling years. Lingcod had the lowest overall catch of analyzed species, creating a data poor condition with larger uncertainties in analysis than the other species. In addition, seasonal migrations further compound analysis, as these fish are not sedentary year round (Table 8).

To analyze differences in diversity between locations, species richness is a poor metric due to the highly sporadic catch of several species. Shannon-diversity values are a better metric as it incorporates species evenness and shows that Piedras Blancas and Big Creek had similar diversity levels, while Cambria was less diverse. Big Creek showed no differences in diversity between years. After the MPAs establishment at Cambria fishable diversity in the MPA was significantly higher than the reference site. This difference was not preexisting, implying that the MPA significantly increased trap fishable piscine diversity. The Piedras Blancas reference site held consistently higher fishable diversity than the MPA, but in 2009 this was not significant. In coming years it will be possible to determine if the MPA and reference site begin to diverge from one another with regards to diversity.

Following traditional wisdom on MPAs, Big Creek should hold larger and denser populations than nearby locations due to its long period of protection, but abundance of cabezon, kelp greenling and lingcod are equal to or less than nearby-fished locations. Other variables such as depth, location, recruitment and past fishing pressure must be taken into account before comparing locations to one another as all affect potential catch. Longer-term protection within 
the Big Creek MPA and lower fishing pressure at Piedras Blancas relative to Cambria has skewed the size distribution of cabezon, gopher and black and yellow rockfish towards larger fish. Baseline data from Cambria shows evidence that the shorter-term protection within Cambria is already causing an increase in length of gopher rockfish and possibly kelp greenling as well. In addition, cabezon and kelp greenling are becoming more abundant within the MPA than the reference site at Cambria. This suggests that protection within the MPA has created changes over a short time scale for these fast growing species. At Piedras Blancas, there is also evidence for higher abundances of black and yellow rockfish within the reserve, but lacking baseline data it is impossible to determine if these differences were preexisting. In addition to increases in abundance and length, the Cambria MPA has increased in diversity relative to the reference site. Differences between the sites at Cambria predated the MPAs establishment, but were exacerbated and became significant in the following years.

Not all sample species at Cambria show increased length and abundance within the MPA, and some species show the opposite trend with the reference site becoming larger or more abundant. After two-years of protection, the Cambria MPA is not showing any distinct overall trends in terms of abundance and size of nearshore fish relative to the reference site. Likewise, at Piedras Blancas, which had lower fishing pressure, there are no discernable overall trends in abundance and size of fish between the two sites. It is likely with these slower growing, longlived fish that differences between the MPA and reference sites at these locations will take more years to manifest themselves.

Big Creek is a good metric against which to measure the other South Central California MPAs. It is far from fishing ports, and been protected for a long period, creating a more pristine nearshore environment. All sampling locations are spatially nearby, have similar exposure, and 
contain rocky reef habitats. It is useful to compare the diversity and size composition between Big Creek and other locations to determine relative differences, and improve management of nearshore fish populations. However, I believe it is inappropriate to compare CPUE between Big Creek and other locations as carrying capacity for individual species varies based upon location and oceanographic conditions. Simply because an area has been protected, does not mean that it will contain the highest density of targeted fish species. Baseline data and continued long-term datasets within the same locations allow for a better analysis on how specific MPAs and there fish populations change over time. With continued sampling within Big Creek, Cambria and Piedras Blancas we will receive a better understanding of how fish populations and diversity change with the absence of fishing pressure, and will be able to compare protected populations to the fished populations in the reference sites to ensure that observed changes are due to fishing, and not large scale changes in populations.

Sampling needs to be continued in future years as the power of these datasets vastly increases with every sampling year. In addition, with further sampling it will be possible to track changes in fish populations overtime, and assess divergence patterns in size and abundance between the MPA and reference site at each location. The conversion experiment should be run over several years to fine tune conversion rates to ensure that the baseline information for these sites is as accurate as possible. It also needs to be expanded to other sampling locations to ensure that the constants hold up in different areas. The conversion experiment should be expanded as well through the use of video recorders mounted on several traps. This would allow for the entry and exit of different fish to be tallied and recorded. Entry and exit data would allow for a better approximation of trap saturation, and provide evidence for predator/prey or size exclusion interactions. In addition, with continued sampling we will increase the number of recaptures in 
each area, allowing for accurate assessments of population size to be made. Once we have accurate numbers of population size and density of fish in each area, assessments of biomass of each fish species can be made.

Expanding the current protocols through the addition of different gear types and survey methods would allow for a more complete picture of fish populations within these areas. Including additional gear such as sticks would allow for a broader size range of captured fish. With a broader size range, several of the captured fish could be sacrificed to obtain localized von Bertalanffy growth estimates, and length-weight relationships. These sacrificed individuals could also undergo genetic testing to determine relatedness, and if they are from the same population or are from different subpopulations. Money and time permitting, the SMURF program should continue sampling the Cambria, Cayucos, Avila Beach and Shell Beach locations to better estimate the number of recruits each year, and how location influences recruitment rate. In addition, invertebrates were not analyzed in this study, but they have been recorded in the datasets. In future years both fish and invertebrate CPUEs and diversity levels can be analyzed to determine the effects that the MPAs are having upon their populations. With further sampling, the data collected will become more valuable, and allow for a highly effective review of changes inside and outside of South Central California MPAs to be conducted, allowing for more informed management decisions for nearshore fish and invertebrate stocks. 


\section{Literature Cited}

Barrett, N.S. et al., 2007. Changes in fish assemblages following 10 years of protection in Tasmanian marine protected areas. Journal of Experimental Biology and Ecology 345, 141157.

Bianchi et al., 2000. Impact of fishing on size composition and diversity of demersal fish communities. ICES Journal of Marine Science 57(3) 558-571

Bohnsack, J.A. 1998. Application of marine reserves to reef fisheries management. Australian Journal of Ecology 23(3), 298-304

Bryant, M. 1978. Ecological studies of the striped perch Embiotoca lateralis and the kelp greenling Hexagrammos decagrammus in Carmel Bay, California. Cal State Fresno. Master's Thesis

Buxton, C.D. and M.J. Smale. 1989. Abundance and distribution patterns of three temperate marine reef fish (Teleostei: Sparidae) in exploited and unexploited areas off the southern cape coast. Journal of Applied Ecology 26, 441-451.

California Department of Fish and Game. 2000-2008. California Commercial Landings for Morro Bay from 2000-2008.

California Department of Fish and Game. 2002. Nearshore Fishery Management Plan. 1-201.

Claudet, J. et al., 2006. Assessing the effects of marine protected area (MPA) on a reef fish assemblage in a northwestern Mediterranean marine reserve: identifying community-based indicators. Biological Conservation 130, 349-369.

Cope, J.M and A.D. MacCall. 2005. Status of kelp greenling (Hexagrammos decagrammus) in Oregon and California Waters as Assessed in 2005. Pacific Fishery Management Council.

Cope, J.M. and M. Key. 2009. Status of cabezon (Scorpaenichthys marmoratus) in California and Oregon Waters as Assessed in 2009. Pacific Fishery Management Council.

Cope, M.J and A.E. Punt. 2005. Status of cabezon (Scorpaenichthys marmoratus) in California Waters as Assessed in 2005. University of Washington. pp. 10-48.

Cowley, P.D. et al., 2002. The role of Tsitsikamma National Park in the management of four shore-angling fish along the southeastern cape coast of South Africa. South African Journal of Marine Science. 24, 27-36.

Dayton, P.K. et al., 1998. Sliding baselines, ghosts and reduced expectations in kelp forest communities. Ecological Applications 8, 309-322. 
Duran, L.R. and J.C. Castilla. 1989. Variation and persistence of the middle rocky intertidal community of central Chile, with and without human harvesting. Marine Biology 103, 555562

Echeverria, T.W. 1987. Thirty-Four species of California rockfishes: Maturity and seasonality of reproduction. Fishery Bulletin 85(2) 229-250

Edgar, G.J. et al., 2004. Bias in evaluating the effects of marine protected areas: the importance of baseline data for the Galapagos Marine Reserve. Environmental Conservation 31, 212218.

Erwin, B. 2010. Number of commercial fishermen operating out of Morro Bay with nearshore permits and either commercial or nearshore landings. California Department of Fish and Game.

Eschemeyer, W.N. et al.,, 1983. Pacific coast fishes. Houghton Mifflin Company, New York, New York, 336p.

Faunce, C.H et al., 2002. Size structure of gray snapper (Lutjanus griseus) within a mangrove 'no-take' sanctuary. Bulletin of Marine Science 70, 211-216.

Francour, P. 1991. The effect of protection level on a coastal fish community at Scandola. Corsica. Rev. Ecol. Terre Vie 46, 65-81.

Gell, F.R., and C.M. Roberts. 2003. Benefits beyond boundaries: the fishery effects of marine reserves. TRENDS in Ecology and Evolution 18(9): 448-455

Gray, J.S. 1997. Marine biodiversity: patterns, threats and conservation needs. Biodiversity and Conservation 6, 153-175.

Grebel, J. 2003. Age, growth, and maturity of cabezon, (Scorpaenichthys marmoratus), in California. San Jose State University. Master's Thesis

Griffiths, A.M and L.A. Gosselin. 2008. Ontogenetic shift in susceptibility to predators in juvenile northern abalone, Haliotis kamtschatkana. Journal of Experimental Marine Biology and Ecology 360(2), 85-93

Haggarty, D.R., and J.R. King. 2006. CPUE as an index of relative abundance of nearshore reef fishes. Fisheries Research Vol.81(1): 89-93

Hamel, O.S., Sethi, S.A., and T.F. Wadsworth. 2009. Status and Future Prospects for lingcod in Waters off Washington, Oregon, and California as Assessed in 2009. Pacific Fishery Management Council.

Hammer, Ø., Harper, D.A.T., and P. D. Ryan, 2001. PAST: Paleontological Statistics Software Package for Education and Data Analysis. Palaeontologia Electronica 4(1): 9pp 
Harmelin-Vivien, M. et al., 2008. Gradients of abundance and biomass across reserve boundaries in six Mediterranean marine protected areas: Evidence of fish spillover? Biological Conservation 141, 1829-1839.

Jennings, S. et al., 1996. Seychelles' marine protected areas: comparative structure and status of reef fish communities. Biological Conservation 75-201-209.

Johnson, J.W. 1999. Annotated checklist of the fishes of Mereton Bay, Queensland, Australia. Memoirs of the Queensland Museum 43(2), 709-762.

Karpov, et al., 1995. The marine recreational fishery in northern and central California. Fish Bulletin 176, 195.

Karpov, K.A., and G.S. Kwiecien. 1988. Conversions between Total, Fork, and Standard Lengths for 41 Species in 15 Families of Fish from California Using Preserved and Fresh Specimens. California Department of Fish and Game.

Kasumyan, A.O. and K.B. Doving. 2003. Taste preferences in fish. Fish and Fisheries 4, 289347

Key, M, MacCall A.D., Bishop, T., Leos B. 2005. Stock Assessment of the gopher rockfish (Sebastes carnatus). Pacific Fishery Management Council.

Key, M, MacCall A.D., Field, J, Aseltine-Neilson, D., Lynn, K. 2008. The 2007 Assessment of Blue Rockfish (Sebastes mystinus) in California. Pacific Fishery Management Council.

Kramer, D.L and M.R. Chapmann. 1999. Implications of fish home range size and relocation for marine reserve function. Environmental Biology of Fishes 55(1-2), 65-79

Lea, R.N., McAllister, R.D. and D.A. VenTresca. 1999. Biological Aspects of Nearshore Rockfishes of the Genus Sebastes from Central California with Notes on Ecologically Related Sport Fishes. Fish Bulletin 177

Leet, W.S., et al., 2001. California's Living Marine Resources: A Status Report. California Department of Fish and Game. 592p.

Love, M.S. 1996. Probably more than you want to know about the fishes of the Pacific coast. Really Big Press, Santa Barbara, CA

Love, M.S and J.E Caselle. 1998. Declines in nearshore rockfish recruitment and populations in the southern California Bight as measured by impingement rates in coastal electrical power generating stations. Fishery Bulletin 96, 492-501.

Love, M.S., Yoklavich, M. and L.K. Thorsteinson. 2002. The Rockfishes of the Northeast Pacific. University of California Press, pp. 140-143. 
Magurran, A.E. 2004. Measuring Biological Diversity. Blackwell Publishing, Oxford.

Martell, S.J., Walters, C.J., Wallace, S.S. 2000. The use of marine protected areas for conservation of lingcod (Ophiodon elongatus). Bulletin of Marine Science 66(3) 729-743

Mason, J.E. 1998. Declining rockfish lengths in the Monterey Bay, California, recreational fishery, 1959-94. Marine Fisheries Review 60(3), 15-28.

Mireles, C. 2005. A Mark and Recapture Investigation on the Commercial cabezon (Scorpaenichthys marmoratus) Fishery off of Estero Reef: assessment of catch statistics and behavior on the south Central Coast of California. Cal Poly, San Luis Obispo, Senior Project. pp. 1-32.

Morgan, G.R., Philips, B.F., Joll, L.M. 1982. Stock and recruitment relationships in Panulirus Cygnus, the commercial rock (spiny) lobster of western Australia. Fish. Bull. 80(3), 475-486

Mosqueira, I., Côté, I.M., Jennings, S., Reynolds, J. 2000. Conservation benefits of marine reserves for fish populations. Animal Conservation 4, 321-332.

Motulsky. 2010. Intuitive Biostatistics. A Nonmathematical Guide to Statistical Thinking. Oxford University Press, New York, NY. 296-314

O'Connell, C.P. 1953. The life history of the cabezon Scorpaenichthys marmoratus (Ayers). California Department of Fish and Game, Fish Bulletin vol. 93, 76p.

Pillans, S. et al., 2007. The impact of marine reserves on nekton diversity and community composition in subtropical eastern Australia. Biological Conservation 136, 455-469.

Rasmussen, D.E. 2006. Comparisons of size, weight and catch of Scorpaenichthys marmoratus in Big Creek marine ecological reserve and off Point Estero. Cal Poly, San Luis Obispo, Senior Project. pp. 1-24.

Reilly, P.N. et al., 1993. Onboard sampling of the rockfish and lingcod commercial passenger fishing vessel industry in northern and central California, May 1987 to December 1991. California Department of Fish and Game, Mar. Resour. Admin. Rep. No. 93-4

Reilly, P.N. et al., 1998. Onboard sampling of the rockfish and lingcod commercial passenger fishing vessel industry in northern and central California, January through December 1995. California Department of Fish and Game, Mar. Resour. Admin. Rep. No. 93-4

Reinecke, S. 2006. Analysis of rockfish and lingcod fishery. Master's Thesis, California Polytechnic State University, San Luis Obispo

Roughgarden, J., Gaines, S., Possinghamn, H. 1988. Recruitment dynamics in complex life cycles. Science 241, 1460-1466 
Sheaves, J.M. 1995. Effect of Design Modifications and Soak Time Variations on Antillean-Z Fish Trap Performance in a Tropical Estuary. Bulletin of Marine Science. 56(2), 475-489

Shroeder, D.M., and M.S. Love. 2002. Recreational fishing and marine fish populations in California. California Cooperative Oceanic Fisheries Investigations 43, 182-190.

Smith, B.D. and G.A. McFarlane. 1990. Growth Analysis of Strait of Georgia lingcod by Use of Length-Frequency and Length-Increment Data in Combination. Transactions of the American Fisheries Society. 119(5): 802-812.

Stephens, J. S. Jr., D. E. Wendt, D. Wilson-Vandenberg, J. Carroll, and R. Nakamura, E. Nakada, S. Reinecke, J. Wilson. 2006. A review of the groundfish assemblage of California's south central coast, 1980-2004. Is there an argument for regional management of this rockfish resource? CalCOFI Reports 47,140-155

Villablanca, F., and Nakamura, R. 2008. Population genetics of the commercially important cabezon. Sea Grant R/MLPA-05, Cal Poly San Luis Obispo, San Luis Obispo.

Warner, R.R., Swearer, S.E. and J.E. Caselle. 2000. Larval accumulation and retention implications for the design of marine reserves and essential fish habitat. Bulletin of Marine Science. 66(3) 821-830

Willis T.J. et al., 2003. Protection of exploited fishes in temperate regions: high density and biomass of snapper Pagrus auratus (Sparidae) in northern New Zealand marine reserves. Journal of Applied Ecology 40, 214-227.

Wilson, J.R. 2006. Spatiotemporal patterns in recruitment of rockfish and cabezon along the south central California coast. California Polytechnic State University. Master's Thesis 


\section{Appendix 1:}

\section{Interpretation of Ordinal and Binary Logistic Regression Models}

Both Ordinal and Binary Logistic Regression Models were used throughout the analysis of CPUE to determine significance. These differ from a parametric statistical output in that they do not return numbers based upon the data such as mean, median, and standard deviation, but rather they provide an odds ratio. The odds ratio tells us how if a particular x-value or variable is increased by 1.0 (while keeping the other independent variables are kept the same) how much the logarithm of the odds ratio would be expected to increase. If the odds ratio is near 1.0 then the independent (explanatory) variable has little impact upon the outcome of the test, but if the value varies from 1.0 then a change in the independent variable will cause a change in the value of the dependent variable (Motulsky 2010).

To provide an example of how this test works in practice, please refer to figure 11a. You will notice that there are three bars corresponding to the three different sampling locations. In this figure, "Location" is the explanatory variable being analyzed. Big Creek has a bar of height 1.0, Cambria 1.77 and Piedras Blancas 1.1. The first bar, Big Creek is a "dummy" variable as in this figure the CPUE for cabezon at Big Creek is being compared to the CPUE of cabezon at both Cambria and Piedras Blancas. As mentioned previously, if the bars for the variables Cambria and Piedras Blancas have an odds ratio that is similar to 1.0 that variable (Location) has little impact on the outcome of the test, or in this case on the CPUE for cabezon. You can see that the odds ratio for Cambria is 1.77 , which means that when all other variables are kept the same (i.e. depth, year, soak time, fishermen...) compared to Big Creek you can expect that on average, a trap set in Cambria will have 1.77 times the CPUE for cabezon than the same trap would have if it were set in Big Creek. Piedras Blancas has an odds ratio of 1.1, indicating that 
if all other variables are held the same, that a trap set in Piedras Blancas will on average have 1.1 times the CPUE for cabezon than one set in Big Creek.

This tells us little about if these differences are significant though, so we must refer to the p-value of the output and the $95 \%$ confidence intervals to determine significance. If the bars for the $95 \%$ confidence interval overlap with 1.0 (the value for the first "dummy" variable, in this case Big Creek), then the data is said to not be significantly different. However, if the bars do not overlap with 1.0, then the data is significantly different. In the case of Figure 11a, we can see that the bars for Cambria do not overlap with 1.0 (The bar from Big Creek), so these data must be significantly different. The odds ratio tell us that Cambria has a significantly higher CPUE for cabezon than Big Creek by an order of 1.77 times. Piedras Blancas does overlap with the bar from Big Creek, indicating that Piedras Blancas and Big Creek are not significantly different from one another with regards to CPUE for cabezon.

Also, notice that figure 11a only directly compares Big Creek to Cambria, and Big Creek to Piedras Blancas, and does not directly compare Cambria to Piedras Blancas. Using the Logistic Regression Model, all combinations were tested against one another, and significant differences are noted by asterisks in the figure, and in the text. Graphs of all of the combinations were not included to reduce confusion, as a single graph is sufficient to convey differences between the variables. 


\section{Figures and Tables}

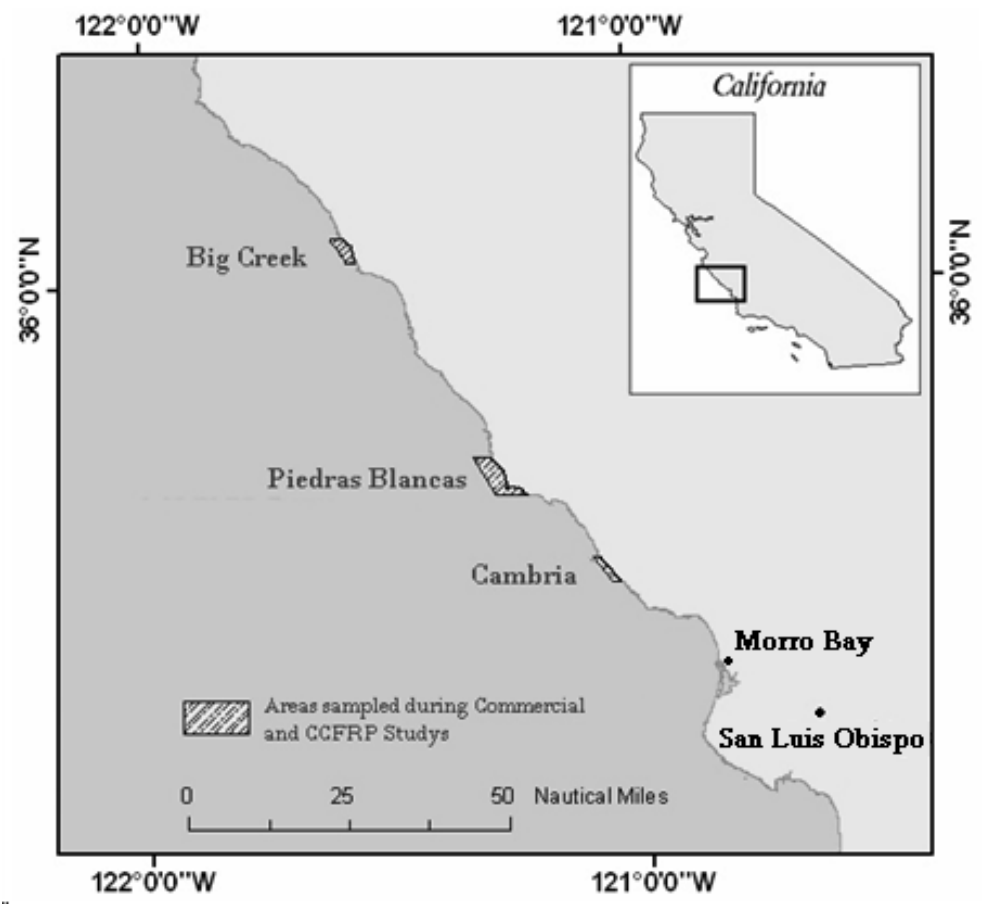

Figure 1: Locations of Cambria, Piedras Blancas and Big Creek.

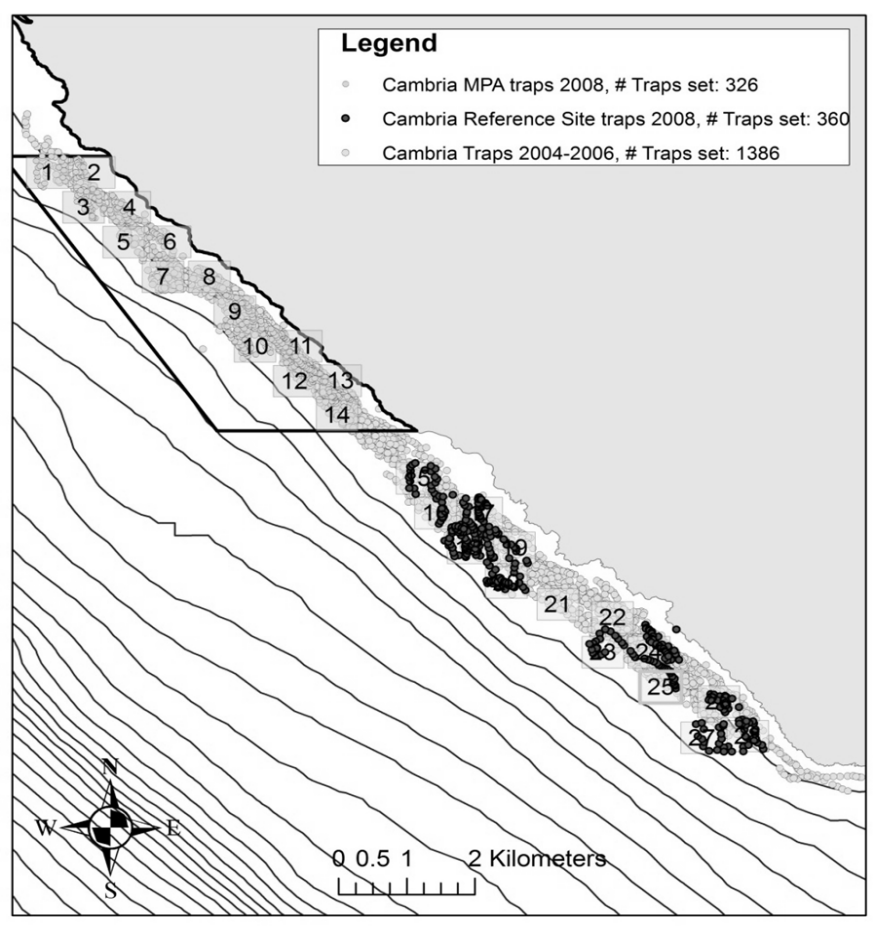

Figure 2: Location of traps set at Cambria, CA from 2004-2008. Note, different colors denote different trapping periods. 


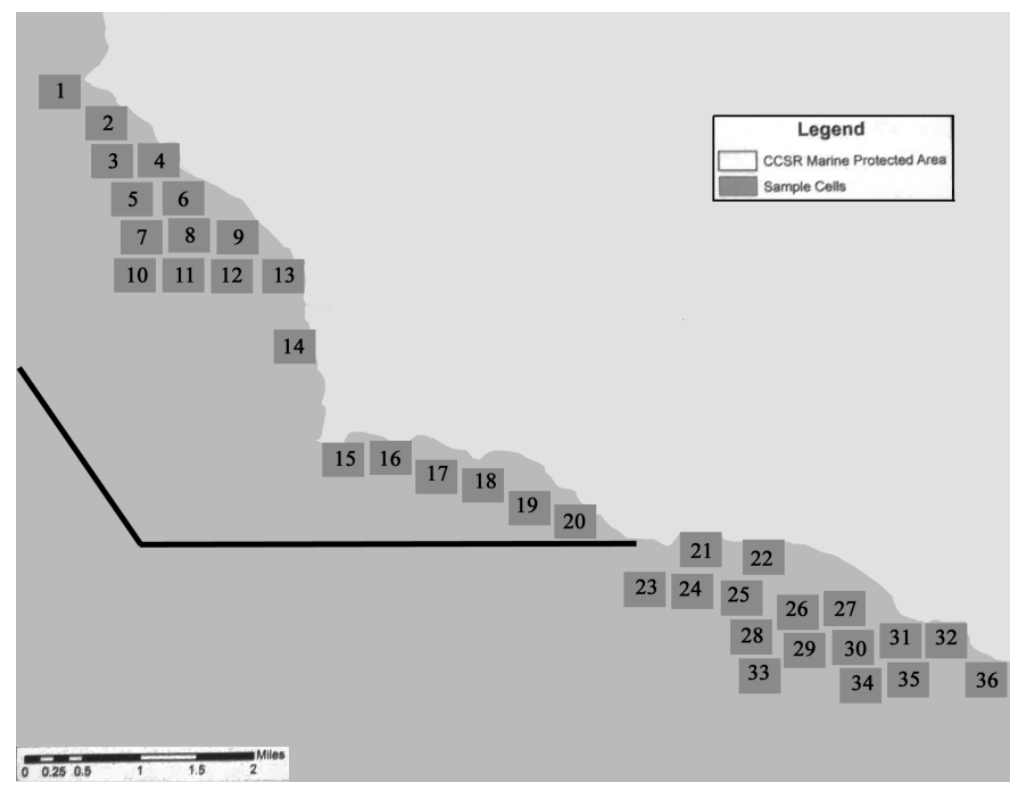

Figure 3: Location of grid cells at Piedras Blancas, CA from 2008-2009.

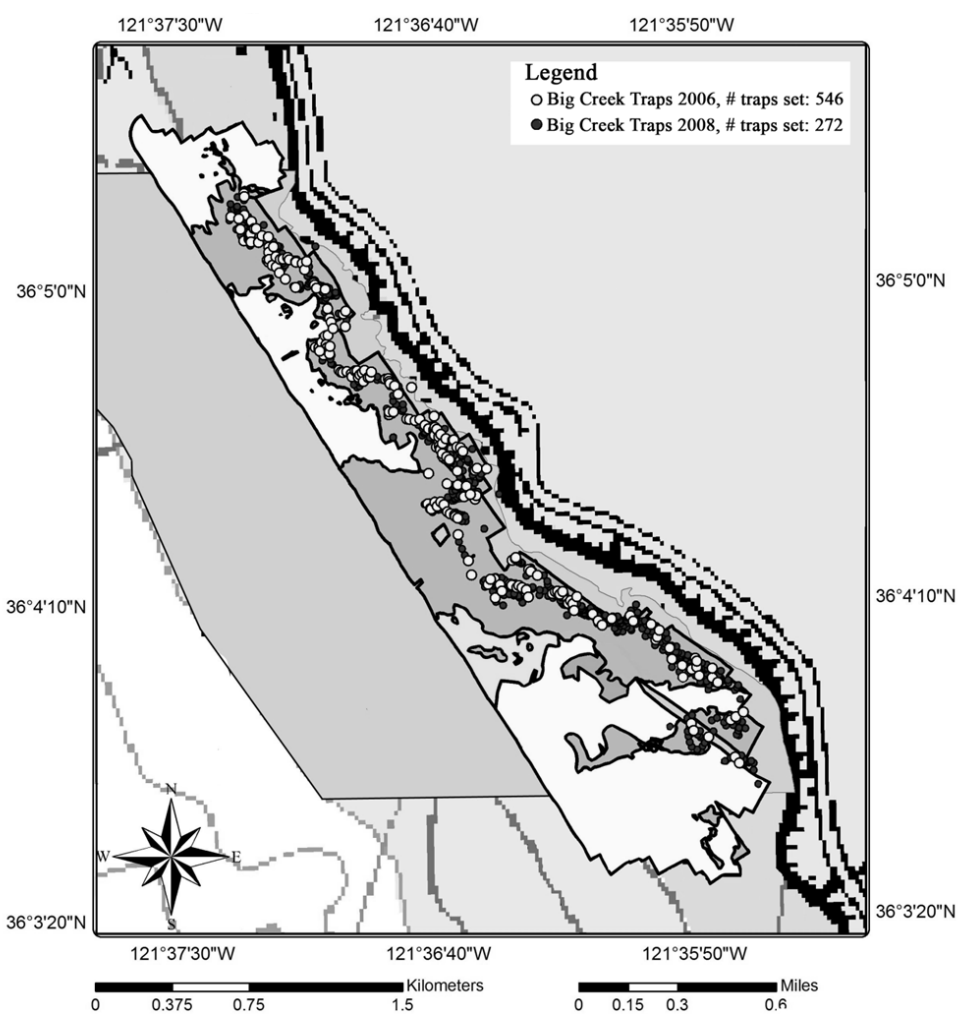

Figure 4: Location of traps set at Big Creek, CA in 2006 and 2008. Note, different colors denote different trapping periods. 


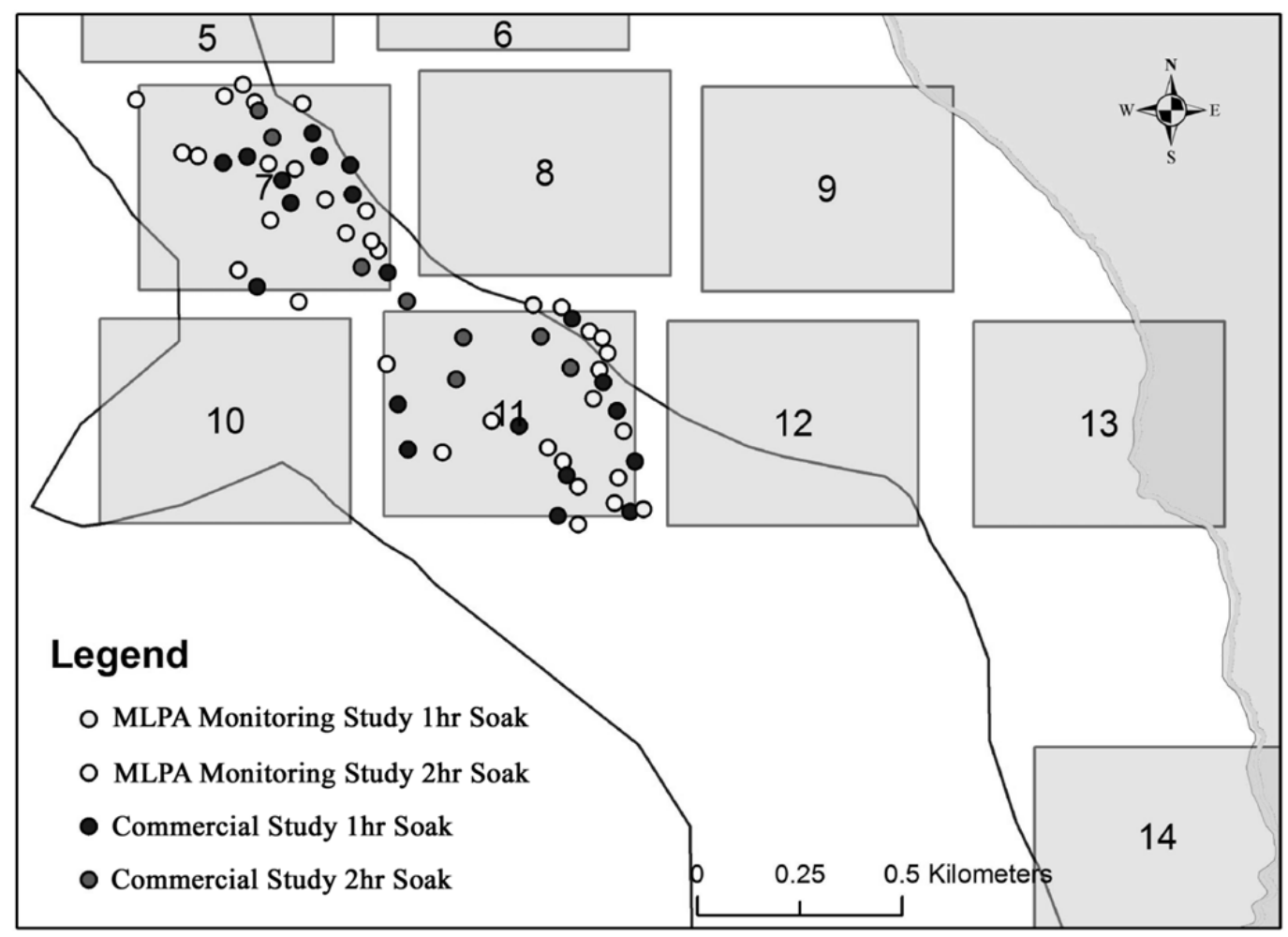

Figure 5: Location of both MLPA monitoring study and Commercial study traps set in two cells of Piedras Blancas MPA during Conversion study. Note, colors denote different trap types and soak times.

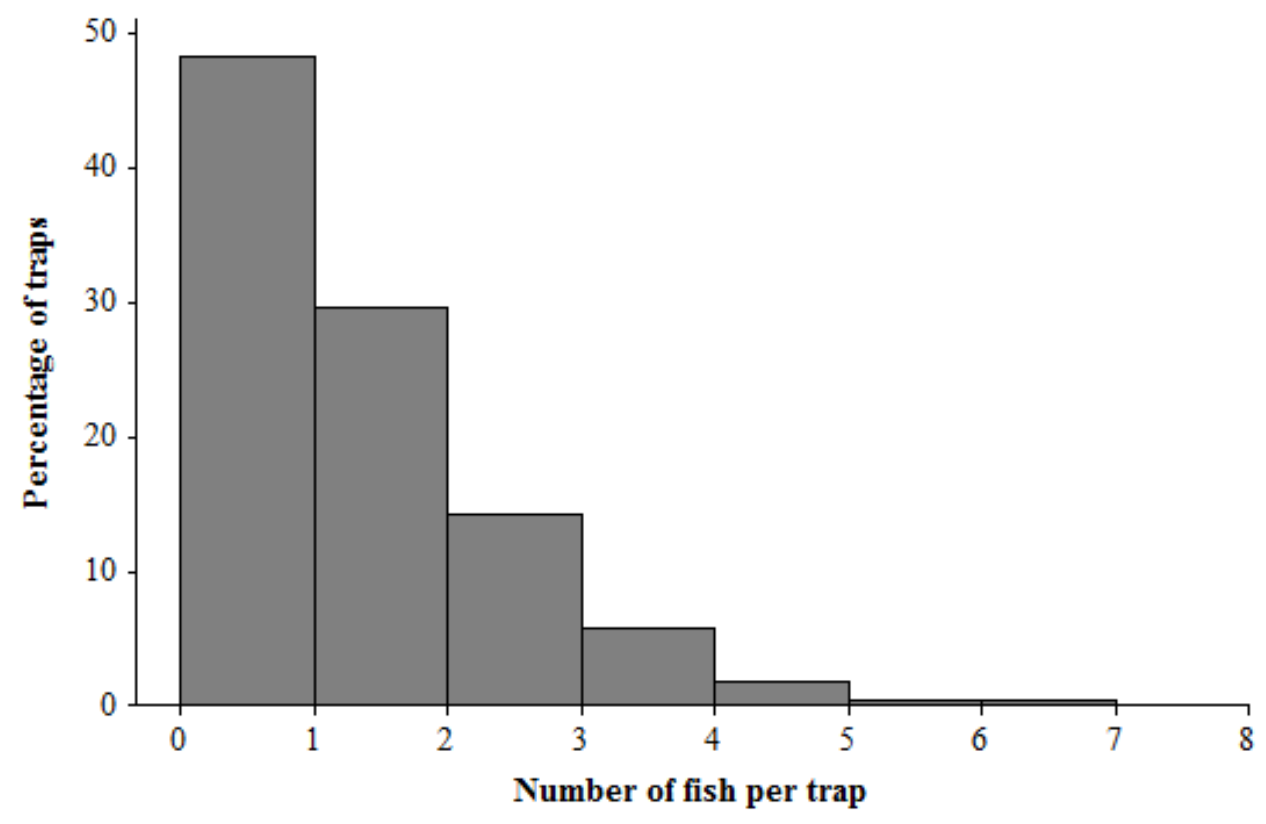

Figure 6: Percentage of traps returning with different numbers of fish. 


\section{A. Cabezon}

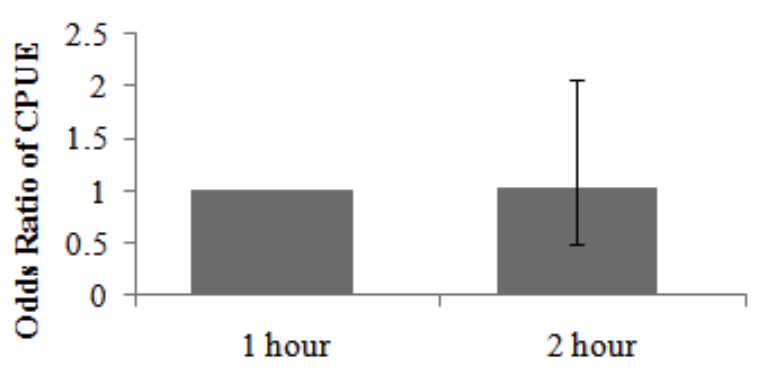

C. Black and Yellow Rockfish

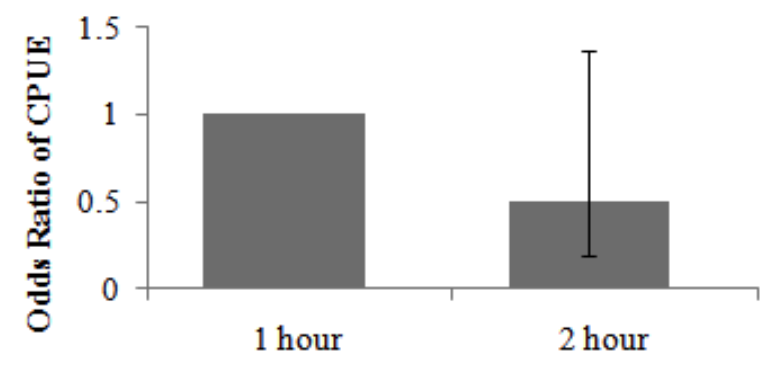

\section{E. Lingcod}

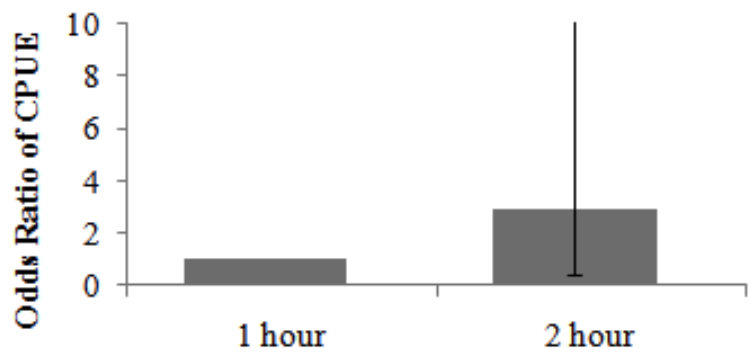

\section{B. Gopher Rockfish}

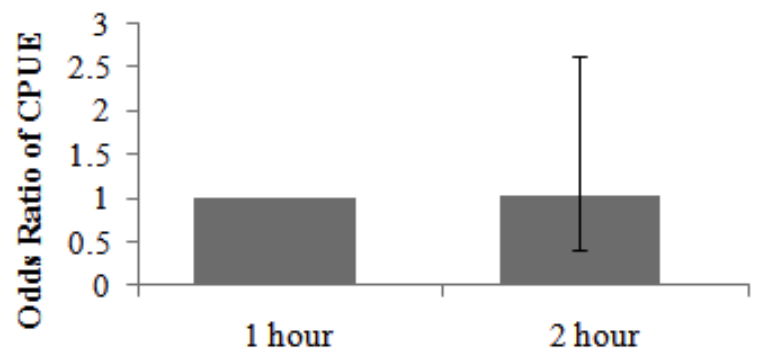

D. Kelp Greenling

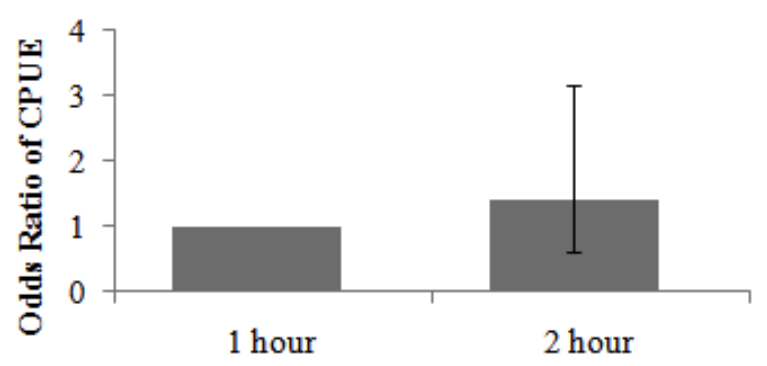

Figure 7: Effect of soak time on CPUE from conversion experiment. Error bars represent 95\%

confidence intervals. There are no significant differences in CPUE for the analyzed soak times. See appendix 1 for interpretation of Ordinal Regression. 


\section{A. Cabezon}

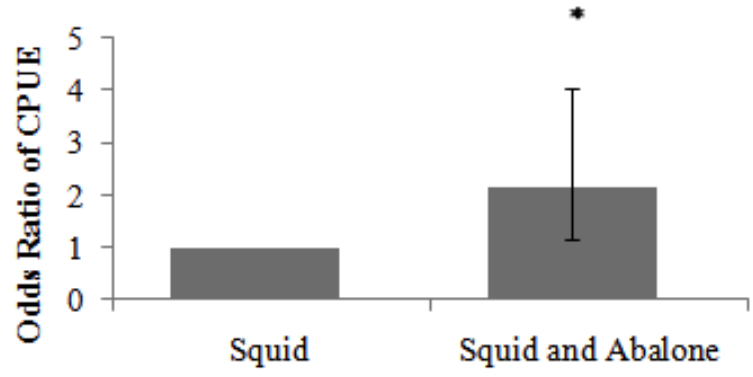

\section{Black and Yellow Rockfish}

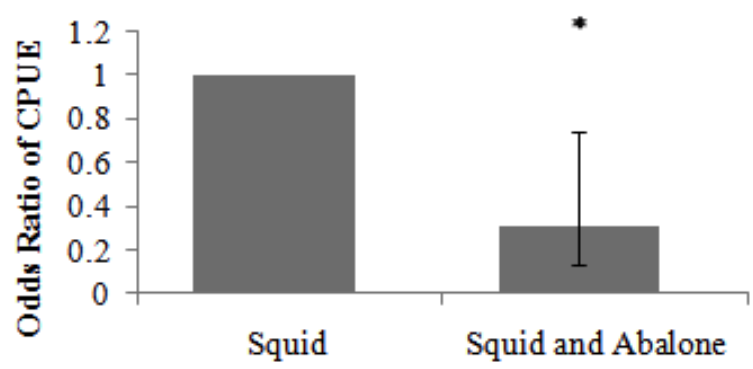

\section{E. Lingcod}

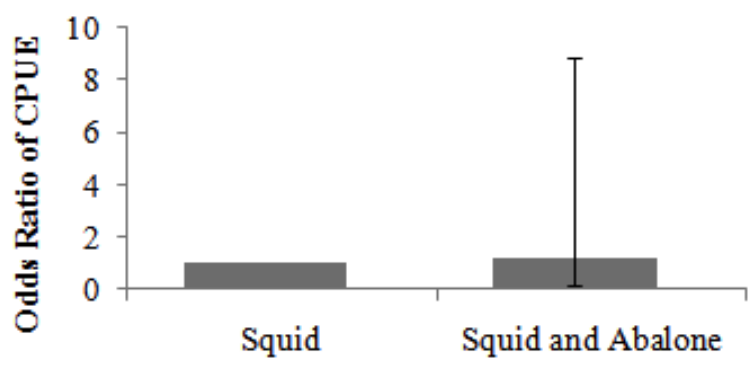

\section{B. Gopher Rockfish}

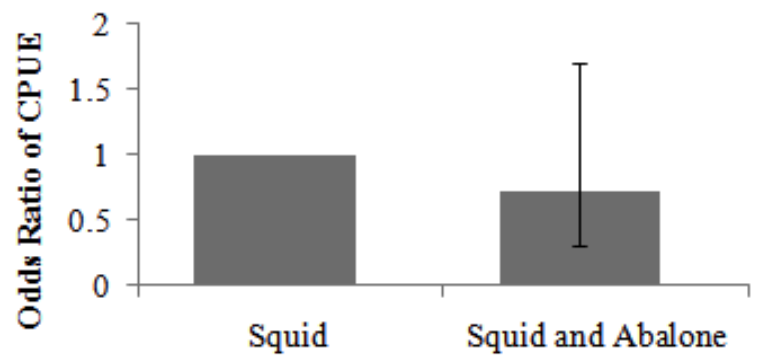

\section{Kelp Greenling}

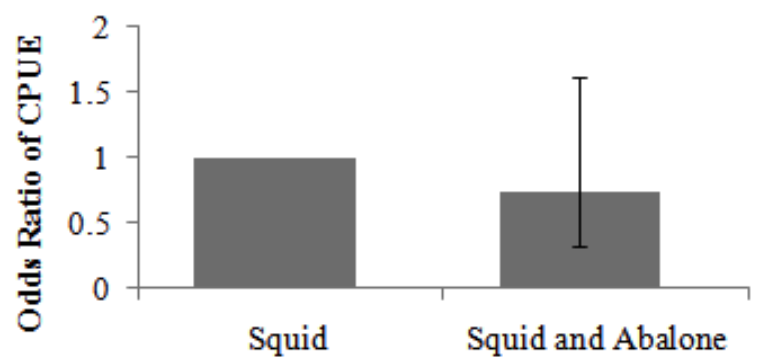

Figure 8: Effect of bait on CPUE from conversion experiment. Error bars represent $95 \%$ confidence intervals. Note, asterisk indicates significant differences in CPUE between treatments. 


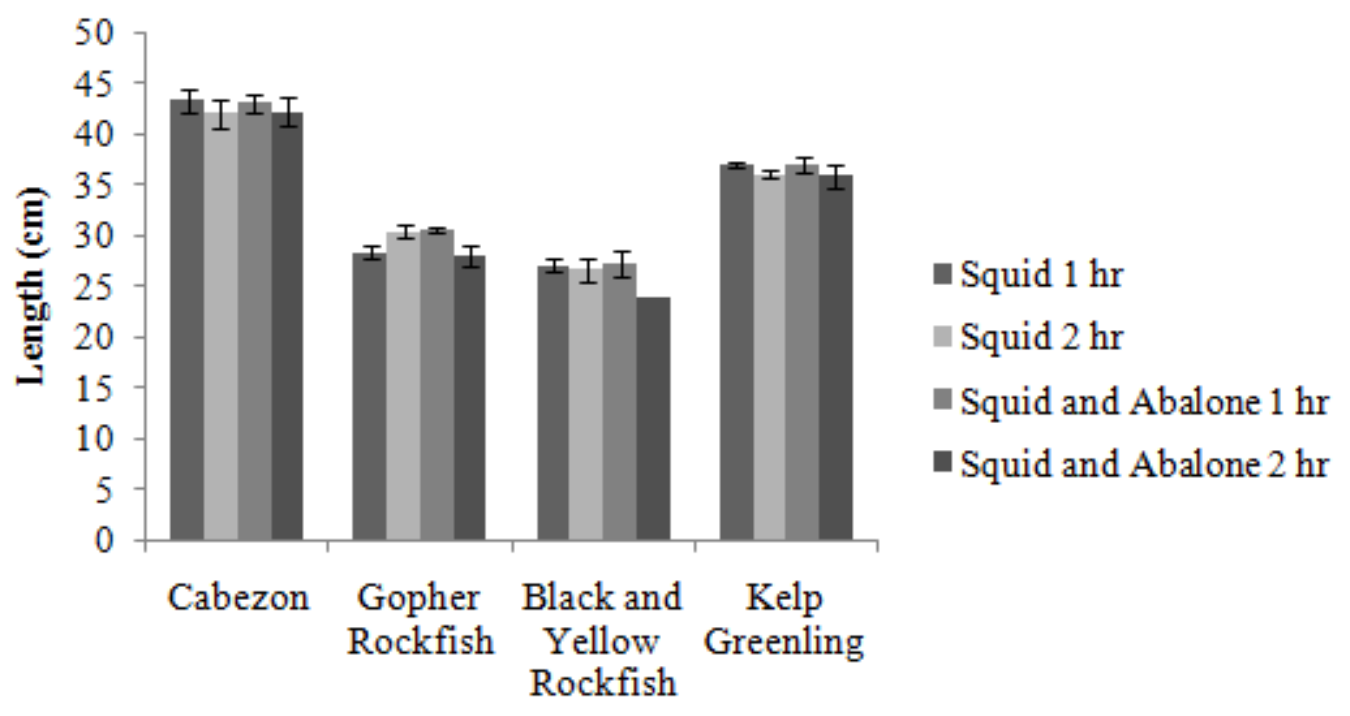

Figure 9: Mean total length of nearshore fish species under different treatments in conversion experiment. Note, Lingcod is not included due to low sample size. Error bars represent standard error of the mean. There were no significant differences in sample fish length between treatments.

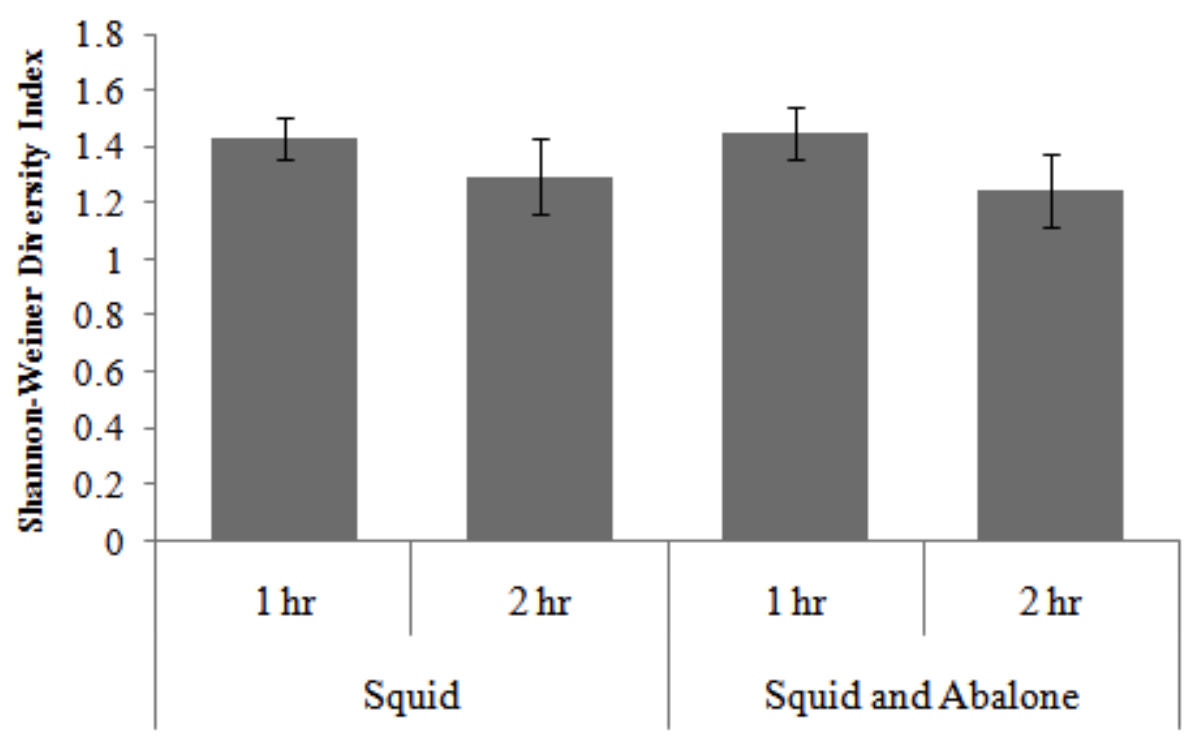

Figure 10: Shannon-Weiner diversity values under different treatments in conversion experiment. Error bars represent standard error of the mean. There were no significant differences in diversity between treatments. 


\section{A. Cabezon}

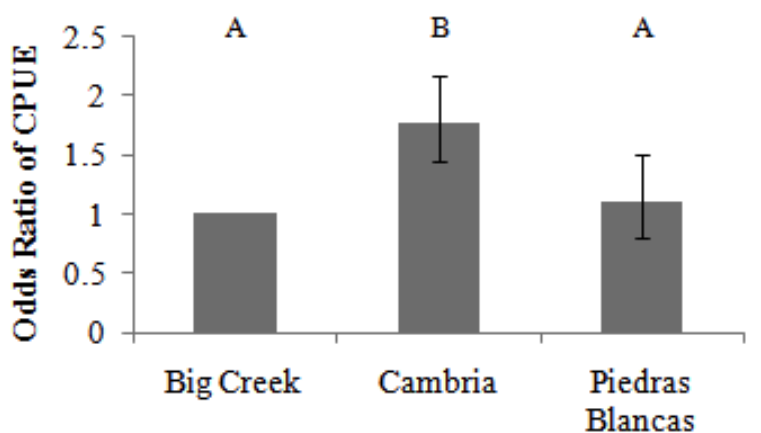

C. Black and Yellow Rockfish

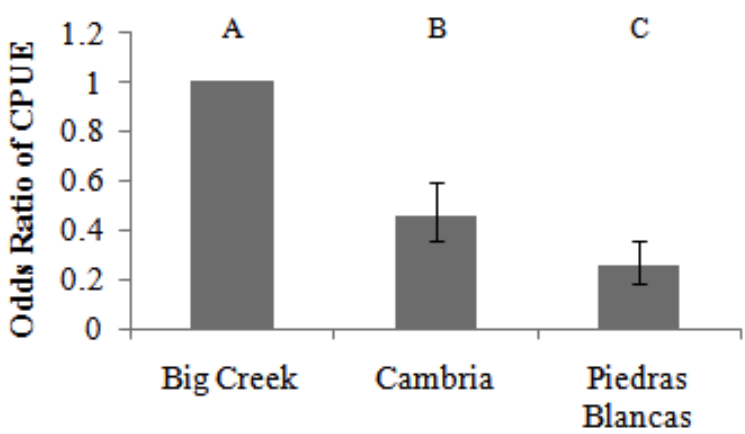

\section{E. Lingcod}

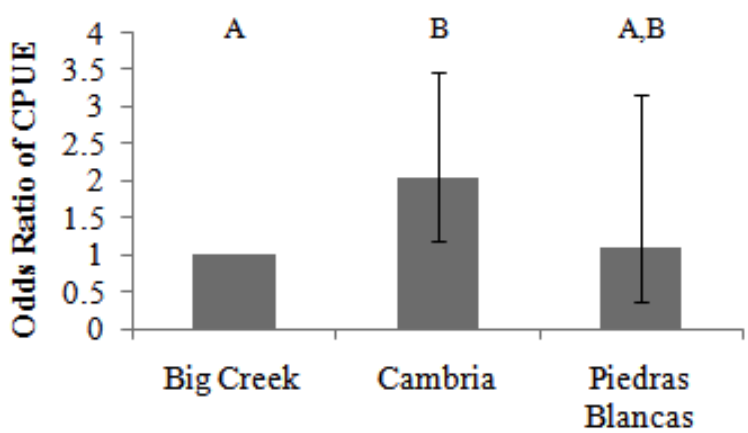

\section{B. Gopher Rockfish}

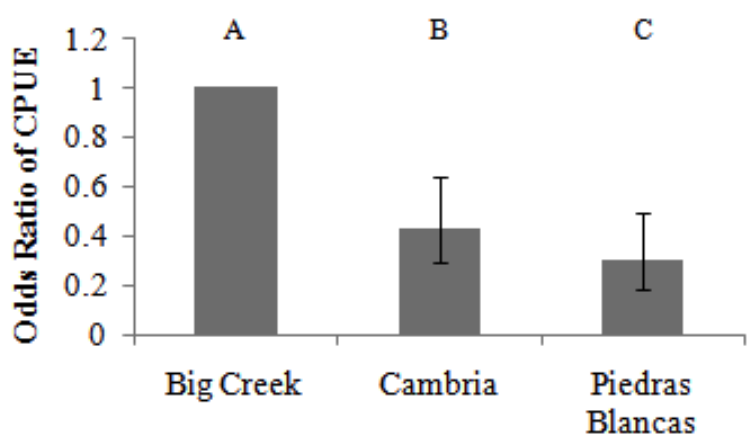

\section{Kelp Greenling}

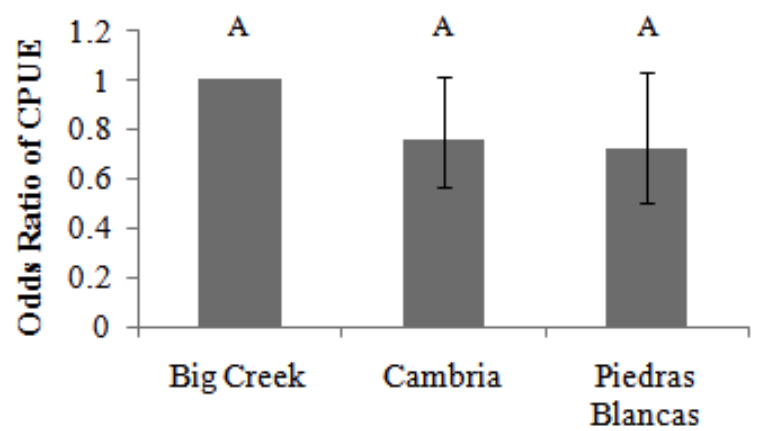

Figure 11: Differences in CPUE between locations across all sampling years. Error bars represent 95\% confidence intervals. Note, different letters indicate significant differences in CPUE between locations. 


\section{A. Cabezon}

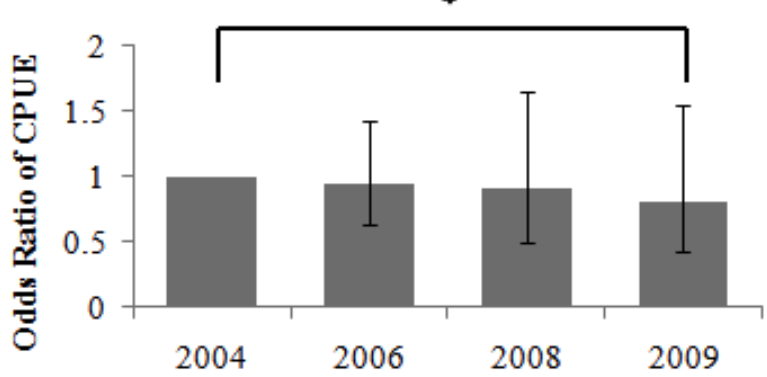

C. Black and Yellow Rockfish

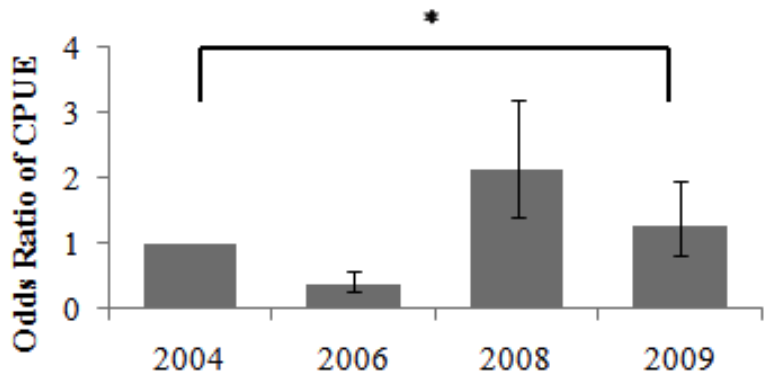

\section{E. Lingcod}

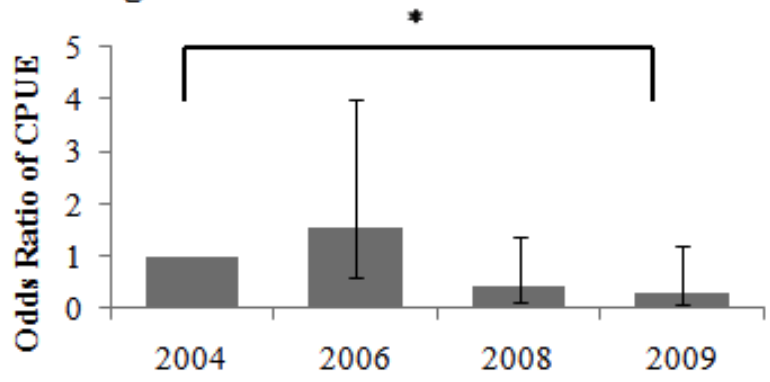

\section{B. Gopher Rockfish}

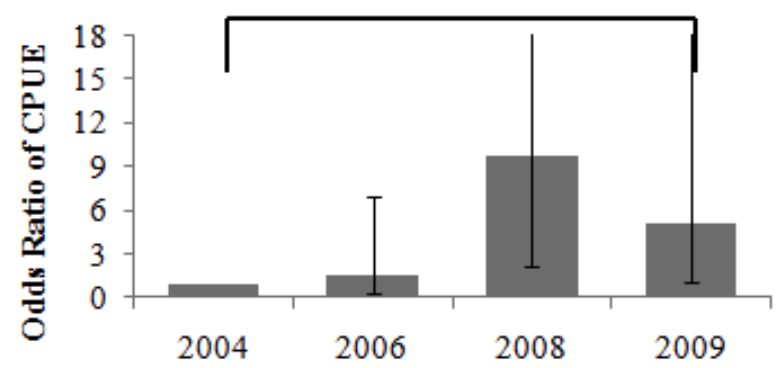

\section{Kelp Greenling}

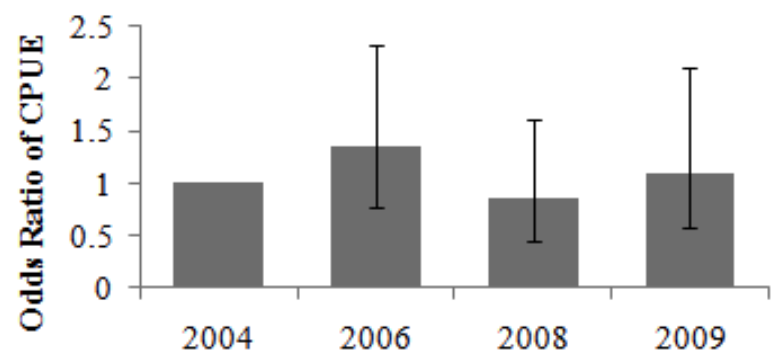

Figure 12: CPUE from 2004-2009 at Cambria regardless of site. Error bars represent $95 \%$ confidence intervals. Note, asterisks indicate significant trends in CPUE across 2004-2009. 
A. Cabezon

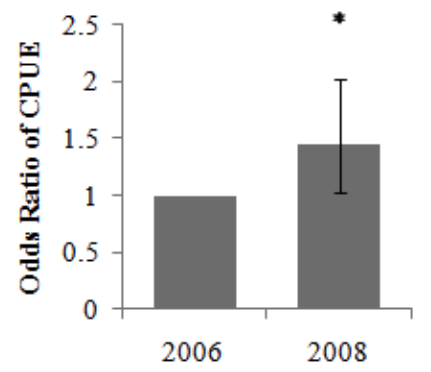

D. Kelp Greenling

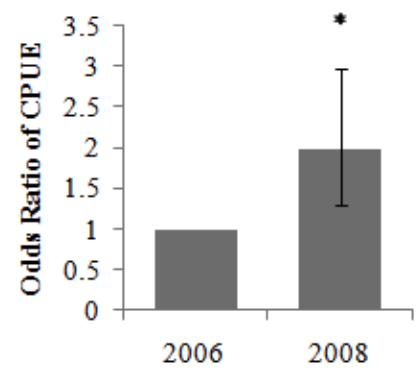

B. Gopher Rockfish

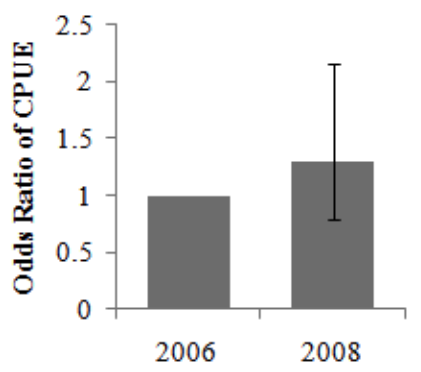

\section{E. Lingcod}

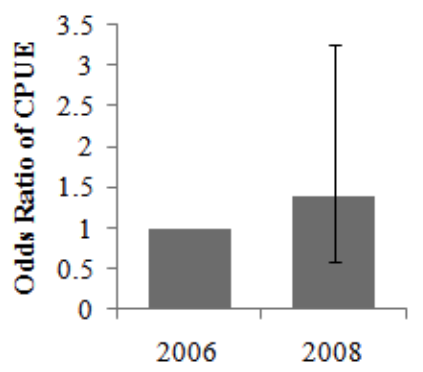

C. Black and Yellow

Rockfish

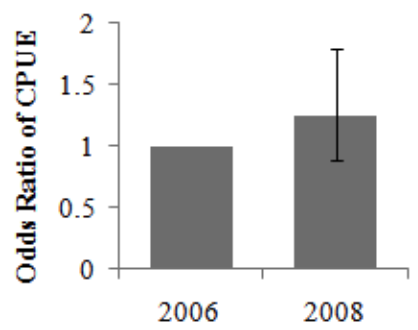

Figure 13: CPUE from 2006-2008 at Big Creek. Error bars represent 95\% confidence intervals. Note, asterisks indicate significant differences in CPUE between years.

A. Cabezon

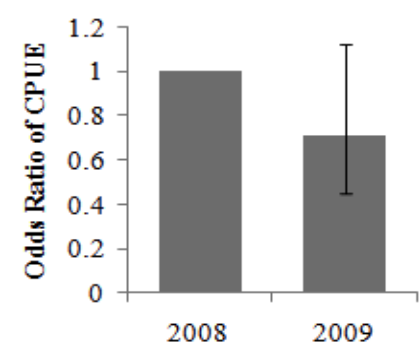

D. Kelp Greenling

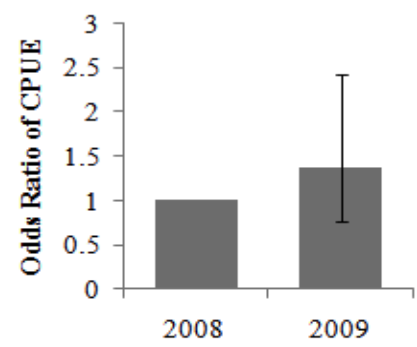

B. Gopher Rockfish

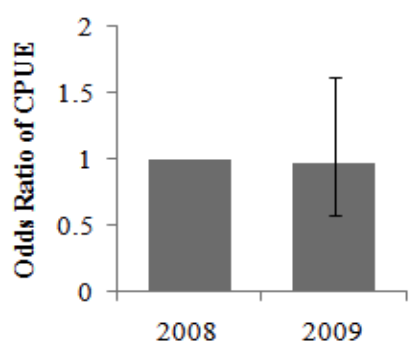

E. Lingcod

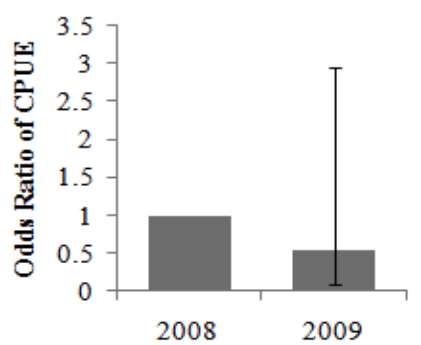

\section{Black and Yellow}

Rockfish

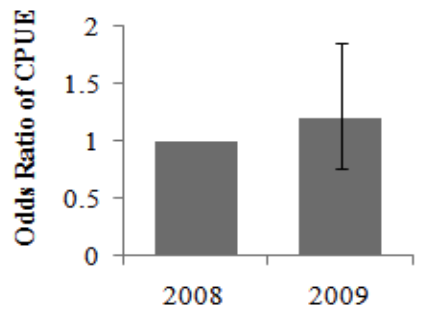

Figure 14: CPUE from 2008-2009 at Piedras Blancas. Error bars represent 95\% confidence intervals. There are no significant differences in CPUE between years for all species. 


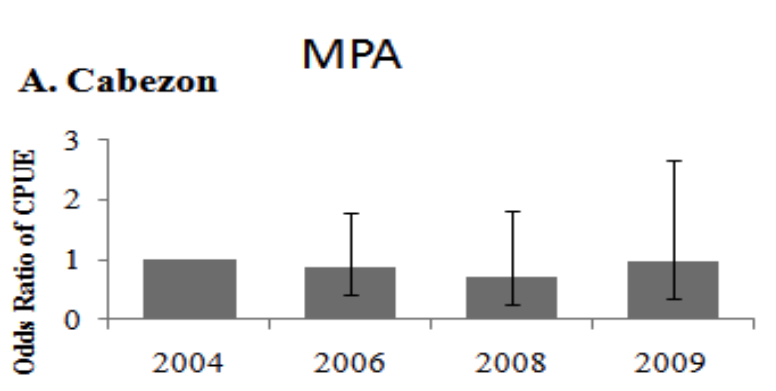

B. Gopher Rockfish

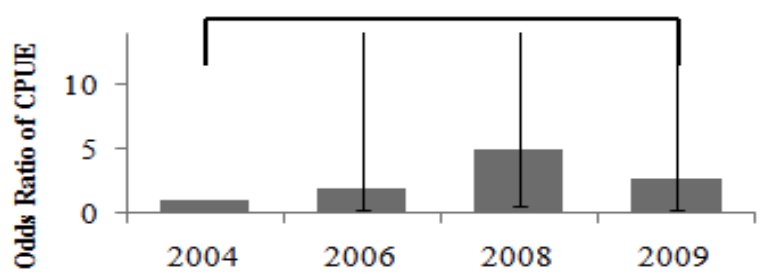

C. Black and Yellow Rockfish

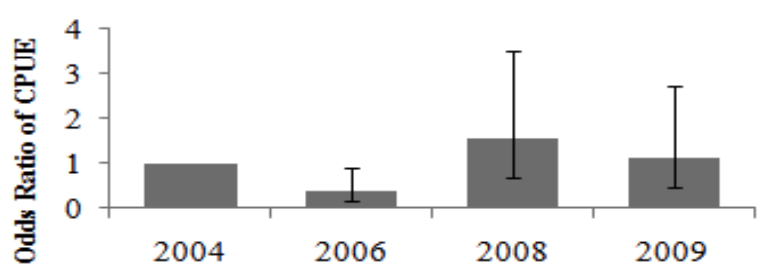

\section{Kelp Greenling}

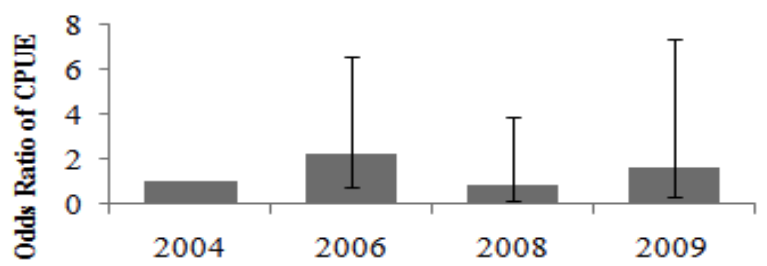

E. Lingcod

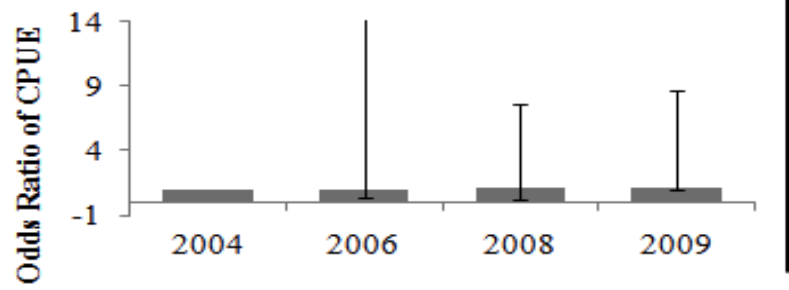

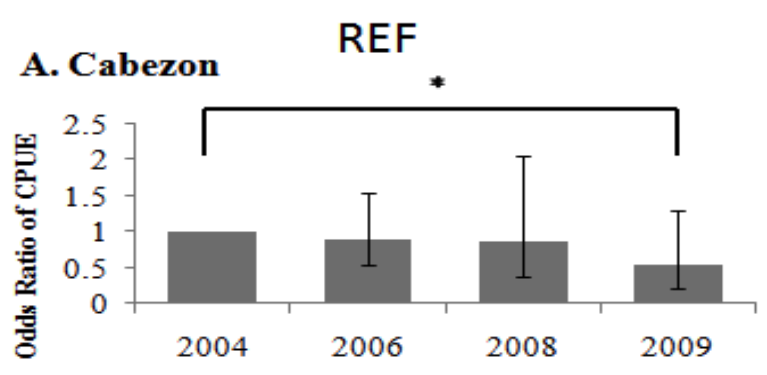

B. Gopher Rockfish

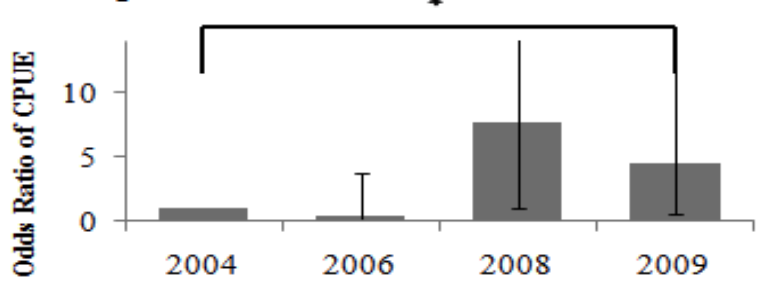

C. Black and Yellow Rockfish

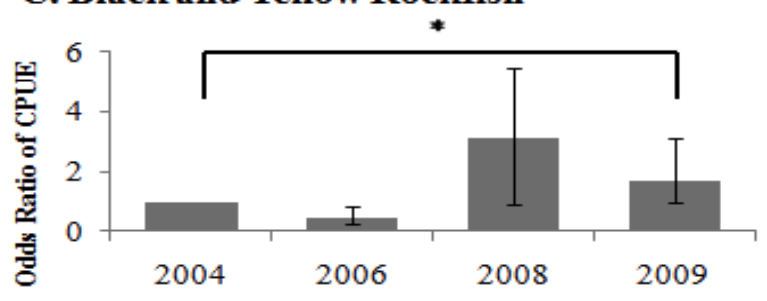

D. Kelp Greenling

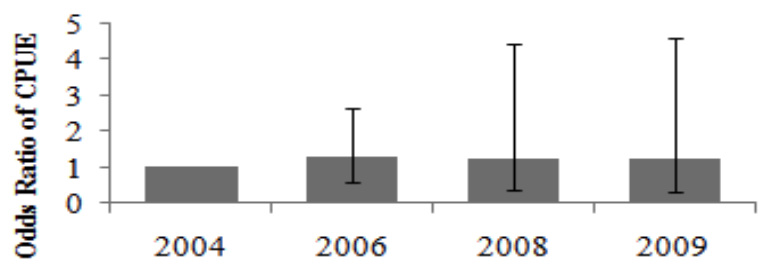

Figure 15: CPUE from 2004-2009 at Cambria separated into MPA and reference sites. Error bars represent 95\% confidence intervals. Lingcod reference site absent due to low capture numbers, Kruskallwallace test used instead of logistic regression. Note, asterisks indicate significant trends in CPUE across 2004-2009. 


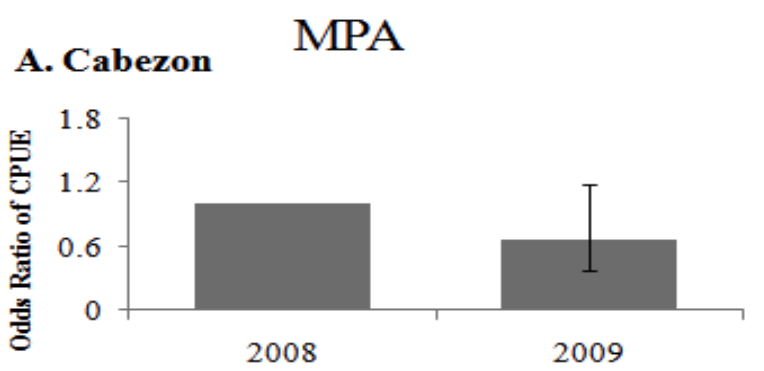

B. Gopher Rockfish

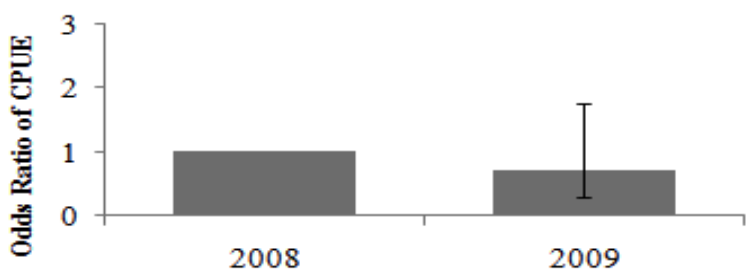

C. Black and Yellow Rockfish

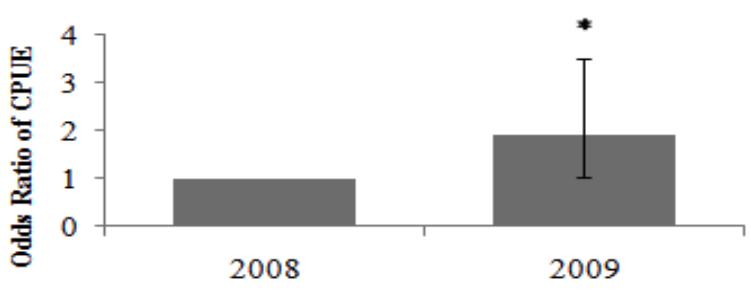

D. Kelp Greenling

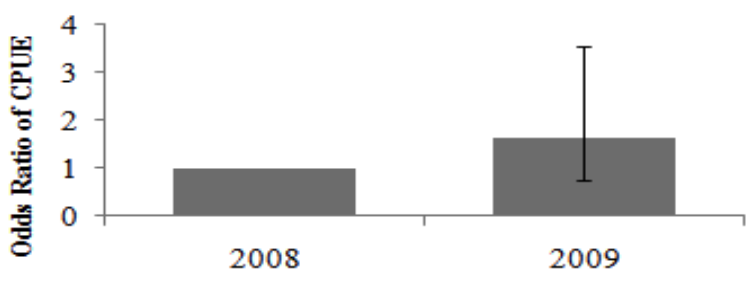

E. Lingcod

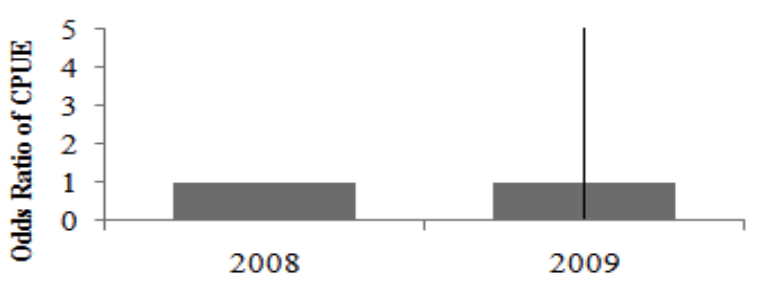

A. Cabezon REF

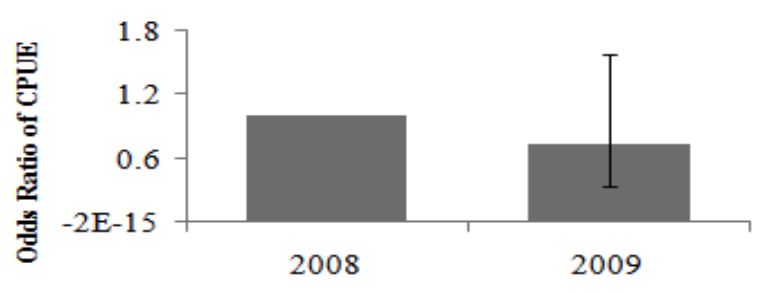

B. Gopher Rockfish

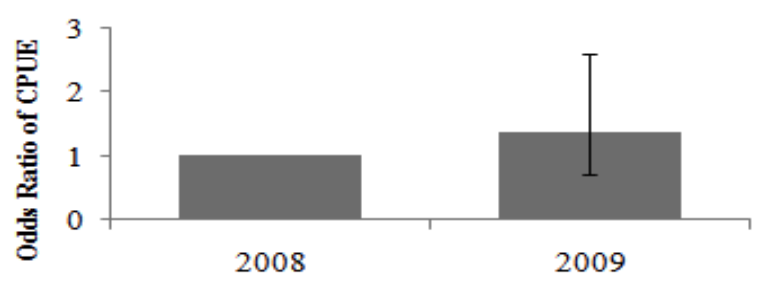

C. Black and Yellow Rockfish
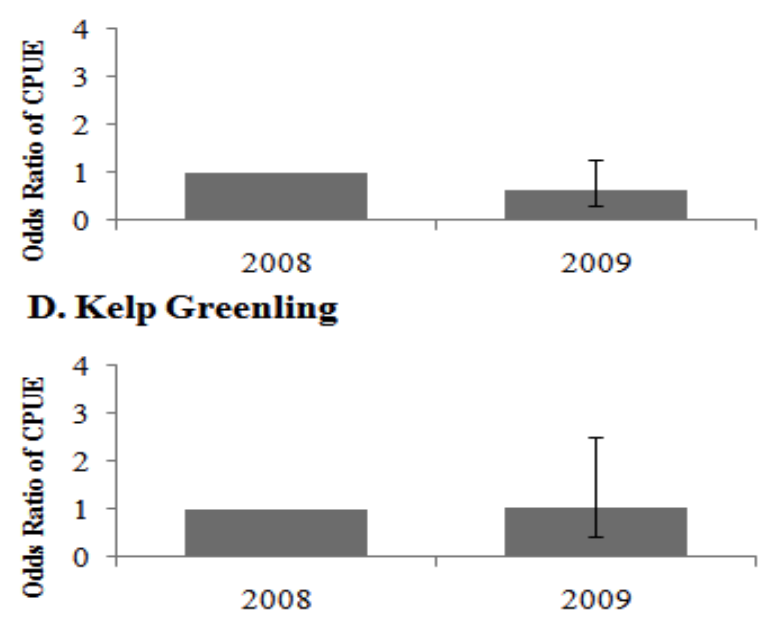

\section{E. Lingcod}

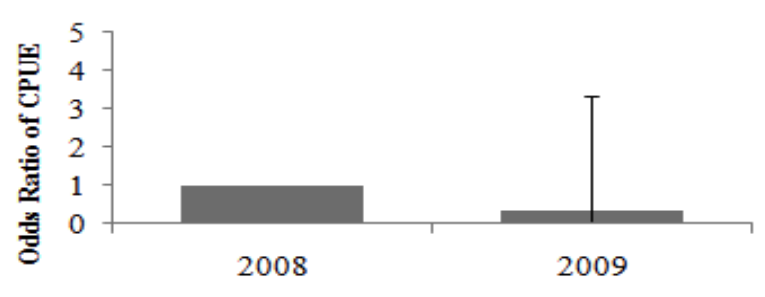

Figure 16: CPUE from 2008-2009 at Piedras Blancas separated into MPA and reference sites. Error bars represent $95 \%$ confidence intervals. Note, asterisks indicate significant differences in CPUE between sampling years. 


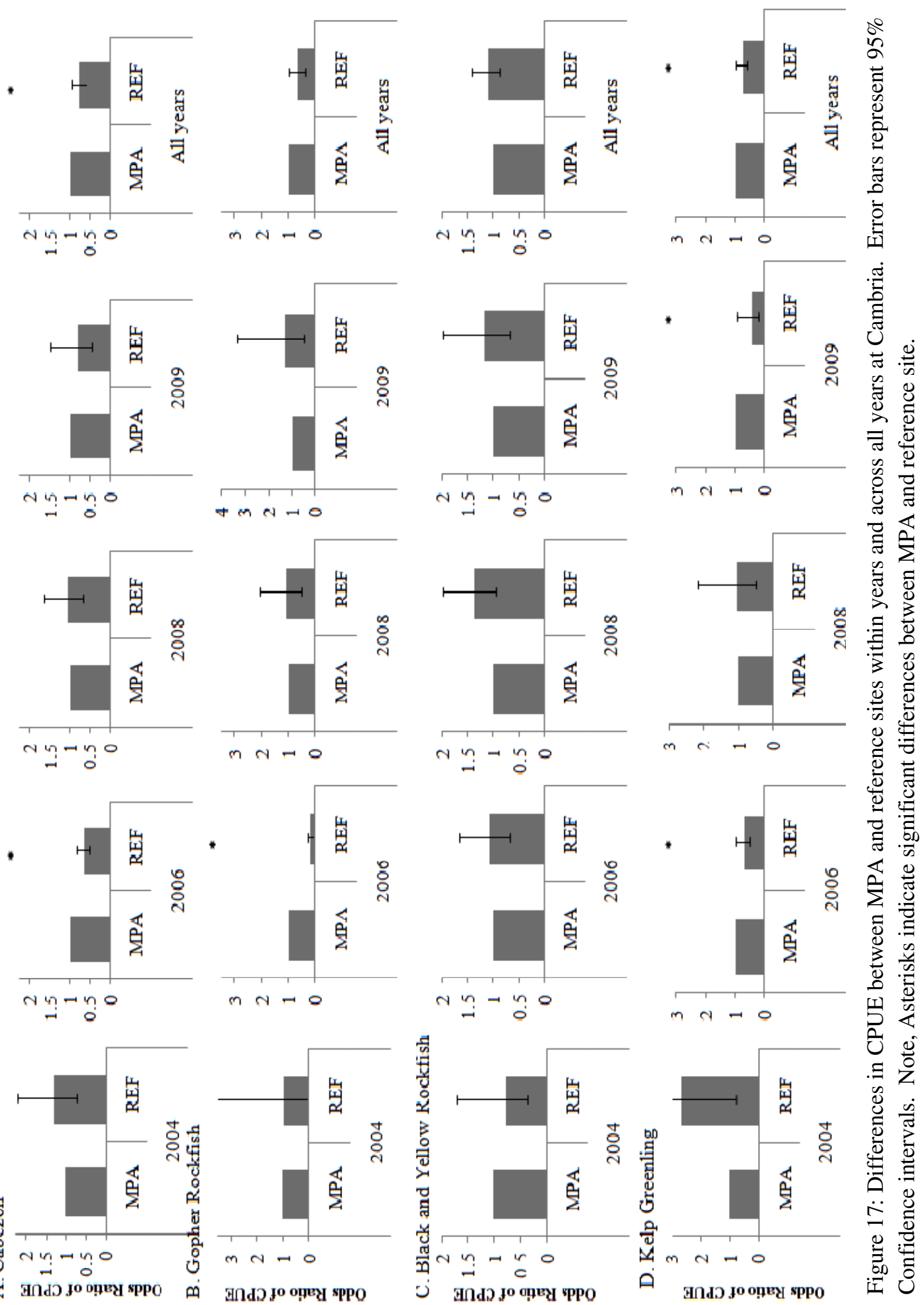




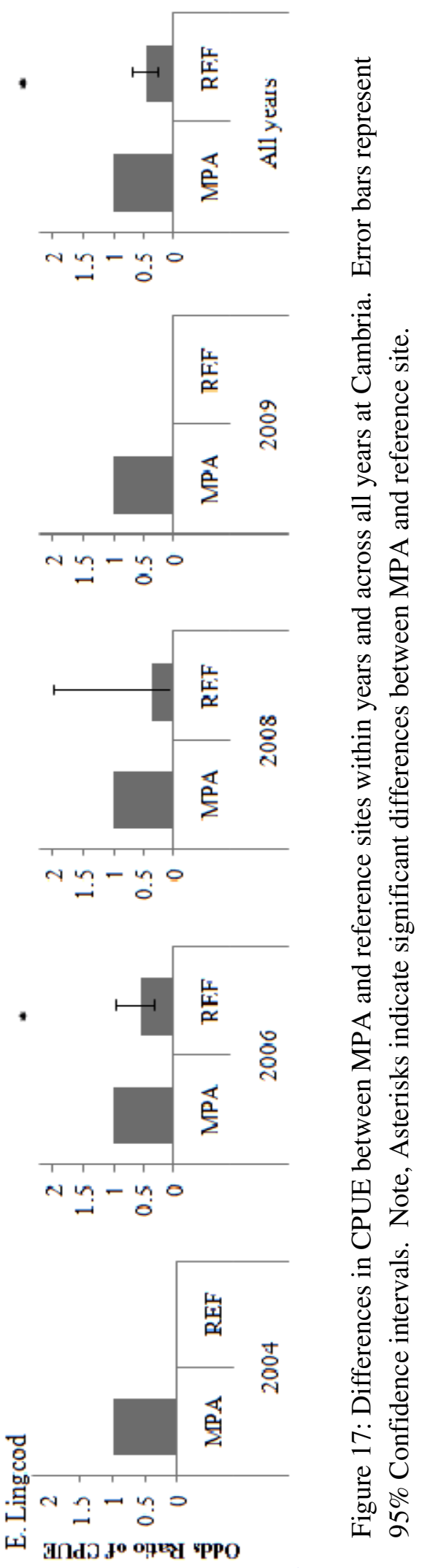



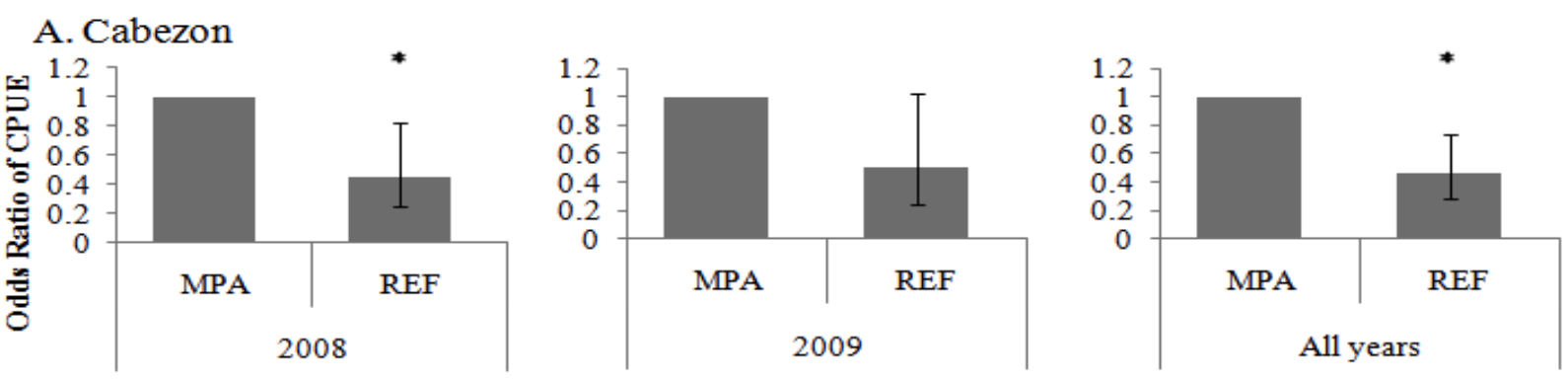

B. Gopher Rockfish
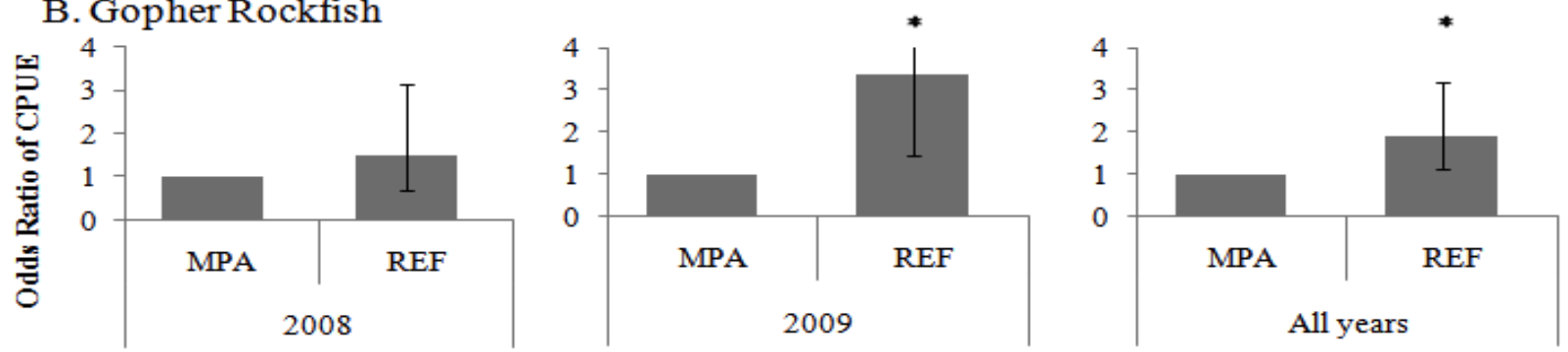

C. Black and Yellow Rockfish
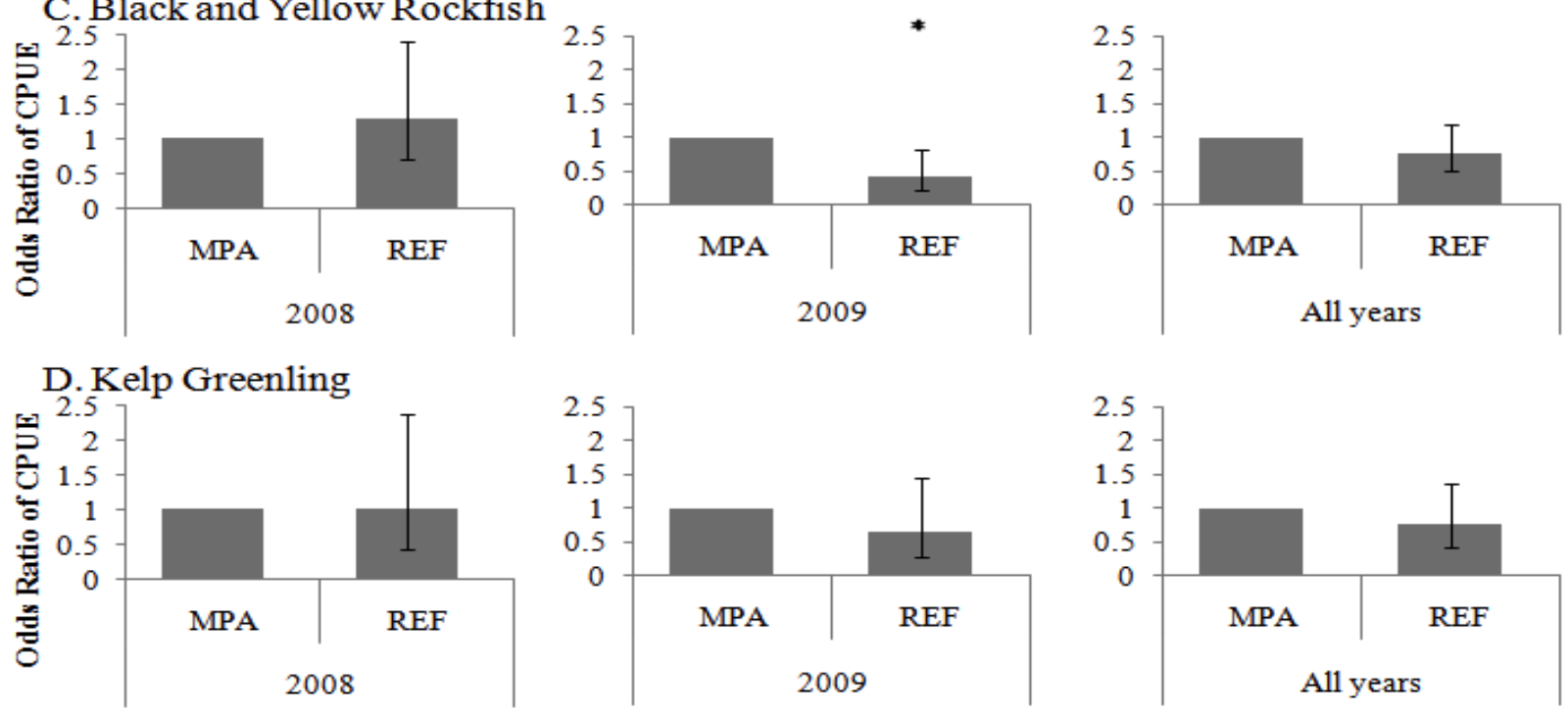

E. Lingcod
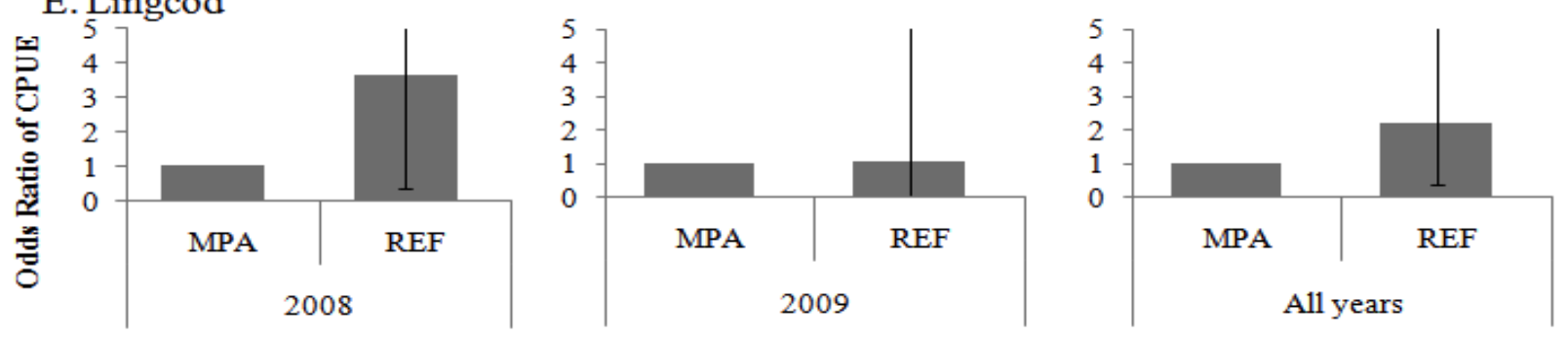

Figure 18: Differences in CPUE between MPA and reference sites within years and across all years at Piedras Blancas. Error bars represent 95\% Confidence intervals. Note, Asterisks indicate significant differences between MPA and reference site. 


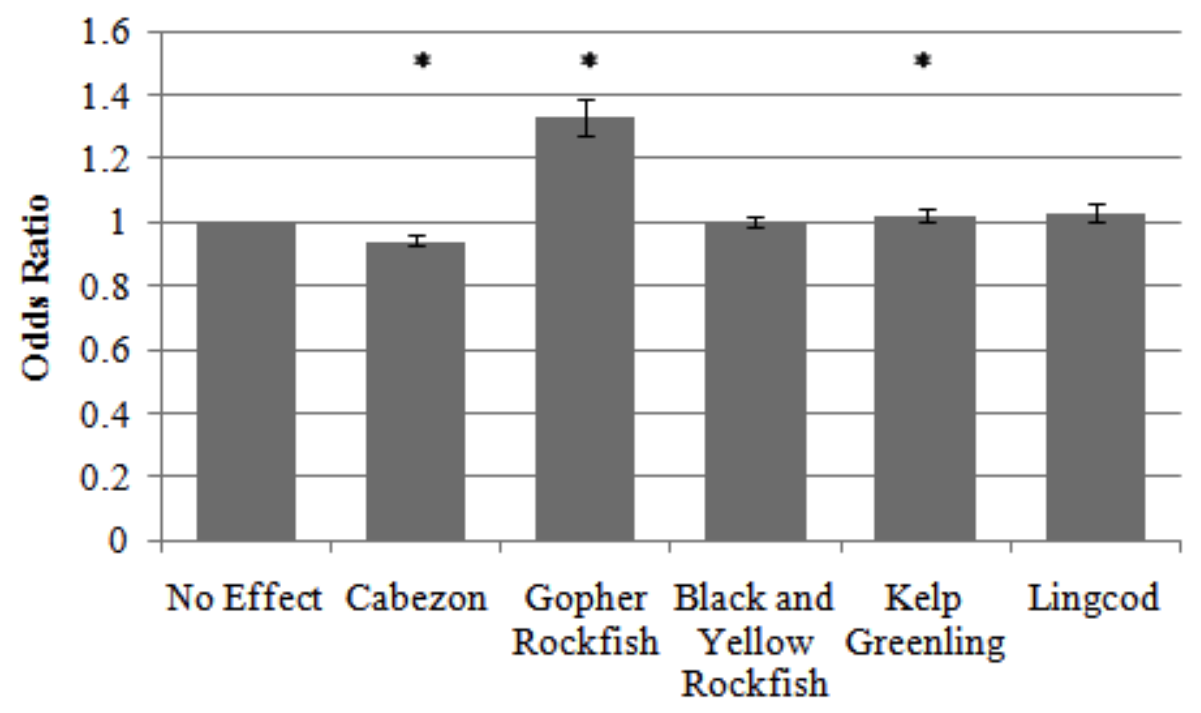

Figure 19: Effect of depth on CPUE. Values greater than one indicates higher CPUE at greater depths, less than one indicates higher CPUE at shallower depths. Note, asterisks indicate species that have a significant effect of depth on CPUE. 
A. Cabezon

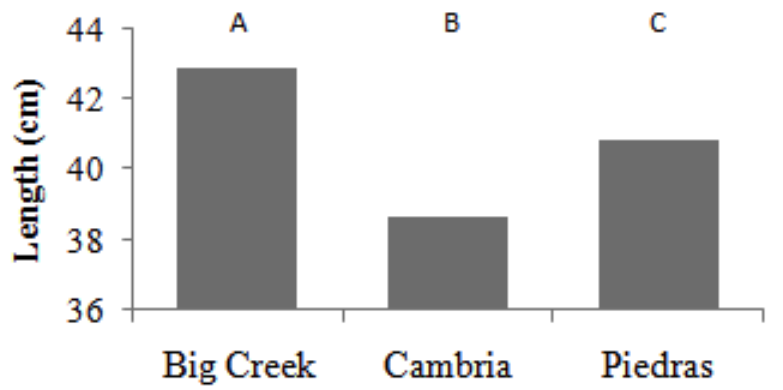

C. Black and Yellow Rockfish

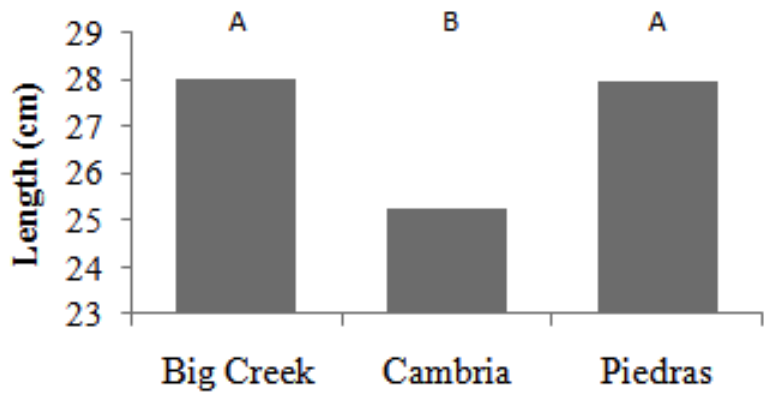

E. Lingcod

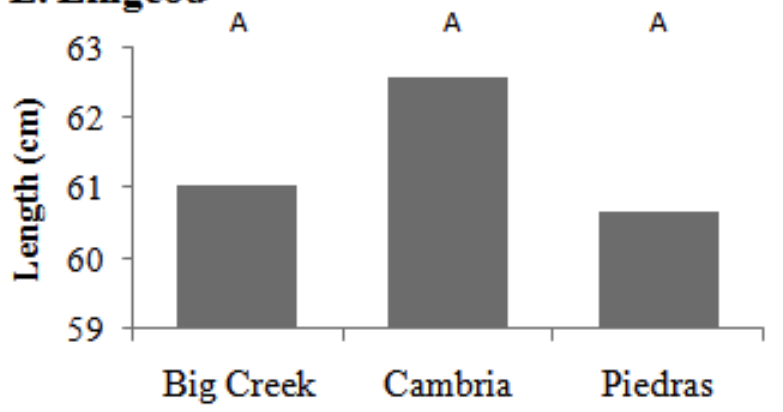

\section{B. Gopher Rockfish}

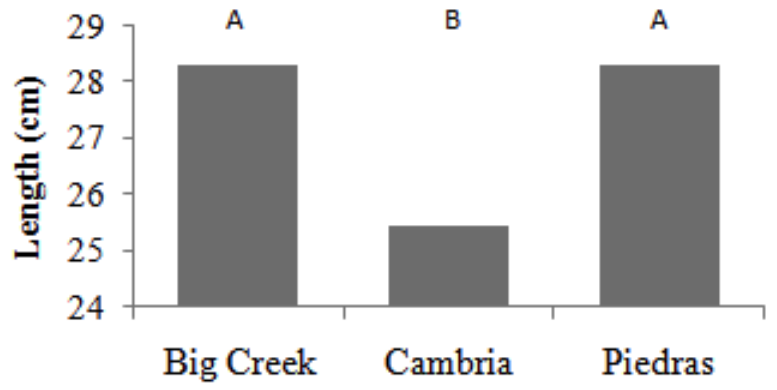

D. Kelp Greenling

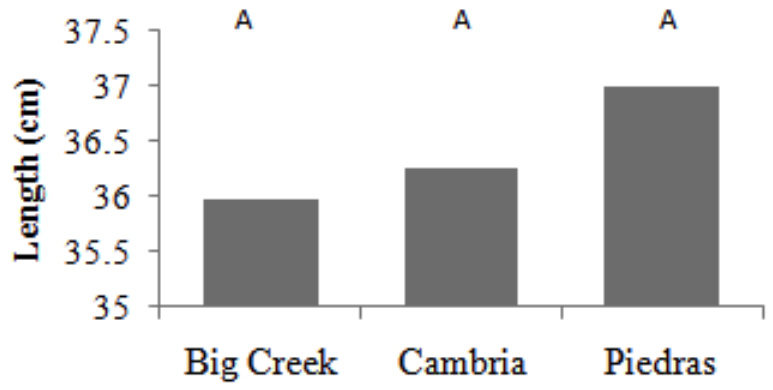

Figure 20: Main effects plot of length across all sampling locations and all years. Note, different letters indicate significant differences in length between locations. 
A. Cabezon

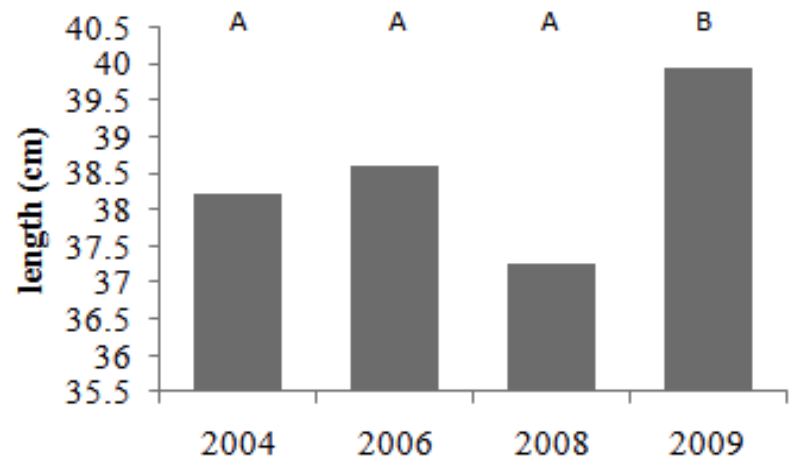

\section{Black and Yellow Rockfish}

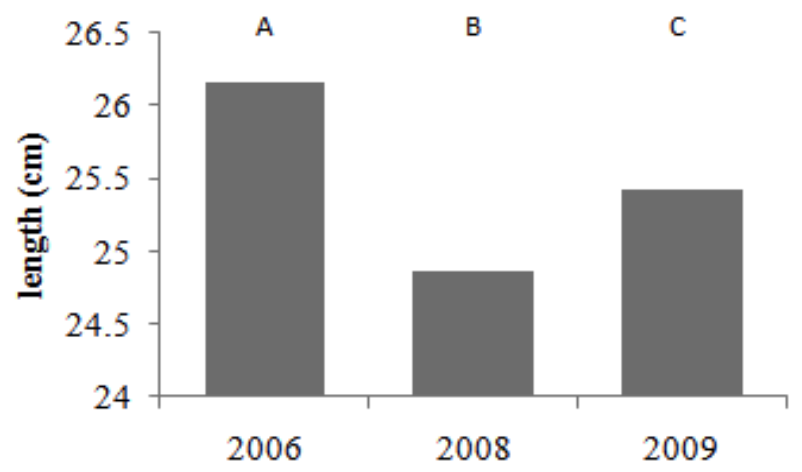

\section{E. Lingcod}

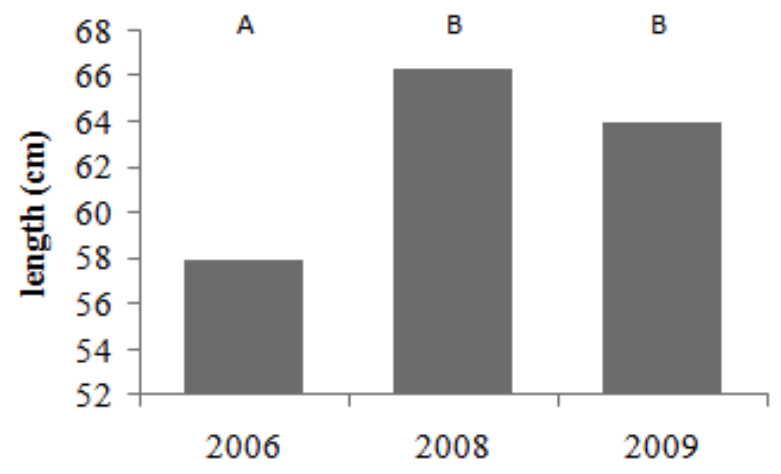

\section{B. Gopher Rockfish}

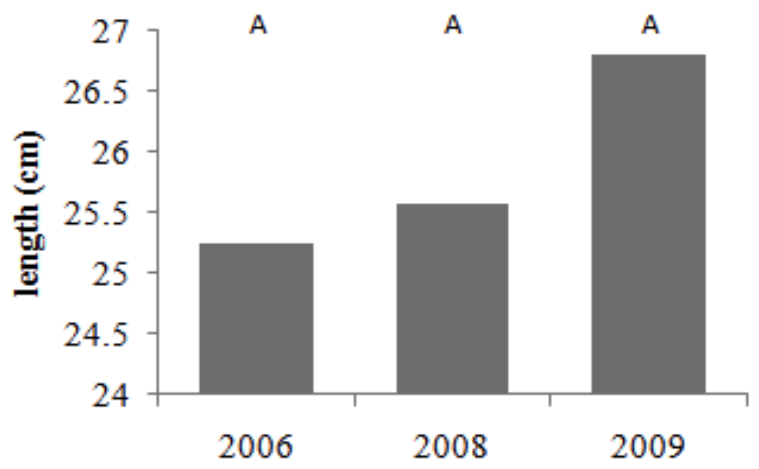

\section{Kelp Greenling}

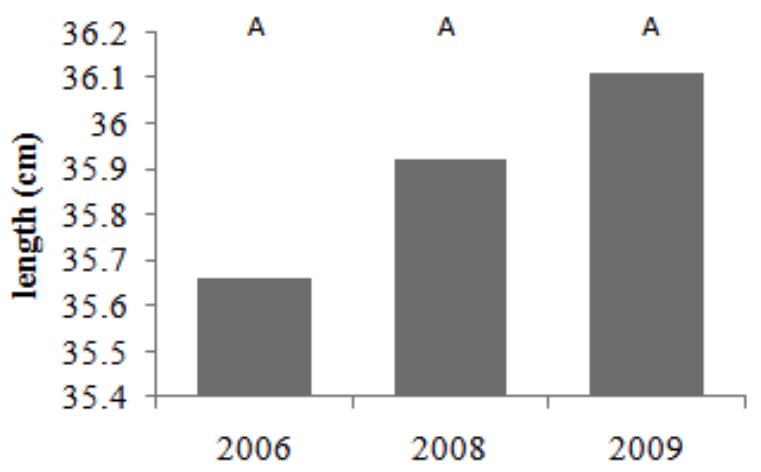

Figure 21: Main effects plot of length across all sampling years at Cambria. Note, different letters indicate significant differences in length between locations. 

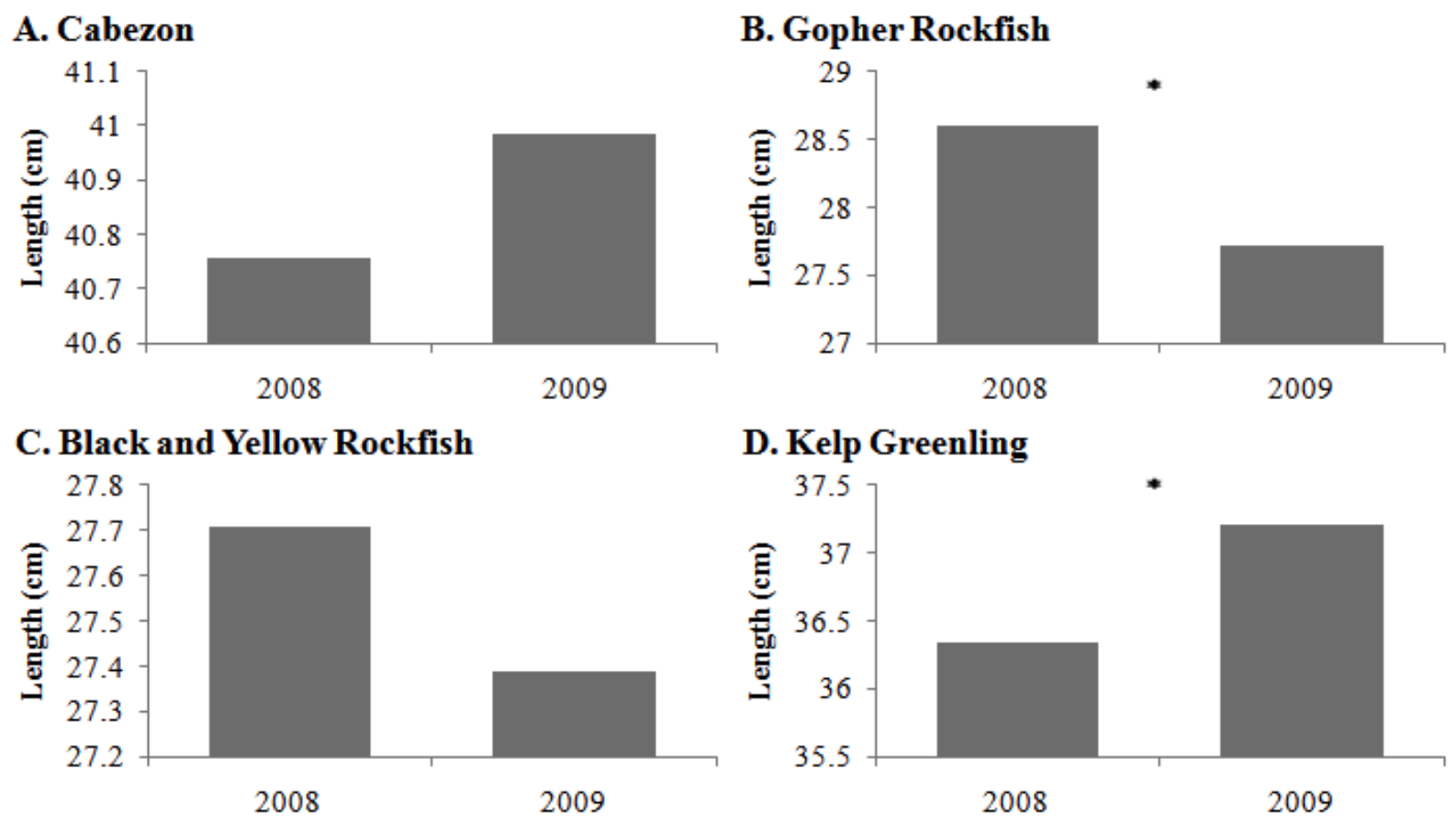

\section{E. Lingcod}

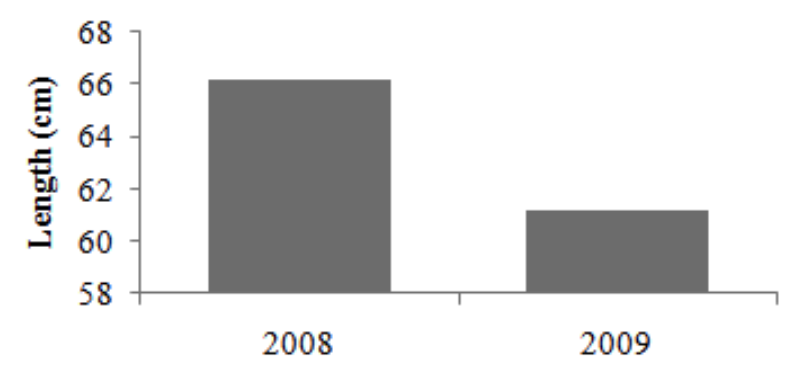

Figure 22: Main effects plots of length across all sampling years at Piedras Blancas. Note, asterisks denote years with significantly different lengths.

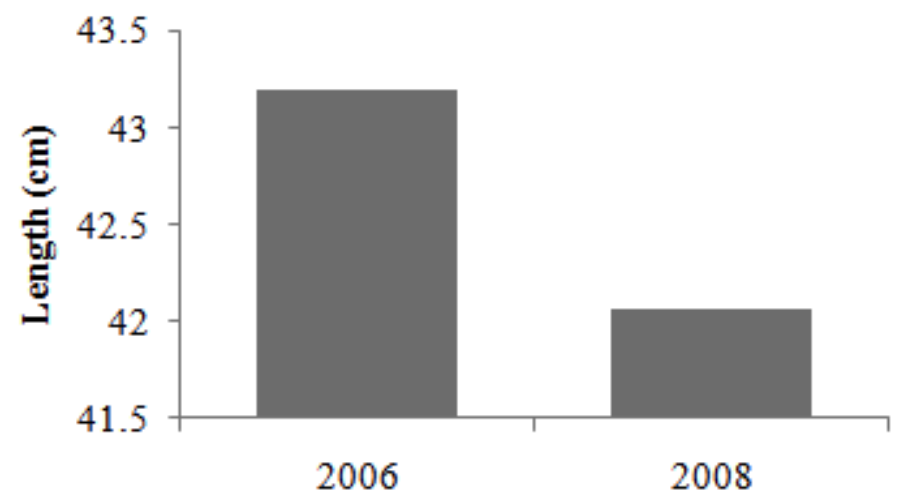

Figure 23: Main effects plot of cabezon length across all sampling years at Big Creek. There was no significant difference in length between years. 
A. Cabezon

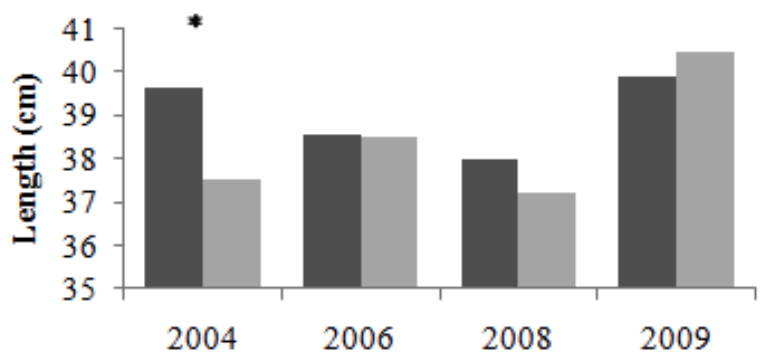

C. Black and Yellow Rockfish

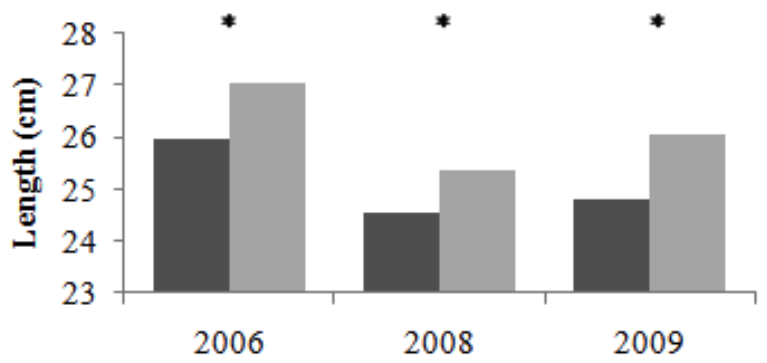

E. Lingcod

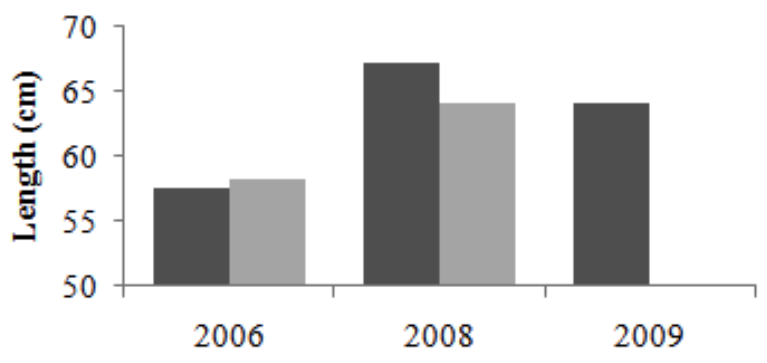

B. Gopher Rockfish

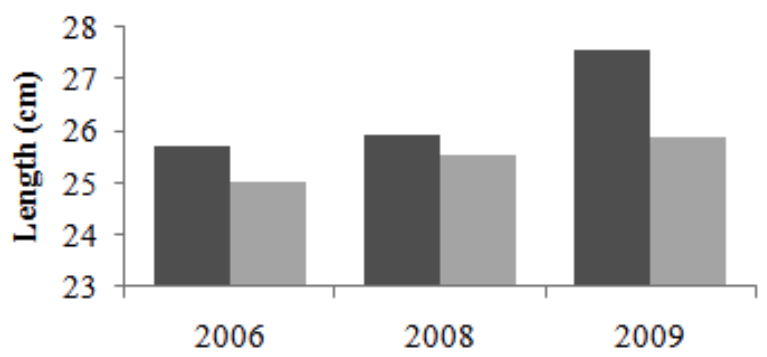

D. Kelp Greenling

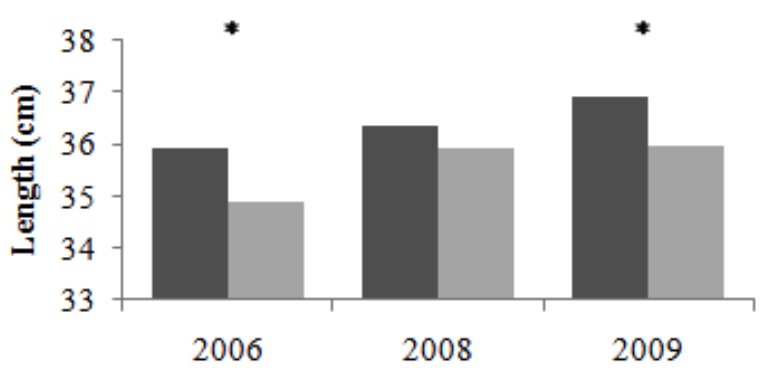

Figure 24: Main effects plot of length across sampling years in the MPA and reference site within Cambria. Note, asterisks denote years that had significantly different length between the MPA and reference site. 
A. Cabezon

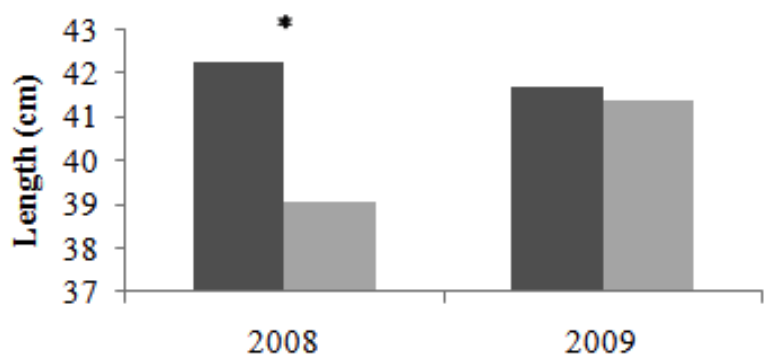

C. Black and Yellow Rockfish

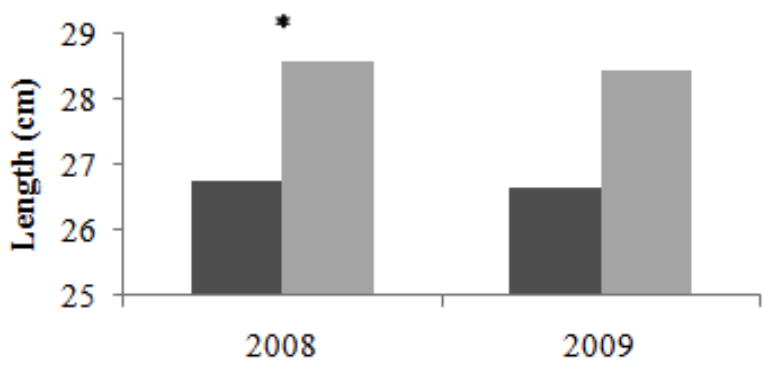

$\rightarrow \mathrm{MPA}$

$\rightarrow-$ Reference Site

\section{B. Gopher Rockfish}

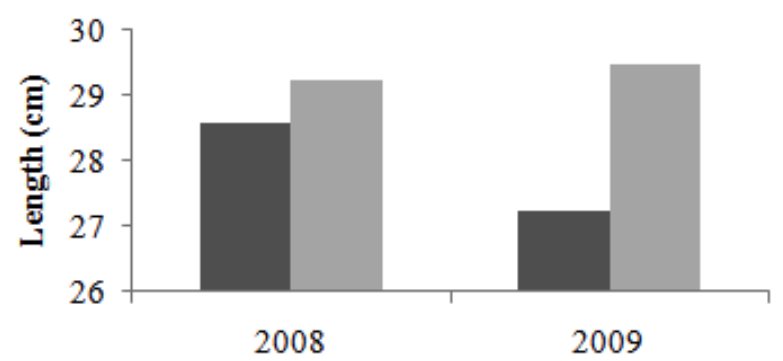

D. Kelp Greenling

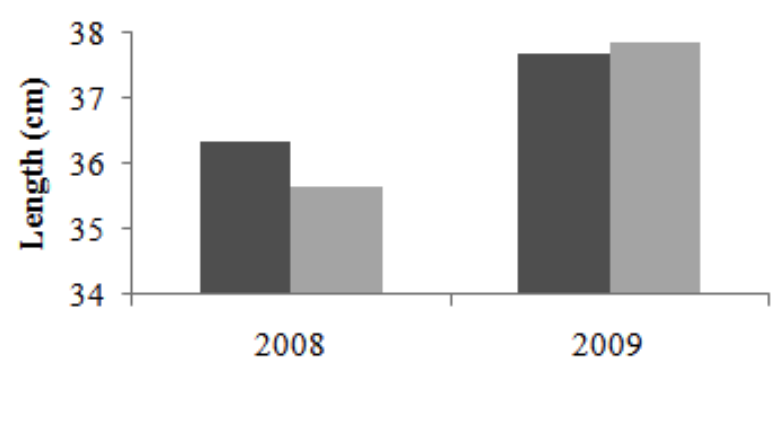

Figure 25: Main effects plot of length across sampling years in the MPA and reference site within Piedras Blancas. Lincod not included due to low capture numbers in 2009. Note, asterisks denote years that had significantly different length between the MPA and reference site.

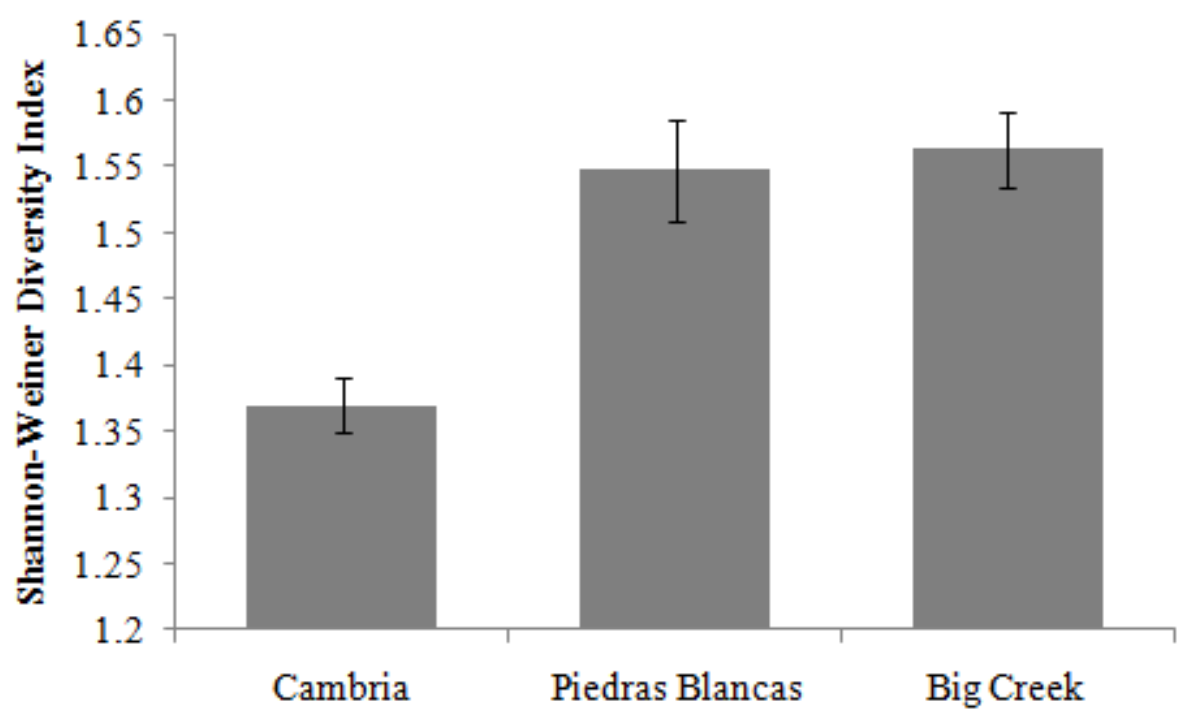

Figure 26: Average Shannon-Weiner diversity values for the three sampling locations across all sampling years. Error Bars represent standard error of the mean. Asterisks denote locations that had significantly different CPUE than the other locations. 


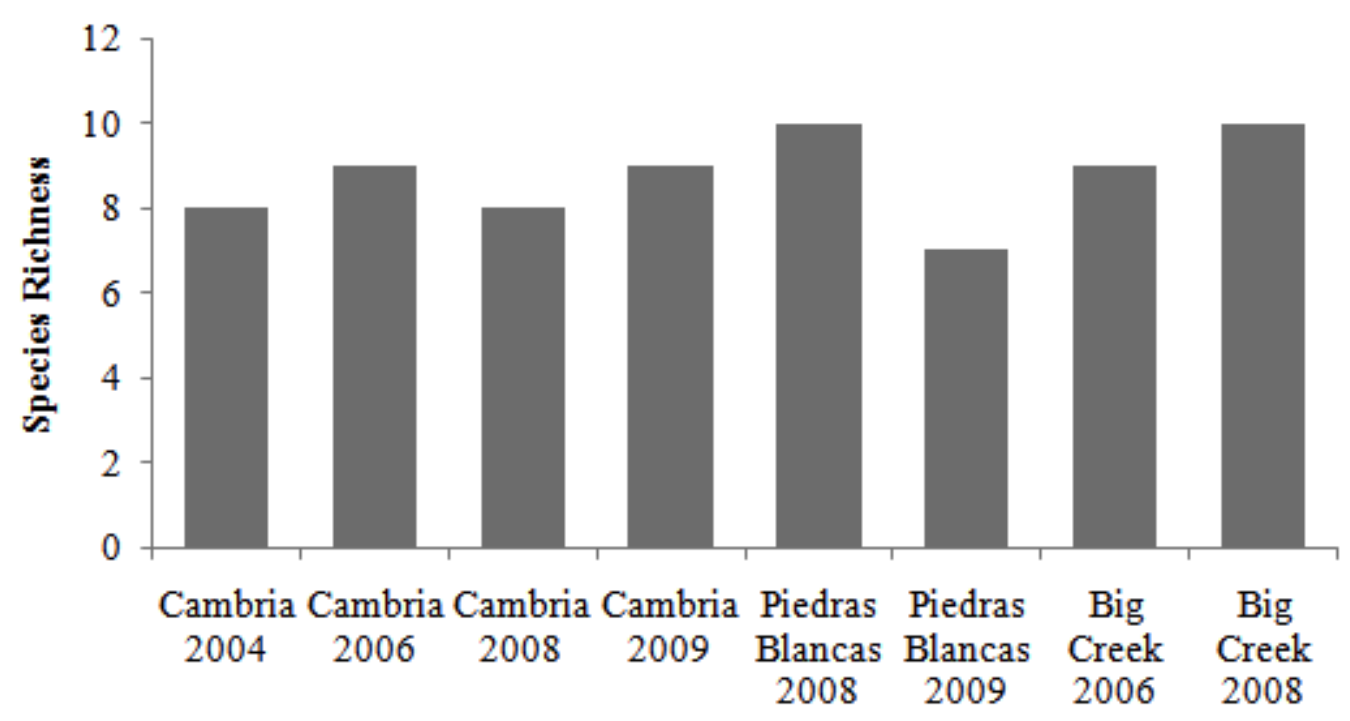

Figure 27: Species richness for all sampling locations and years.

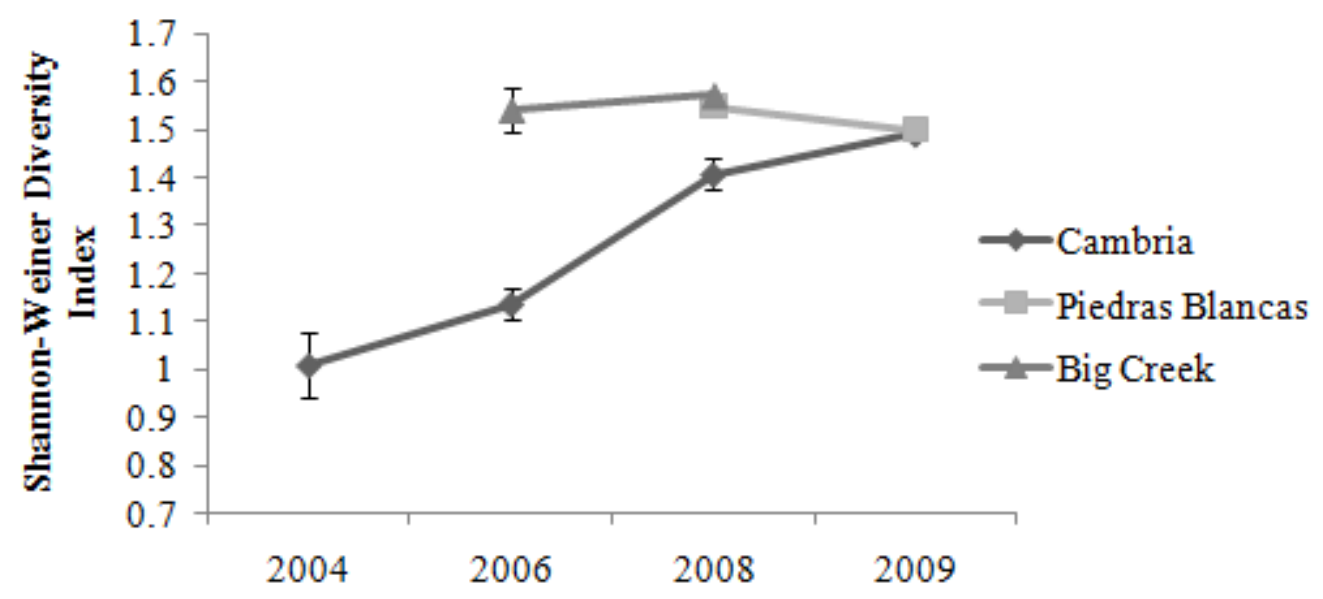

Figure 28: Shannon-Weiner diversity values for Cambria, Piedras Blancas and Big Creek for each sampling year. Error bars represent the standard error of the mean. 


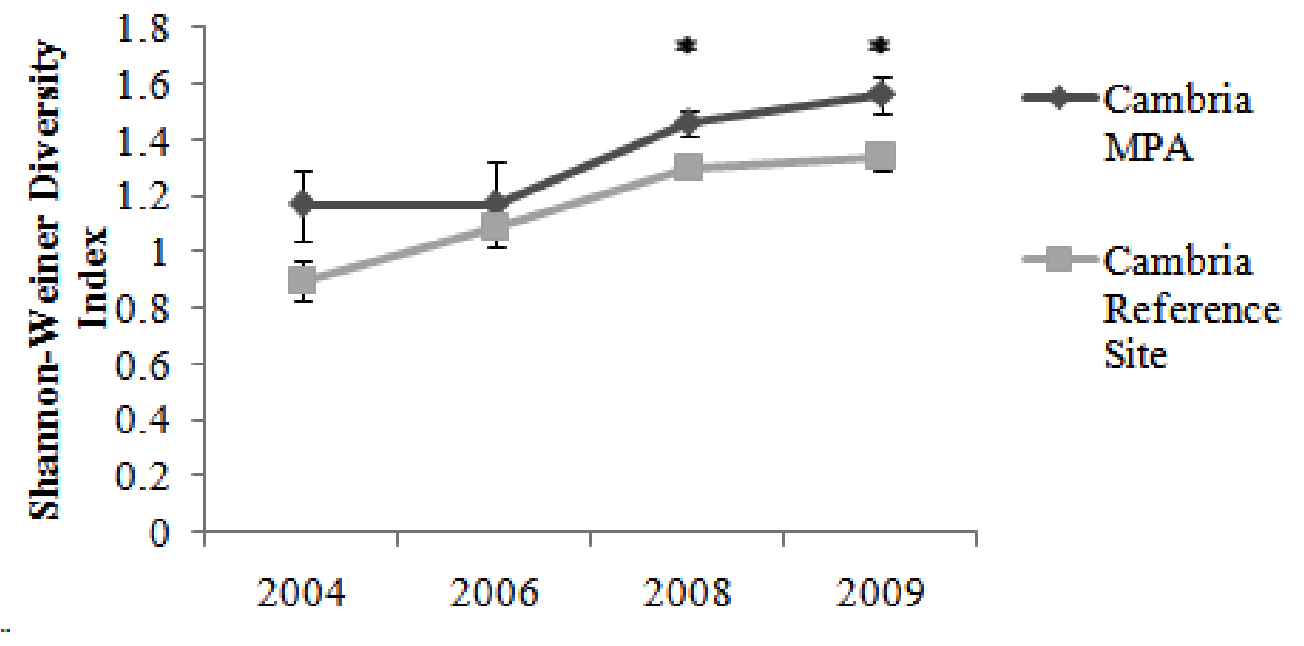

Figure 29: Shannon-Weiner diversity values for the Cambria MPA and reference site across all years. Error bars represent the standard error of the mean. Asterisks denote years that Shannon-Weiner Diversity was significantly different between sites.

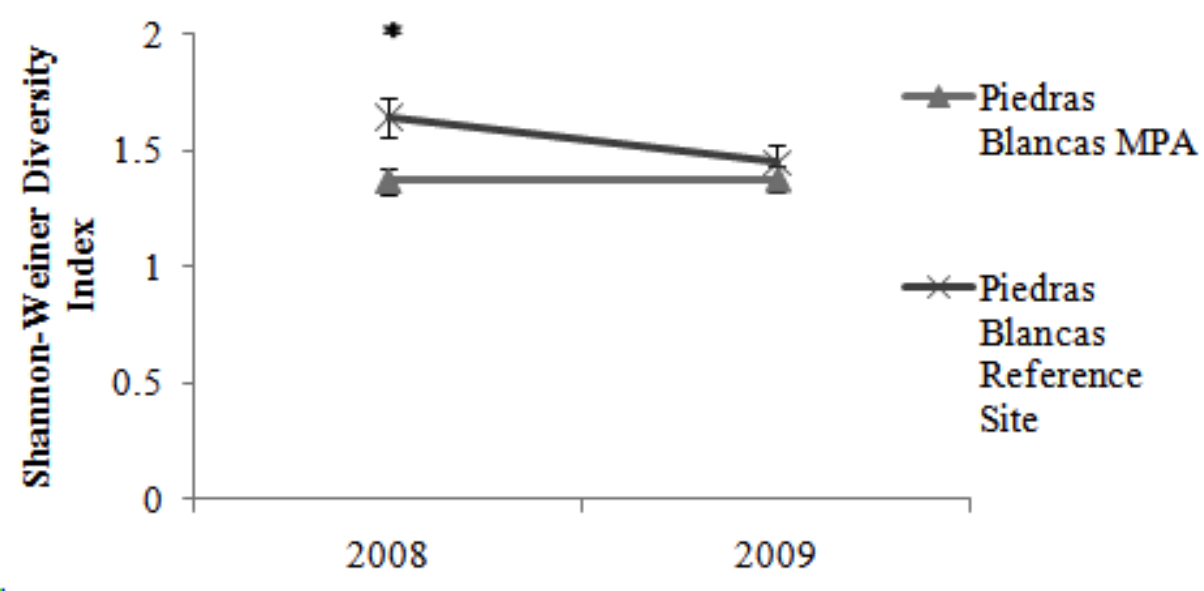

Figure 30: Shannon-Weiner diversity values for Piedras Blancas MPA and reference site across all years. Error bars represent the standard error of the mean. Asterisks denote years that Shannon-Weiner Diversity was significantly different between sites. 


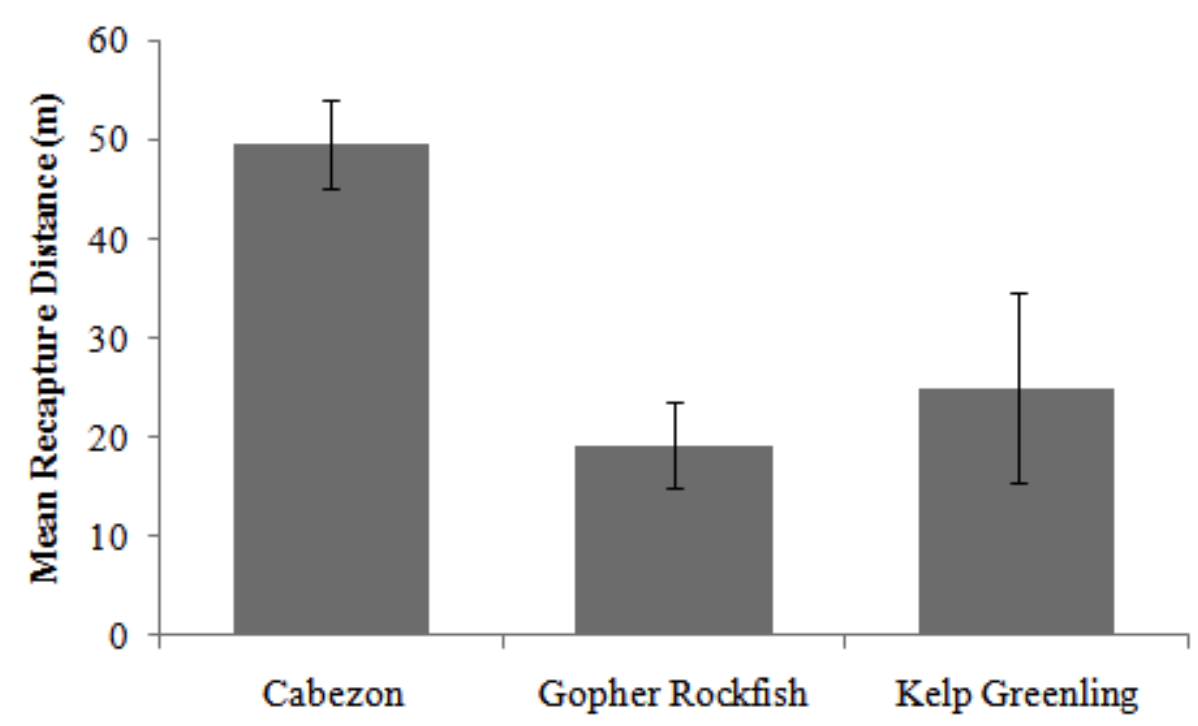

Figure 31: Mean recapture distance for cabezon, gopher rockfish and kelp greenling. Error bars represent standard error of the mean.

\section{A. Cabezon}

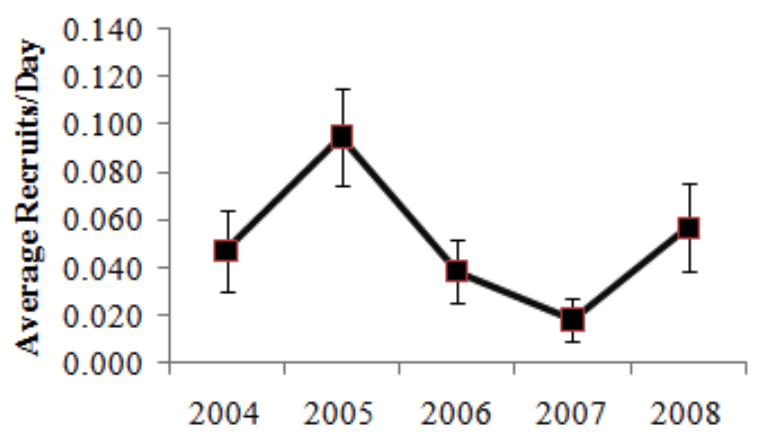

\section{B. KCGB}

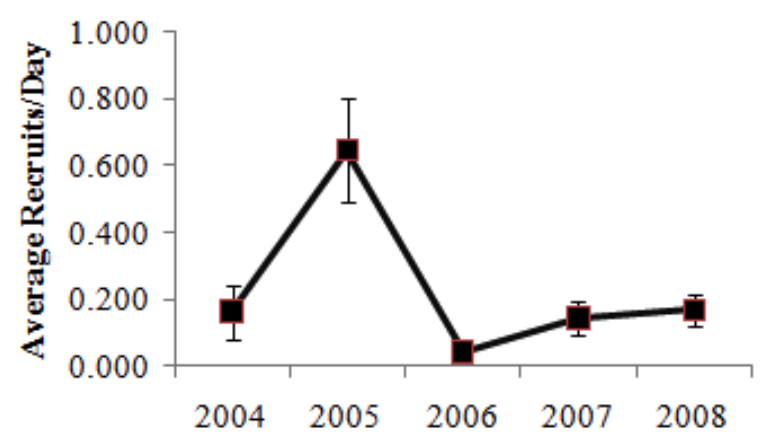

Figure 32: Average recruits per day for cabezon and KCGB complex from 2004-2008. Error bars denote standard error of the mean. Data from 2004-2006 adapted from Wilson 2006. 


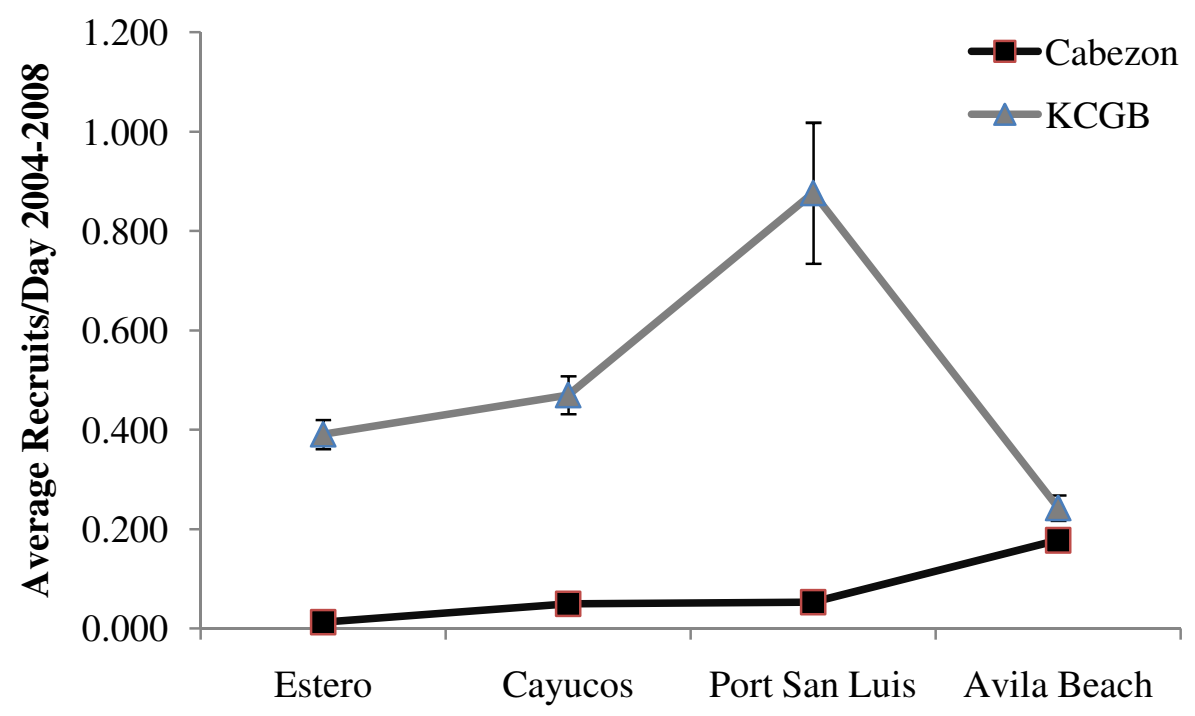

Figure 33: Average number of recruits per day at different SMURF stations from 2004-2008. Error bars represent standard error of the mean. Data from 2004-2006 adapted from Wilson 2006.

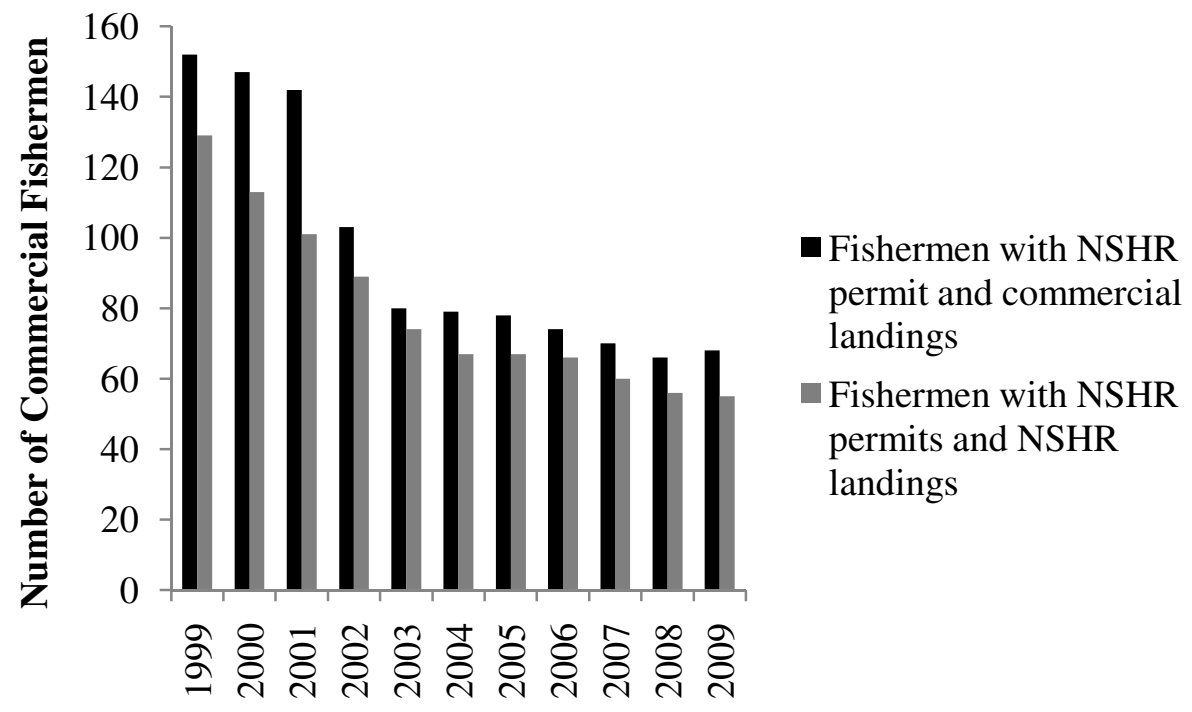

Figure 34: Number of commercial fishermen operating out of Morro Bay with nearshore permits and either commercial or nearshore landings. Adapted from Erwin 2010. 


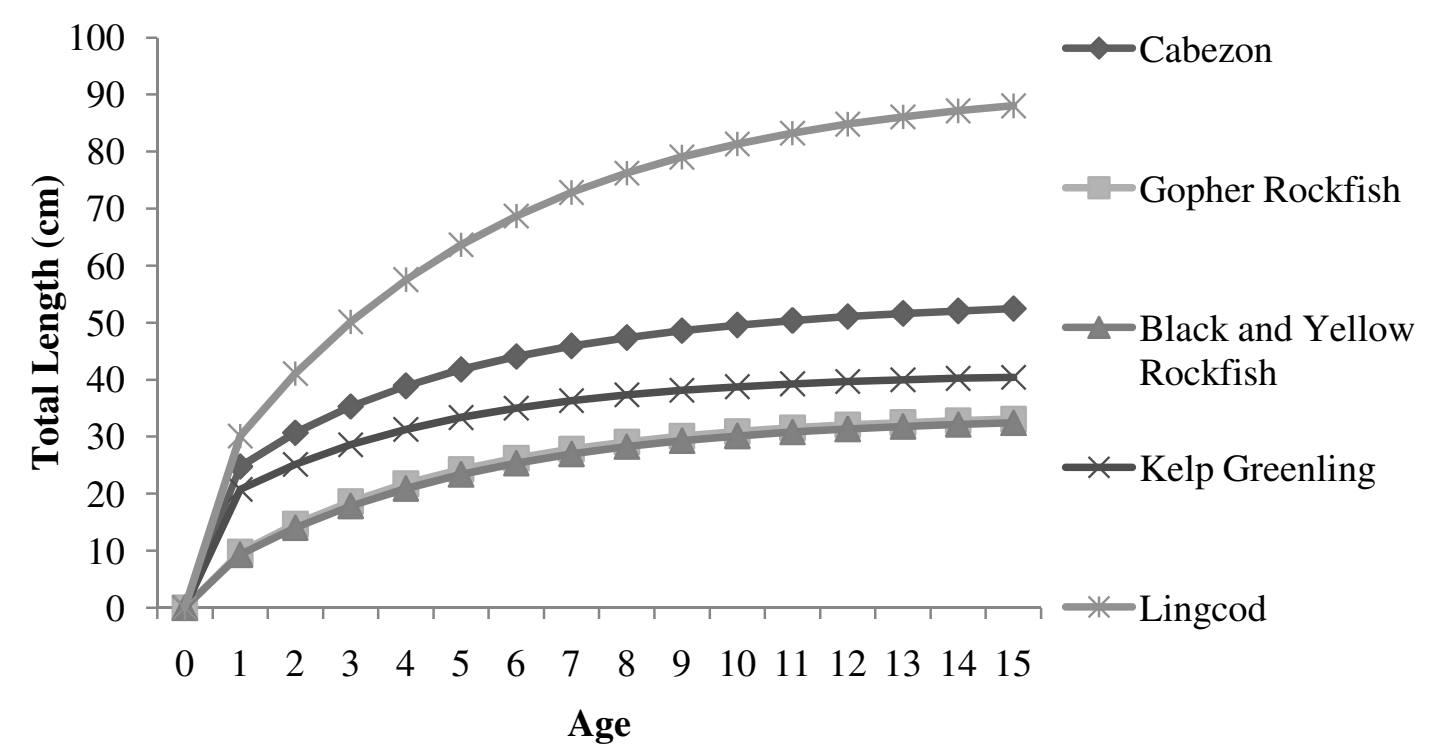

Figure 35: von Bertalanffy growth curves for analyzed fish species. Note, total length of zero assumed at year zero. Data adapted from Grebel 2003, Lea et al.,1999, Bryant 1978, Smith and McFarlane 1990.

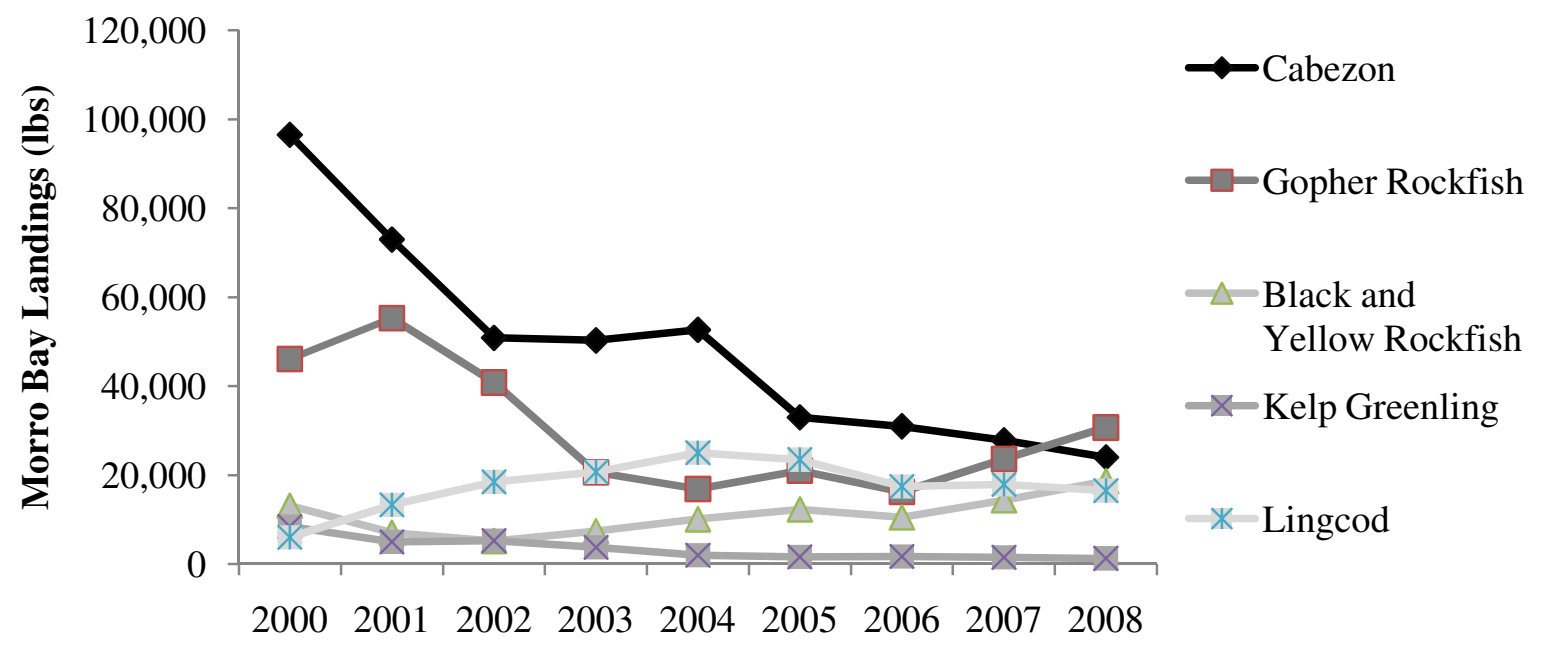

Figure 36: Commercial landings of analyzed fish species in Morro Bay from 2000-2008. Data adapted from CDFG 2000-2008. 


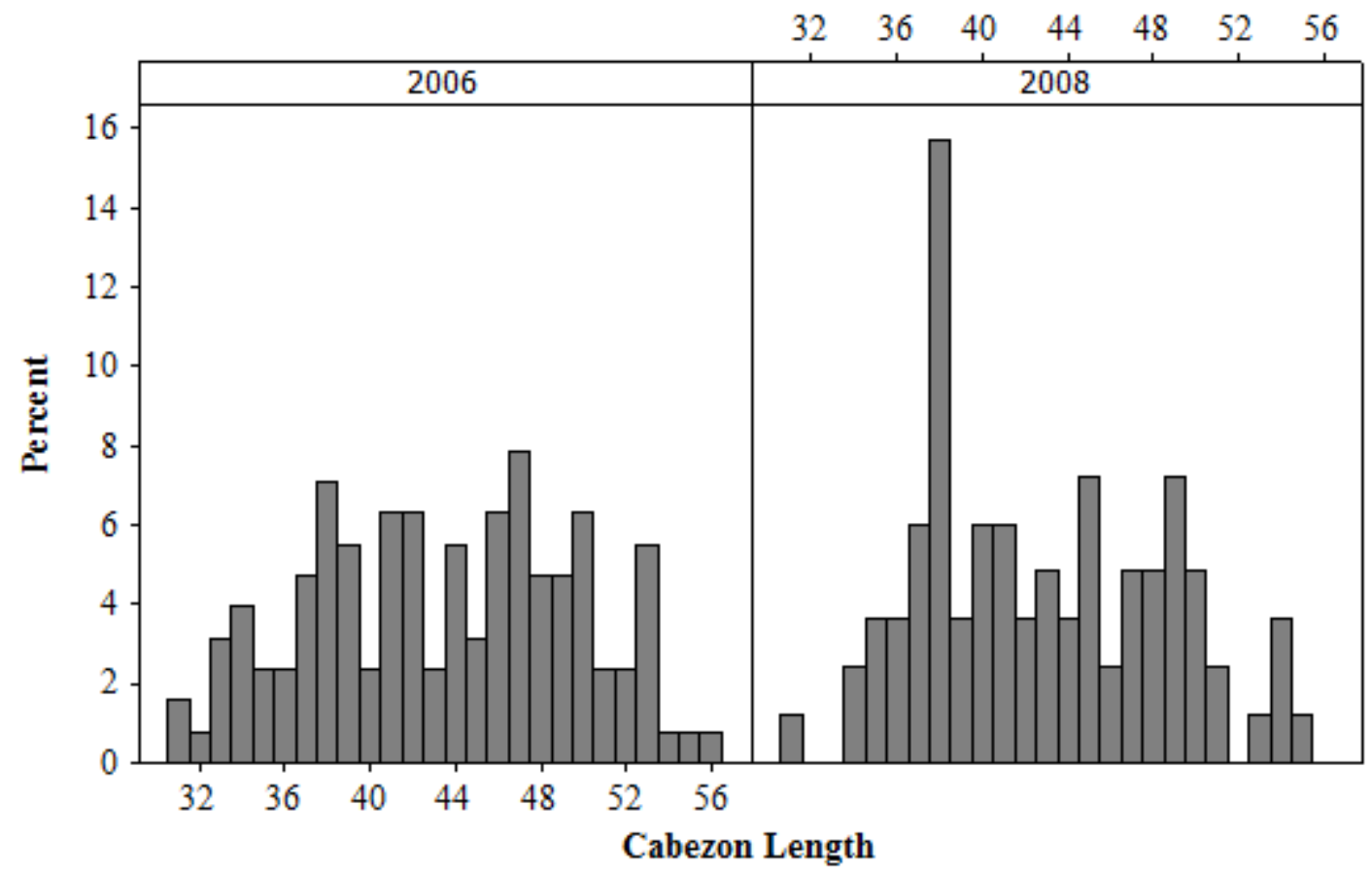

Figure 37: Length frequency histogram of cabezon total length at Big Creek during 2006 and 2008. Note the large percentage increase of $38 \mathrm{~cm}$ cabezon in 2008 relative to 2006 
Table 1: Sampling Periods and Protocols used at the different sampling locations

\begin{tabular}{|c|l|l|}
\hline Year & \multicolumn{1}{|c|}{ Location } & \multicolumn{1}{c|}{ Sampling Protocol } \\
\hline 2004 & Cambria & Commercial \\
\hline \multirow{2}{*}{2006} & Cambria & Commercial \\
\cline { 2 - 3 } & Big Creek & Commercial \\
\hline 2007 & MPAs established at Cambria and Piedras Blancas \\
\hline \multirow{2}{*}{2008} & Cambria & MLPA Monitoring \\
\cline { 2 - 3 } & Big Creek & Commercial \\
\cline { 2 - 3 } & Piedras Blancas & MLPA Monitoring \\
\hline \multirow{2}{*}{2009} & Cambria & MLPA Monitoring \\
\cline { 2 - 3 } & Piedras Blancas & MLPA Monitoring and Conversion \\
\hline
\end{tabular}

Table 2: Counts of fish captured and tagged throughout all studies.

\begin{tabular}{|l|c|c|}
\hline & $\begin{array}{c}\text { Number of } \\
\text { Fish Captured }\end{array}$ & $\begin{array}{c}\text { Number of } \\
\text { Fish Tagged }\end{array}$ \\
\hline Big Creek 2006 & 465 & 145 \\
\hline Big Creek 2008 & 330 & 103 \\
\hline Cambria 2004 & 257 & 175 \\
\hline Cambria 2006 & 1175 & 740 \\
\hline Cambria 2008 & 548 & 548 \\
\hline Cambria 2009 & 280 & 280 \\
\hline Piedras Blancas 2008 & 217 & 217 \\
\hline Piedras Blancas 2009 & 188 & 187 \\
\hline Totals & 3460 & 2395 \\
\hline
\end{tabular}


Table 3: Numbers of individual species captured at each sampling location.

\begin{tabular}{|c|c|c|c|c|c|c|c|c|c|}
\hline & $\begin{array}{c}\text { Big Creek } \\
2006\end{array}$ & $\begin{array}{c}\text { Big Creek } \\
2008\end{array}$ & $\begin{array}{c}\text { Cambria } \\
2004\end{array}$ & $\begin{array}{c}\text { Cambria } \\
2006\end{array}$ & $\begin{array}{c}\text { Cambria } \\
2008\end{array}$ & $\begin{array}{c}\text { Cambria } \\
2009\end{array}$ & $\begin{array}{c}\text { Piedras } \\
\text { Blancas } \\
2008 \\
\end{array}$ & $\begin{array}{c}\text { Piedras } \\
\text { Blancas } \\
2009 \\
\end{array}$ & Totals \\
\hline Cabezon & 152 & 114 & 175 & 779 & 134 & 82 & 67 & 42 & 1545 \\
\hline $\begin{array}{l}\text { Gopher } \\
\text { Rockfish }\end{array}$ & 82 & 44 & 4 & 39 & 128 & 60 & 58 & 50 & 465 \\
\hline $\begin{array}{l}\text { Black and } \\
\text { Yellow } \\
\text { Rockfish }\end{array}$ & 143 & 96 & 51 & 127 & 226 & 98 & 56 & 57 & 854 \\
\hline $\begin{array}{l}\text { Kelp } \\
\text { Greenling } \\
\end{array}$ & 59 & 54 & 16 & 140 & 38 & 28 & 25 & 33 & 393 \\
\hline Lingcod & 16 & 9 & 5 & 61 & 8 & 3 & 4 & 2 & 108 \\
\hline $\begin{array}{l}\text { Grass } \\
\text { Rockfish }\end{array}$ & 8 & 6 & 3 & 24 & 11 & 3 & 2 & 0 & 57 \\
\hline $\begin{array}{l}\text { Kelp } \\
\text { Rockfish } \\
\end{array}$ & 3 & 2 & 2 & 0 & 2 & 2 & 1 & 0 & 12 \\
\hline $\begin{array}{l}\text { Tree } \\
\text { Rockfish } \\
\end{array}$ & 0 & 1 & 0 & 0 & 0 & 0 & 0 & 0 & 1 \\
\hline $\begin{array}{l}\text { Copper } \\
\text { Rockrish }\end{array}$ & 1 & 0 & 0 & 0 & 0 & 0 & 0 & 0 & 1 \\
\hline $\begin{array}{l}\text { Vermillion } \\
\text { Rockfish }\end{array}$ & 0 & 1 & 0 & 0 & 0 & 0 & 0 & 0 & 1 \\
\hline WolfDel & 1 & 0 & 1 & 0 & 1 & 0 & 0 & 2 & 5 \\
\hline $\begin{array}{l}\text { Swell } \\
\text { Shark } \\
\end{array}$ & 0 & 3 & 0 & 1 & 0 & 2 & 2 & 0 & 8 \\
\hline $\begin{array}{l}\text { Blue } \\
\text { Rockfish } \\
\end{array}$ & 0 & 0 & 0 & 2 & 0 & 2 & 1 & 0 & 5 \\
\hline $\begin{array}{l}\text { Brown } \\
\text { Rockfish } \\
\end{array}$ & 0 & 0 & 0 & 1 & 0 & 0 & 1 & 2 & 4 \\
\hline Totals & 465 & 330 & 257 & 1174 & 548 & 280 & 217 & 188 & \\
\hline
\end{tabular}



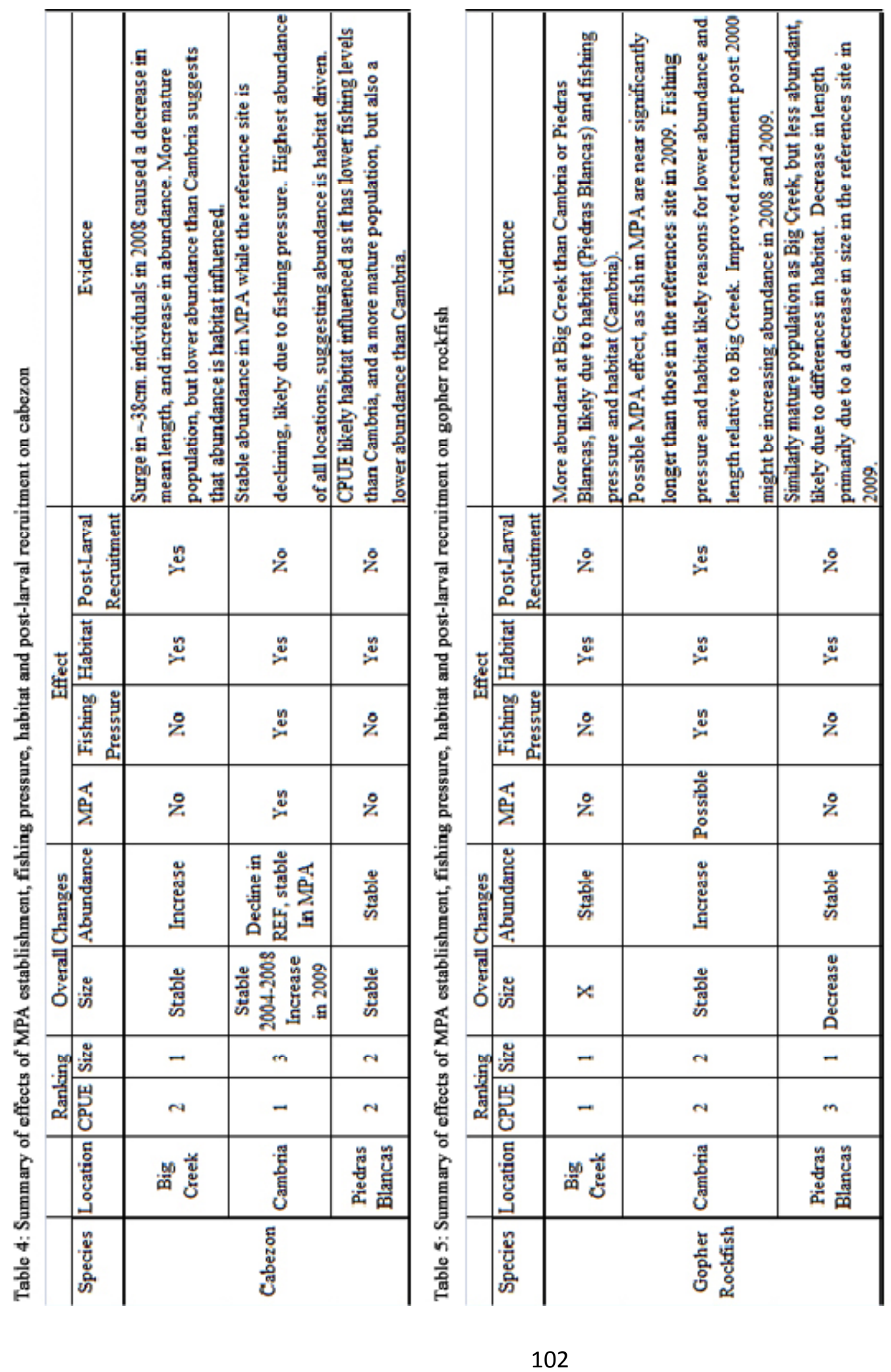

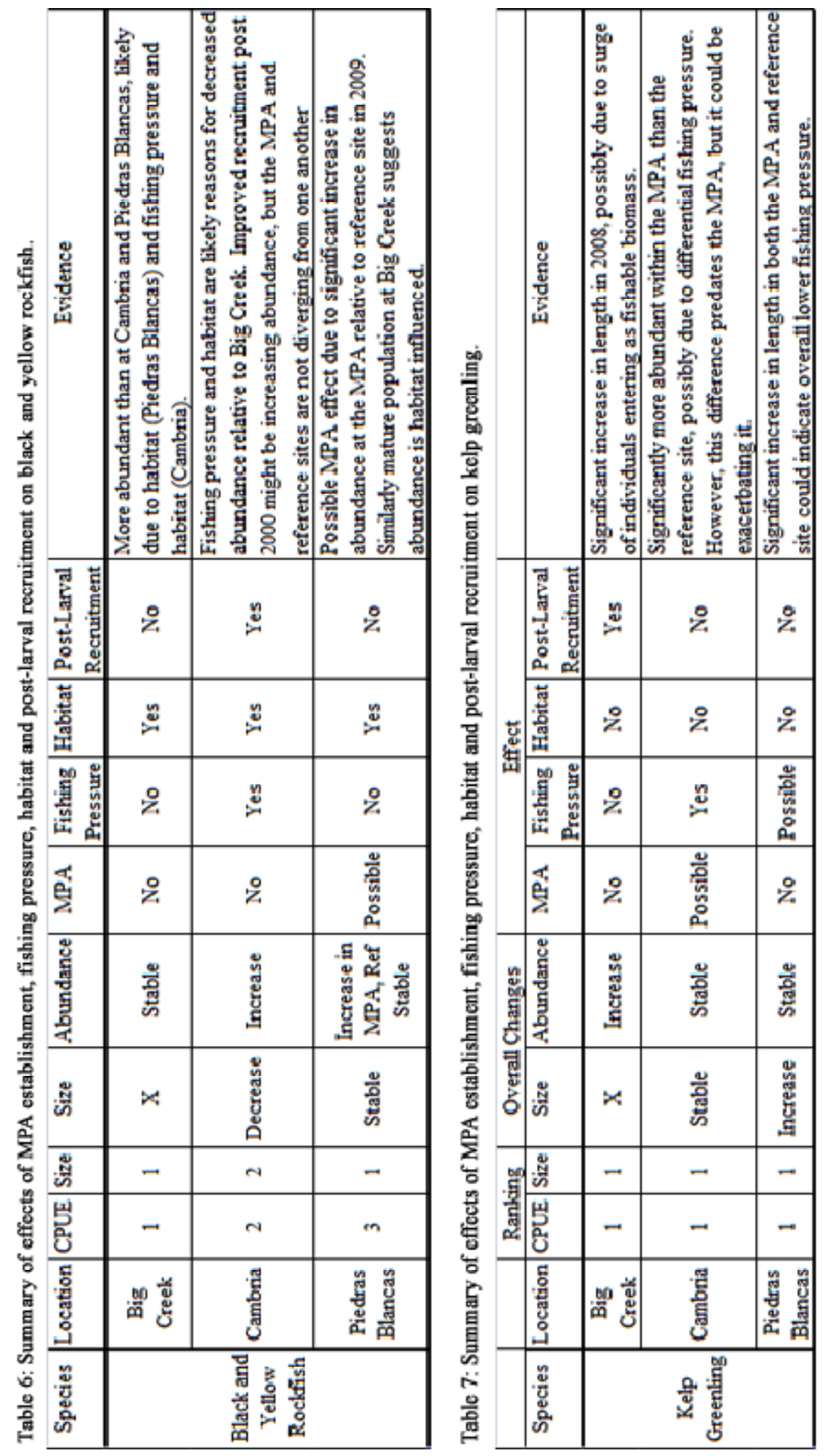


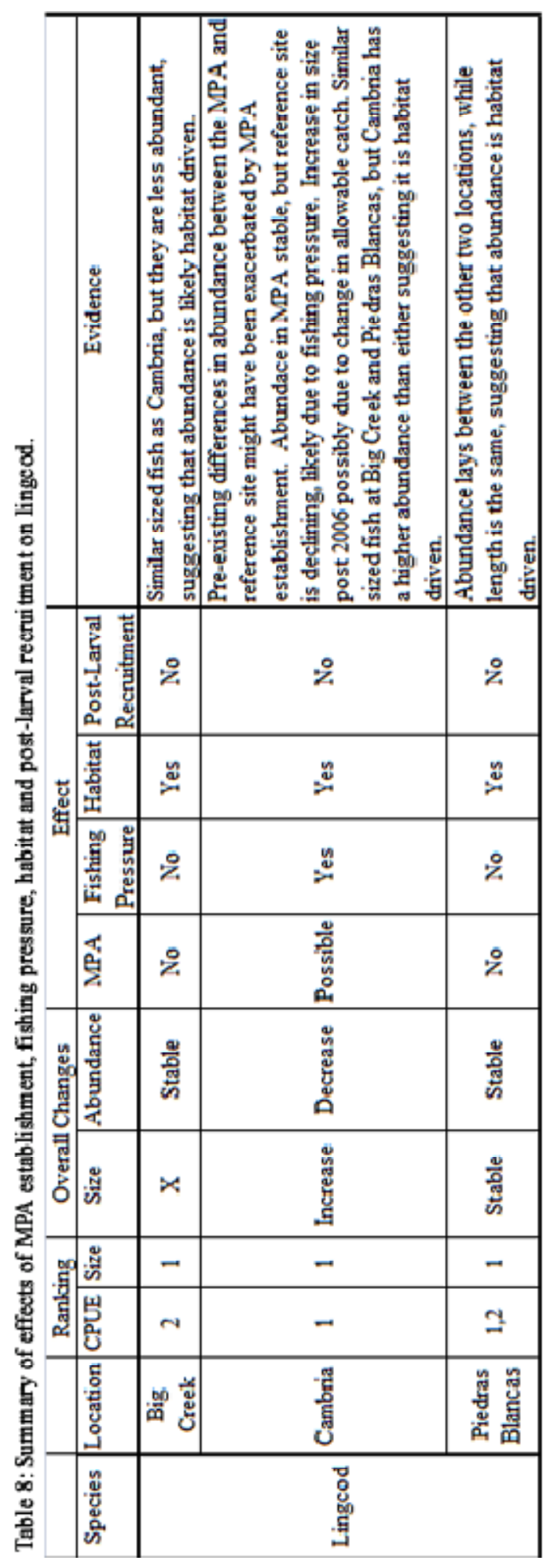

